\title{
Employee selection
}

Citation for published version (APA):

Baruah, R. (2021). Employee selection: the role of recruitment channels, compensation, and resources in selection. [Doctoral Thesis, Maastricht University]. Maastricht University.

https://doi.org/10.26481/dis.20210830rb

Document status and date:

Published: 01/01/2021

DOI:

10.26481/dis.20210830rb

Document Version:

Publisher's PDF, also known as Version of record

\section{Please check the document version of this publication:}

- A submitted manuscript is the version of the article upon submission and before peer-review. There can be important differences between the submitted version and the official published version of record.

People interested in the research are advised to contact the author for the final version of the publication, or visit the DOI to the publisher's website.

- The final author version and the galley proof are versions of the publication after peer review.

- The final published version features the final layout of the paper including the volume, issue and page numbers.

Link to publication

\footnotetext{
General rights rights.

- You may freely distribute the URL identifying the publication in the public portal. please follow below link for the End User Agreement:

www.umlib.nl/taverne-license

Take down policy

If you believe that this document breaches copyright please contact us at:

repository@maastrichtuniversity.nl

providing details and we will investigate your claim.
}

Copyright and moral rights for the publications made accessible in the public portal are retained by the authors and/or other copyright owners and it is a condition of accessing publications that users recognise and abide by the legal requirements associated with these

- Users may download and print one copy of any publication from the public portal for the purpose of private study or research.

- You may not further distribute the material or use it for any profit-making activity or commercial gain

If the publication is distributed under the terms of Article $25 \mathrm{fa}$ of the Dutch Copyright Act, indicated by the "Taverne" license above, 


\section{EMPLOYEE SELECTION:}

The role of recruitment channels, compensation, and resources in selection.

Raginee Baruah

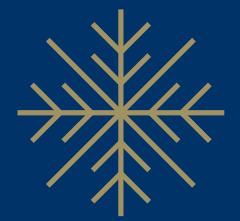





\section{EMPLOYEE SELECTION:}

The role of recruitment channels, compensation, and resources in selection.

Raginee Baruah 
ISBN: 978-94-6423-364-3

Printed by: ProefschriftMaken | www.proefschriftmaken.nl

Cover and layout: ProefschriftOntwerp | www.proefschriftontwerp.nl

Copyright: @ Raginee Baruah, 2021 


\title{
EMPLOYEE SELECTION:
}

The role of recruitment channels, compensation, and resources in selection.

\author{
Dissertation
}

to obtain the degree of Doctor at the Maastricht University, on the authority of the Rector Magnificus Prof.dr. Rianne M. Letschert in accordance with the decision of the Board of Deans, to be defended in public on Monday $30^{\text {th }}$ of August 2021 at 1300 hours.

by

Raginee Baruah 


\section{Supervisors}

Prof. dr. Frank Moers

\section{Co-supervisor}

Prof. dr. Isabella Grabner

\section{Assessment Committee}

Prof. dr. Alexander Brüggen (Chairperson)

Prof. dr. Bart Golsteyn (Maastricht University)

Prof. dr. Melissa Martin (University of Illinois at Chicago)

Prof. dr. Gerhard Speckbacher (WU Vienna) 




\section{Acknowledgement}

This dissertation is a result of a small dream, strong intentions, some degree of commitment, but most of all, it is a result of the support of a lot of people. Hence, I take this opportunity to thank the wonderful people I met along my $\mathrm{PhD}$ journey, in order of chronology. My journey began about seven years back when I realized how much I enjoyed doing research and that pursuing a $\mathrm{PhD}$ was the next obvious step in my career.

I thank my parents for their instant support for my decision. I am grateful to my father Deuta for always believing in my dreams and capabilities. I thank my mother Maa for teaching me how to live my decisions fearlessly. Both of you have taught me how to be sincere, tenacious, and ambitious in life. I cannot be grateful enough for that. I thank my grandmother Aita for showering me with her love and blessings at every step of my life. I thank my sister, Antara for holding the fort there so that I can be miles away from home in pursuit of my dreams. I am also very grateful for all her love and support. I thank my brother-in-law, Subodh for his sincerity and support towards my family, without which this journey would not have been possible. I thank our dog, Louis for being a constant source of joy in our lives.

I would like to thank Rana Hasan (Asian Development Bank) for introducing me to the wonderful world of research and recommending my application for the research master program at Maastricht University (UM). I would also like to thank Ram Singh (Delhi School of Economics) for recommending my application to UM. I would like to thank Andries de Grip for supervising my master thesis during my master program at UM. I thank Olivier Marie for giving me the opportunity to work as a research assistant with him. I would also like to thank Hans Peters, Antonius (Ton) Storcken, and (late) Jean-Pierre Urbain for their excellent tutelage during the research master's program. I would like to thank Arunava Sen (Indian Statistical Institute) for recommending the research master program at $\mathrm{UM}$ as the first step to the $\mathrm{PhD}$ program.

I would like to thank my supervisors, Frank Moers and Isabella Grabner. They have been the most instrumental in making this dissertation possible. I cannot thank you enough for accepting my application for the $\mathrm{PhD}$ program and putting your trust in me. Thank you, Frank and Isabella, for all the patience, training, and encouragement all throughout. I could not have asked for better supervisors than you. They say that "the best teachers are those who show you where to look, but don't tell you what to see". I am very grateful to have found the best teachers in you and whatever little I now know about doing research, I owe it to both of you.

I would like to thank my wonderful colleagues at the department for making my $\mathrm{PhD}$ journey memorable in many ways. I would like to specially thank Ann for her guidance and support during the $\mathrm{PhD}$ program as well as during the job search period. Thank you, Ann, for recommending my job applications. I would also like to express 
my sincere gratitude towards Alex and Annelies for their words of encouragement on several occasions, especially after my seminars. I am very fortunate to have met such kind and warm colleagues: I thank you, Katlijn, for the special Eurovision evening at your place and the nice walks and conversations. Christoph and Mathijs, thank you both for your helpful feedback and the enriching pre-discussions. Thank you, Anant, for keeping the Indian alive in me through our conversations about India and our occasional display of what it is to be an Indian on the dance floor. Judith, Lena, and Florian, thank you very much for helping me out with teaching sometimes. Britt, thank you for being such a fun person to be around. Mark, thank you for your help and support during the teaching semesters. I thank Patrick, Lu, Oscar, Simon, Harry, Iver, Rick, Rogier, Roger, Leon, Banu, Harold, Elisa, and Peter for being wonderful colleagues. I would also like to thank Tanja, Sasha, Sabine, Miranda, Juliette and Elize for their support.

Thank you, Olga, for being a friend and a confidante. Thank you for all the coffee walks and the candid conversations about research, family, and life in general. Ulrike, I am grateful to have had you as my officemate and eventually as a friend. I always admire your honesty and dedication to everything you do, including our friendship. I thank you, Caren, for your kindness, warmth, and friendship. I could always count on you for most things, spanning from water emergencies to advice on more serious career concerns. I am extremely grateful for that. I would like to thank you, Lei for being one of my first friends in the department and for sharing the love for Baileys.

I would like to thank my support system of friends. I thank Giang and Anastas for their friendship and support since my first day at UM. I am grateful for all those times we spent together studying, talking, walking, travelling and most of all, eating together. I would always cherish these special memories. I would also like to thank Thomas, Fiona (Wanqing Zhang), and Wei for making the first two years at UM such a wonderful and warm experience. I would like to thank a few other wonderful people I met during my study at UM who made a difference in one way or the other: Sofya, thank you for your positivity and warmth. Sasha and Markus, I am so grateful to have met you in Vienna and am even more grateful for staying in touch and having such wonderful times at the Nice Conference. I would also like to thank all my students who added a special meaning to my $\mathrm{PhD}$ journey.

Anu and Rene, I am grateful for your friendship all these years. I am thankful for all the wonderful time we spent drinking and talking about random and personal stuff. I am forever grateful for having my gang-of-girls in every journey of my life, the PhD included: thank you Basu, Saha, Piya, Pal, Mathur, and Gyanu for being a part of my life. I thank you, Jaishiv for being such an integral part of my close circle of friends. Medha, thank you for our eighteen-year long close friendship and for all the love and tears we shared. I would like to thank you, Sanne for being who you are-a sincere and a loving friend. I thank you, Kim for being your warm and inspirational self. I will always cherish our Sunday dates. I thank you, Julia and Charlotte for your warmth and 
friendship. I thank you, Seher, for always showing interest in my work and life. I thank you Merve, for your sweetness and warmth. I thank you, Domingo for being such a supportive friend. I would also like to thank you, Albin for your sincere friendship and I wish that it only grows with time.

Finally, I would like to thank my dearest paranymphs: Inge, Maja, and Sonal. Thank you, Inge for brightening my otherwise geeky life with new friends and lots of laughter. I cherish our days of working and walking together. Thank you for all the positivity and encouragement, especially in the final years of the $\mathrm{PhD}$. Thank you, Maja, for always being interested in my life. In you, I found a perfect partner for all kinds of activities, whether it is going for long walks or sharing an evening binging on Netflix. Thank you for supporting me with your warmth, kindness, and time. Thank you, Sonal, for being a constant witness to my life and willingly so. Right from the time when I first confided in you my decision to pursue a $\mathrm{PhD}$ to now, you have seen it all: the tears, the frowns, the joy. Thank you for being my confidante and my advisor throughout. This dissertation would not have been possible without you by my side.

I would also like to acknowledge the Assessment Committee for their time and valuable comments on the manuscript and would like to express my gratitude. Thank you, Alexander Bruggen (Maastricht University), Bart Golsteyn (Maastricht University), Melissa Martin (University of Illinois at Chicago), and Gerhard Speckbacher (WU Vienna).

Maastricht, July 2021. 


\section{Contents}

$1 \quad$ CHAPTER 1: $\quad 13$

Introduction

1.1 Introduction to Research Questions and Overview 15

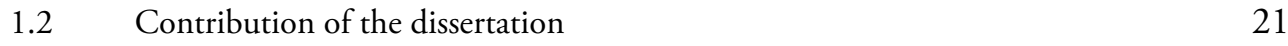

$\begin{array}{lll}1.3 & \text { Outline of the dissertation } & 23\end{array}$

2 CHAPTER 2: $\quad 25$

In Search of Intrinsic Motivation: The Complementarity between

Recruitment Strategy and Compensation Contract Design

2.1 Introduction $\quad 27$

$2.2 \quad$ Related Literature $\quad 31$

2.3 Analytical Model 33

$2.4 \quad$ Empirical Method $\quad 38$

2.5 Empirical Results 43

2.6 Conclusion $\quad 52$

3 CHAPTER 3: $\quad 57$

Sorting and the use of stock-based compensation: evidence from CEO contracts.

3.1 Introduction $\quad 59$

3.2 Prior Literature and Hypothesis Development 64

$\begin{array}{lll}3.3 & \text { Empirical Method } & 70\end{array}$

$\begin{array}{lll}3.4 & \text { Empirical Results } & 77\end{array}$

3.5 Additional Analysis $\quad 87$

3.5.1 Incentive-story Argument 87

3.5.2 Analysis within External CEOs 93

3.5.3 Skills-Premium Argument 99

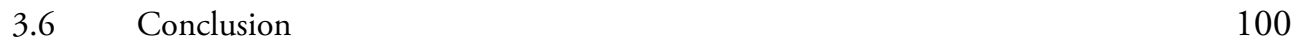

$4 \quad$ CHAPTER 4: $\quad 109$

Employee Selection and Training: A Complementarity View

4.1 Introduction $\quad 111$

4.2 Prior Literature and Hypothesis Development 114

$\begin{array}{lll}4.3 & \text { Empirical Method } & 121\end{array}$

$4.4 \quad$ Empirical Results 128

4.5 Additional Analysis: Types of desired attributes at the time of selection 136

$\begin{array}{ll}4.6 \text { Conclusion } & 140\end{array}$ 
5 CHAPTER 5:

Conclusion

5.1 Summary of main findings

5.2 Contribution and implications

5.3 Limitations and future research

Bibliography

Impact-Paragraph

Summary

173

Samenvatting (Dutch summary)

177

Curriculum Vitae 

Chapter 1

Introduction 
Hiring talent remains the number one concern of Chief Executive Officers (CEOs) in the most recent Conference Board Annual Survey. According to Society for Human Resource Management estimates, a US firm spends as much as 4,129 dollars per job only on employee selection activities (Cappelli, 2019). Clearly, hiring the 'right' employee is not a trivial matter for firms and hence, studying employee selection strategies of firms is of utmost importance to both researchers and practitioners. Academic researchers also recognize that selecting the right employees is as important as providing right incentives or implementing other forms of controls (Beasley \& Ghatak, 2005; Prendergast, 2008; Campbell, 2012; Abernethy et al., 2015; Merchant \& Van der Stede, 2017; Donnelly et al., 2018). The three studies of my dissertation are focused on this topic-employee selection.

\subsection{Introduction to Research Questions and Overview}

Management control includes all the devices or systems that managers use to ensure that the behaviors and decisions of their employees are consistent with the organization's objectives and strategies (Merchant \& Van der Stede, 2017). Management control has a behavioral orientation as it places employees at the heart of the management problem, by asking the question: Are our employees likely to behave appropriately? With the overall objective of directing employees to the right behavior, management control systems (MCSs) can be divided into three types (based on the object of control): results controls (to control results produced), action controls (to control actions taken), and personnel controls (to control the types of people employed, based on their values and attributes such as skills and motivation).

This dissertation (and the three studies herein) focuses on the role of employee selection, within the broader topic of personnel controls, in achieving the overall objective of aligning the interest of the employees to those of the organizations. Employee selection can serve as means of controlling employee behavior ex-ante because it regulates the antecedents of performance, namely, knowledge, skills, abilities, intrinsic motivation, and values (Snell, 1992). The fact that individuals are heterogenous in terms of these observed as well as unobserved antecedents of performance makes the role of employee selection very important. Employee selection strategies include various types of mechanisms firms use to induce self-selection (or sort) and/or screen the right type of employees based on the desired antecedent of performance, especially the unobserved ones (Barron et al., 1985; Barron et al., 1989; Barron et al., 1997). Previous research has acknowledged that employee selection is an equally important input-based control mechanism as are output-based controls (such as output contracting) and behavior controls (such as monitoring) (Beasley \& Ghatak, 2005; Campbell, 2012; Abernethy et al., 2015; Prendergast, 2008; Donnelly et al., 2018). However, despite this important 
role of employee selection as a control mechanism, there is relatively limited research on this topic compared to the other two topics of output-based controls and behavior controls. This dissertation attempts to fill in this gap with its three studies.

In the three studies of the dissertation, I examine the role of employee selection in three different settings and provide important insights into the usage of different tools to serve the purpose of attracting (and selecting) the right employee. In the first study, I examine the role of recruitment channels for attracting highly motivated employees for the job when there is low individual output contractibility. In the second study, I examine the use of stock-based compensation to induce self-selection of the 'right-fit' Chief Executive Officer (CEO). Finally, in the third study, I examine the extent of resource intensity (with respect to time and money) in selecting employees based on certain employee attributes that potentially affect the returns to training.

In the first study (Chapter 2), I examine how a firm's recruitment strategy complements the provision of fixed wage contracts in order to attract highly intrinsically motivated employees. Selecting employees based on their (unobserved) intrinsic motivation is particularly useful when firms need to rely on intrinsic motivation to induce the desired effort (Beasley \& Gathak, 2005; Delfgaauw \& Dur, 2007; Prendergast, 2008) when extrinsic motivation such as incentive contracts are difficult to implement. ${ }^{1}$ An important, yet understudied challenge in the employee selection process is that in order to be able to select a highly motivated candidate, firms first need to ensure that a sufficient number of highly motivated candidates apply for a certain position (i.e., self-select into the applicant pool). Employee attraction can occur via various channels, each of which creates a potentially different applicant pool, which has important implications for 'who the firm selects' eventually. Thus, to be able to select a highly intrinsically motivated candidate it is important to first use a recruitment channel that successfully attracts such a candidate into the applicant pool (Delfgaauw \& Dur, 2007). Hence, the recruitment strategy, which affects the applicant pool, becomes a very crucial control choice, especially when output contractibility is low. By examining the choice of recruitment channel, I focus on the part of the employee recruitment process that affects whom the firm attracts into the applicant pool, an area that has received limited attention to date.

The study argues that recruitment channels that imposes an application cost (such as implicit search cost and/ or explicit application fee) on candidates can serve in discouraging less motivated people from entering the applicant pool. For example, formal channels of recruitment, such as vacancy posting on newspapers, tend to impose a higher application cost on candidates because of its formal nature (as well as outward nature of sourcing information) compared to informal channels of recruitment, such as referrals. Building on the analytical model of Delfgaauw and Dur (2007), this study

1 Deci (1972) describes intrinsic motivation as follows: a person is intrinsically motivated to perform an activity if there is no apparent reward except the activity itself or the feelings that result from the activity. 
analytically shows that higher application costs result in a higher likelihood of attracting highly intrinsically motivated candidates but results in a lower likelihood of filling the vacancy. The economic intuition is relatively straightforward; higher application costs make the job opening less attractive, which discourages candidates and especially those who have less intrinsic motivation for the job. Thus, compared to informal channels, formal channels induce a more favorable self-selection of candidates based on their unobservable intrinsic motivation for the job, albeit fewer candidates might get attracted for the job. Intuitively, when a firm can only provide fixed wages, then it needs to rely on the intrinsic motivation of the candidates, which triggers a preference for formal channels over informal channels because of the higher sorting capability of the former compared to the latter. Alternatively, the greater the incentives a firm can provide, the less it cares about attracting highly intrinsically motivated candidates (since incentive contracts might be enough to direct effort) and in turn, the more it cares about filling the vacancy per se. This triggers a preference for informal channels over formal channels since the former has a relative advantage of reaching a larger number of candidates (irrespective of their level of intrinsic motivation) compared to the latter. Relatedly, I argue, with the analytical model, that the marginal benefits of providing incentives are lower when using a formal channel compared to using an informal channel. As a result, the key prediction (of the model) in the study is that formal channels (informal channels) and fixed wages (incentives) are complements. Using data for a cross-section of 337 British firms (surveyed by 2011 Workplace Employment Relations Survey (WERS), I find strong empirical support for the theoretical prediction, namely, formal channels (informal channels) and fixed wages (incentives) are complements. Broadly, the study argues and shows that recruitment strategy (in particular, recruitment channels) and compensation design are complements.

In the second study (Chapter 3), I examine the use of stock-based compensation to serve sorting purposes when hiring Chief Executive Officers. A Chief Executive Officer (CEO) is a distinct employee within a firm because of her critical role in affecting the firm's value and hence, appointments of CEOs are critical turning points for organizations (Berns \& Klarner, 2017). For the same reason, the compensation contracts offered to CEOs have attracted a lot of attention in both academia and practice. Most literature on CEO compensation focus on either a moral-hazard perspective (Murphy,1999; Conyon et al., 2011; Fernandes et al., 2012; Edmans \& Gabaix, 2016) or a governance perspective (Abowd \& Kaplan,1999; Bebchuk et al., 2002; Bebchuk et al., 2011) to justify the significant variation in CEO compensation observed across CEOs. However, there is limited empirical research on examining the role of compensation contracts from an adverse-selection perspective among CEOs. Most of the research linking compensation to adverse-selection concerns have been theoretical in nature (Lazear, 2005; Cadenillas et al., 2005; Moen \& Rosen, 2005; Palomino \& Peyrache, 2013; Bénabou \& Tirole, 2016). The few empirical research on this topic 
have focused on lower-level employees (Hall \& Murphy, 2003; Oyer \& Schaefer, 2005). Hence, this study aims to provide empirical evidence on an understudied topic of the role of compensation in addressing adverse-selection concerns among CEOs, with a focus on the stock-based component in compensation. Hence, the use of stock-based pay in solving adverse selection problems has been discussed in the economics literature before but mostly using theoretical models, and there is paucity of empirical work on this topic, especially at the CEO level. This study attempts to bring empirical evidence to this stream of literature by showing that stock-based pay is not only used for incentive purposes, but also to solve adverse-selection problems among CEOs. In doing so, the study attempts at providing an additional perspective to the on-going debate on the justification of the increasing use of stock-based compensation in CEO contracts-the share of stock-based performance-pay for Chief Executive Officers (CEOs) of the U.S firms increased from 17 percent in 2009 to around 40 percent in 2018, according to a recent Harvard study on U.S. Executive Compensation Trends. ${ }^{2}$

The general idea of this study is that using a stock-based component in compensation induces self-selection of the 'right fit' CEO (into a contract). The idea is that a CEO who is willing to accept a contract that ties a high share of her wealth to the firm's future value (stock returns) in lieu of fixed-salary must believe that she is a 'right-fit' in the firm. ${ }^{3}$ The CEO must believe that she is the 'right' person to directly affect the firm's future value favorably and in turn, reap all the upside potentials offered by such a contract (Lazear, 2005). ${ }^{4}$ However, the study argues that the relative benefit of using stock-based pay for sorting is higher when the need for sorting is higher. This is crucial because using additional stock-based pay for sorting needs imposes additional firm-risk on the risk-averse CEO affecting her actions sub-optimally, which can be viewed as implicit costs of using stock-based pay for sorting (Moen \& Rosen, 2005; Lazear, 2005; Bénabou \& Tirole, 2016). Hence, going beyond the existing studies that only focus on the benefits of using stock-based pay for sorting, this study argues that for firms to use stock-based pay for sorting profitably the need (or benefit) of using it should outweigh the associated costs (both implicit and explicit). In particular, the study examines if the use of stock-based pay (in lieu of fixed-salary) is positively linked to the severity of informational asymmetry around the CEO's fit in the firm. The argument being that with severity of informational asymmetry the need of using stock-based pay for sorting exceeds the associated costs. I draw upon the 'learning theory' literature in economics (Waldman, 1984, 1990; Gibbons \& Katz, 1991; Farber \& Gibbons, 1996; Altonji \& Pierret, 2001; Pinkston, 2009) and hypothesize that the variation in

2 https://corpgov.law.harvard.edu/2019/04/16/2019-u-s-executive-compensation-trends/

3 Sorting works only when the same contract is valued differently by different applicants depending on their private knowledge about their fit in the firm (which largely depends on their privately known competence for the job).

4 This ability to affect the firm's value directly is the crucial assumption that makes stock-based pay an effective sorting tool for employees such as a CEO. 
the stock-based component in a CEO's compensation at the time of appointment is associated with the varying degree of informational asymmetry around the CEO's fit in the firm - the higher the severity in the informational asymmetry, the higher the share of stock-based pay in compensation at the time of appointment. However, over the CEO's tenure, the firm is expected to learn more about the CEO's fit in the firm (Lazear, 1986; Murphy, 1986; Milbourn, 2003; Pinkston, 2009) and hence the variation in the informational asymmetry across all types of CEO-firm appointments decreases with tenure, all else equal. Thus, I also hypothesize that the difference in the share of stockbased compensation in total compensation observed at the time of appointment across CEOs reduces with tenure, all else equal. Using a pooled cross-section of S\&P 500 firms with 3,162 firm-year observations for the period 2011-2017, I find that the higher the severity of informational asymmetry around the CEO's fit in the firm the higher the share of stock-based pay relative to fixed salary (and in total compensation). In addition, the variation in the share of stock-based pay observed at the time of appointment across different hiring settings (with varying informational asymmetry) reduces over tenure as more information is accumulated about the CEO's tenure.

The third study (Chapter 4) examines an important, yet understudied, question of why firms tend to invest (in terms of resources and time) in both training and employee selection by proposing and testing a complementarity relationship between investment in training and employee selection. This question becomes very important because traditional human-capital theory (Abraham \& Farber, 1987; Altonji \& Shakotko, 1987; Topel, 1991; Neal, 1995; Woodcock, 2008) suggests that higher investment in employee selection processes should substitute training (and other forms of control, such as monitoring) later. However, the traditional human-capital theory seems to fall short of explaining the huge investments in both employee selection and training-these two forms of personnel control seem to claim a huge part of a company's budget. According to the 2017 Training Industry Report, U.S. companies spent over 90 billion dollars on training and development activities in 2017, a year-over-year increase of 32.5\%. ${ }^{5}$ At the same time, companies spend almost $\$ 4,129$ per job in employee selection processes (according to Society for Human Resource Management estimates). ${ }^{6}$ Clearly, these two forms of personnel control are both viewed as very important by firms. Despite their importance, there is only a handful of studies that examine the relationship between these two forms of personnel control (Barron et al, 1985; Cohen \& Pfeffer, 1986; Barron et al., 1989; Barron et al., 1997; Burdett \& Cunningham, 1998). Interestingly, most of the existing studies use only theoretical models to explain the observed positive relationship between investment in employee selection and in training. This study, on the other hand, empirically tests these underlying theoretical explanations and provides the first set of empirical evidence in support of the theoretical arguments proposed by

5 https://hbr.org/2018/10/when-companies-should-invest-in-training-their-employees-and-when-they-shouldnt

6 https://hbr.org/2019/05/your-approach-to-hiring-is-all-wrong 
existing literature.

The study argues that when the firm invests in training, there is a need for selecting employees on certain employee attributes (observable and unobservable) that are expected to affect the returns to training. For instance, a number of studies propose that it is the stability (or longevity) of the employee-firm relationship post training that affects the returns to training (Salop \& Salop, 1976; Blinder \& Krueger, 1996; Acemoglu \& Pischke, 1998). On the other hand, some of the theoretical studies suggest that the returns to training are dependent on the pre-acquired (or innate) ability/skills of the employee that determines their trainability (Thurow, 1975; Barron et al., 1985; Barron et al., 1989; Barron et al., 1997). Hence, firms invest in employee selection to maximize the likelihood of hiring a stable (or reliable) employee and /or a trainable employee. At the same time, studies argue that when firms invest in employee selection to attract scarce talents, they also tend to invest in training these talents as a way to signal their retention motives (Lockwood \& Ansari, 1999). Thus, the study hypothesizes a positive relationship between investment in employee selection and in training, in line with prior studies. But more importantly, the study hypothesizes that there is higher demand for stability as an attribute at the time of selection when investment in training increases, and that there is higher demand for trainability as an attribute at the time of selection with an increasing investment in training. The study also examines this complementarity in the context of varying creativity dependence, mainly because studies on employee creativity suggest that the concerns of stability and 'trainability' of employees are of particular importance for firms that rely heavily on the creativity of their core employees for their competitive edge (Suojanen \& Brooke, 1971; Amabile, 1983, 1988; Mumford \& Gustafson, 1988; Amabile et al., 1996; Oldham \& Cummings, 1996; Fiest, 1999; Caves, 2000; Mumford et al., 2002; Shalley et al., 2004; Peterson \& Seligman, 2004; Gil \& Spiller, 2007; Biswas-Diener et al., 2011; Grabner, 2014). Thus, I also expect the complementarity to be stronger with increasing creativity dependence across firms. Using rich survey data on 457 firms located in Austria, Germany and Switzerland, between the size of 50-500 employees, I find that the complementarity between training and employee selection across all firms in the sample are driven by the need to select employees based on both the attributes of stability of the employee, and ability of the employee (innate or previously acquired). In addition I also find that this positive relationship between employee selection and training investment gets stronger with increasing creativity-dependence, especially in firms involved in R\&D activities and those operating in the creative industries of design, new media, such as software and video games, and creative services, such as advertising. ${ }^{7}$ While such firms do not seem to put an increased emphasis on selecting on trainability, I find evidence that they have a different demand for the stability of the employee-firm relationship. To shed more light

7 The strength of the complementarity relationship is not dependent on the creativity-dependence of firms in the NACE classified non-creative industries. 
into the types of attributes that firms demand, I separately look into the items forming the stability construct, i.e. value congruence, team fit and stability. Interestingly, in the sub-sample of creative industries, the attribute that is prioritized when there is high creativity-dependence is the extent of value congruence between the employee and the firm, over any other attribute. On the other hand, the degree of fit in an existing team is very important in the non-creative industries.

\subsection{Contribution of the dissertation}

Overall, the dissertation (with its three studies) contributes to the management accounting literature by examining important research questions in the understudied, yet relevant, topic of employee selection under the broader field of personnel control. Specifically, the dissertation explains some of the observations made in hiring practices across firms by providing empirical evidence to concepts that are widely discussed across multiple disciplines.

The first study (Chapter 2) shows that there is a strong complementarity between the use of formal recruitment channels (informal recruitment channels) and fixed-pay contracts (incentive-pay contracts). While the provision of (effort) incentives is one of the most widely studied topics in both accounting and economics, much less attention has been paid to an equally relevant problem: how to attract employees who are willing to perform to the best of their abilities even when paid fixed wages. By addressing this important question, this study contributes to the literature on employee selection in two important and interrelated ways. Diverging from the related literature on employee selection that focuses on 'whom the firm selects' and implicitly takes the applicant pool as a given (Abernethy et al., 2015; Grabner \& Speckbacher, 2016), it focuses on that part of the employee selection process that has been understudied as a control mechanism, namely recruitment channels that affect 'who the firm attracts' in the first place. This has important implications for 'who the firm selects' eventually. In doing so, the study contributes to the nascent stream of research in accounting and economics on the consequences of a firm's recruitment strategy, and in particular the ability to attract highly intrinsically motivated employees. The (accounting) literature has been relatively silent about whether formal or informal channels better match with low output contractibility. I show that this higher sorting capacity of the formal channel vis-à-vis the informal channels is a result of the higher application cost imposed by the former on candidates at the time of application, compared to that imposed by the latter. Counter to intuition that informal recruitment channels might be better suited to identify highly intrinsically motivated employees because of the potential information advantage of informal channels such as referrals, firms tend to rely on formal recruitment channels that pose higher hurdles on their prospective employees when the provision 
of incentives is infeasible. Conversely, the findings of the study also imply that if firms tend to rely on formal recruitment channels for other reasons, less (costly) incentives would be needed to induce the same amount of effort, irrespective of their feasibility. The study, further, contributes to the growing stream of literature on complementarities between management control practices (Grabner \& Moers, 2013; Chapman et al., 2020) and in particular on the complementarity between personnel controls and results controls. While prior research has addressed whether employee selection and incentive contracting are complements or substitutes (Campbell, 2012; Abernethy et al., 2015), this study emphasizes that such interdependence (also) depends on the recruitment channels underlying the employee selection process. These results highlight the importance of examining management control practices at a less aggregated level, as also echoed in Grabner and Moers (2013).

The second study (chapter 3) shows that the share in stock-based performance pay component of contracts across CEOs at the time of appointment are positively linked to severity in the degree of informational symmetry around the CEO's fit at the time of appointment. This study makes several contributions. First, the study provides empirical evidence to the topic of using stock-based compensation for sorting executives that has been largely dominated by theoretical studies (Lazear, 2005; Cadenillas et al., 2005; Palomino \& Peyrache, 2013). The findings of this study make a significant contribution to the broader literature on sorting (personnel control) using pay-forperformance contracts (Hall \& Murphy, 2003; Lazear, 2005). However, it is one of the few empirical studies to bring empirical evidence at the CEO level. Second, the study also contributes to the widely discussed topic of CEO compensation by focusing on an understudied yet compelling perspective of sorting and deviates from the extant literature that focuses mostly on the incentive perspective. By doing so, the study aims to also lend an additional perspective to the ongoing debate on the justification and efficacy in the varying mix of stock-based compensations (in lieu of fixed salary) across CEOs. Third, this study adds to the recent and growing literature that explores into the various roles of compensation practices other than incentives (Ittner et al., 2003; Gerakos et al., 2018). Finally, the study also contributes to literature that studies the dynamic evolution of contracts over time by providing interesting observations on the dynamic evolution of the compensation structures within a contract (Gibbons \& Murphy, 1992; Edmans et al., 2012; Edmans \& Gabaix, 2016).

In the third study (Chapter 4), I find that firms tend to select on stability and trainability of employee when they are investing in training. In addition, I find that the complementarity between training and employee selection across all firms in the sample are driven by the need to select employees based on both the attributes of stability of the employee, and ability of the employee (innate or previously acquired). In addition, I also find that this positive relationship between employee selection and training investment gets stronger with increasing creativity-dependence, especially in 
firms involved in $\mathrm{R} \& \mathrm{D}$ activities and those operating in the creative industries. The study contributes to the sparce (and mostly dated) literature examining firms decisions on resource intensity of employee selection process and that of training by bringing in fresh empirical evidence to the complementarity relationship between the two. Most importantly, the study is one of the first to directly test the theoretical explanations that has been widely accepted in the literature. In addition, the study makes a very important contribution to the topic by testing for the validity of these theoretical explanations in varying contexts. In particular, the theoretical explanations of looking for a stable and trainable employee, at the time of selection, when firms are investing in training (for the complementarity relationship between employee selection and training intensity) are supported by this study, at large. However, interestingly, in the sub-sample of creative firms, it is the demand for 'value congruence' between the employee and the firm that is mainly driving the complementarity relationship, instead of the demand for stability and trainability. This finding makes the study very interesting and relevant in two ways. First, it broadens the theoretical framework to include other possible attributes that could determine the returns to training. Second, it highlights that the relative demand for different employee attributes might vary with context, at the time of selection.

\subsection{Outline of the dissertation}

The following three chapters present the three studies that were introduced in this chapter. Chapter 2 presents the study on the relationship between recruitment strategy and compensation design. Chapter 3 presents the study on the role of stock-based pay in sorting Chief Executive Officers. Chapter 4 presents the study on the relationship between resource intensity of employee selection and that of training. Chapter 5 concludes this dissertation by summarizing the main findings of the studies, discussing the implications and limitations, and offering directions for future research. 



\section{Chapter 2}

In Search of Intrinsic Motivation: The Complementarity between Recruitment Strategy and Compensation Contract Design*

* This chapter is a joint work with Isabella Grabner and Frank Moers. 


\begin{abstract}
We examine, both analytically and empirically, how a firm's recruitment strategy complements the provision of fixed wage contracts in order to attract highly intrinsically motivated employees. Employee selection is particularly useful when output contractibility is low and firms need to rely on intrinsic motivation (rather than extrinsic incentives) to induce the desired effort. An important, yet understudied challenge in the recruitment process is that - to be able to select a suitable candidate-firms first need to ensure that a sufficient number of suitable candidates apply for a certain position (i.e., self-select into the applicant pool). Hence, the recruitment strategy, which affects the applicant pool, becomes a very crucial control choice, especially when output contractibility is low. We analytically show that firms align their recruitment strategy with the choice of compensation contracts, in the sense that fixed wage contracts become more beneficial when used in combination with those recruitment channels that are more likely to attract highly intrinsically motivated employees, and vice versa. Using data from the Workplace Employment Relations Survey (WERS), we also find strong empirical support for our key prediction that recruitment strategy and compensation contract design are complements.
\end{abstract}

Keywords: recruitment strategy, compensation contracts, fixed wages, intrinsic motivation, employee selection 


\subsection{Introduction}

We examine, both analytically and empirically, how a firm's recruitment strategy complements the provision of fixed wage contracts to attract highly intrinsically motivated employees. Recruitment strategy refers to the choice between various recruitment channels — such as newspapers, the web, internal referrals, and word-ofmouth - that affect the pool of candidates from whom new employees will be selected.

Previous research has acknowledged that employee selection is an important input-based control when output-based controls (such as explicit incentives) and behavior controls (such as monitoring) become difficult or costly to implement (e.g., Prendergast, 2008; Campbell, 2012; Abernethy et al., 2015). The general argument is that employee selection is particularly useful when firms need to rely on intrinsic motivation (rather than extrinsic incentives) to induce the desired effort. An important, yet understudied challenge in the recruitment process is that - in order to be able to select a suitable candidate - firms first need to ensure that a sufficient number of suitable candidates apply for a certain position (i.e., self-select into the applicant pool). Employee attraction can occur via various channels, each of which creates a potentially different applicant pool, which has important implications for 'who the firm selects' eventually. Thus, to be able to select a highly intrinsically motivated candidate it is important to first use a recruitment channel that successfully attracts such a candidate into the applicant pool (Delfgaauw \& Dur, 2007). By examining the choice of recruitment channel, we focus on the part of the employee recruitment process that affects whom the firm attracts into the applicant pool, an area that has received limited attention to date.

The concept of intrinsic motivation has been discussed in the psychology literature as early as the 1960 s (Porter $\&$ Lawler, 1968), gradually spilling over to other disciplines, including economics (e.g., Benabou \& Tirole, 2003; Prendergast, 2008), accounting (e.g., Kunz \& Pfaff, 2002; Kadous \& Zhou, 2018), and organization behavior (e.g., Deci \& Gagne, 2005; Zhang et al., 2016). Deci (1972) describes intrinsic motivation as follows: a person is intrinsically motivated to perform an activity if there is no apparent reward except the activity itself or the feelings that result from the activity. Importantly, recent literature suggests that, akin to other individual traits such as ability, workers differ in terms of being intrinsically motivated to perform a particular task (Beasley \& Gathak, 2005; Delfgaauw \& Dur, 2007; Prendergast, 2008). This stems from the fact that individuals, in general, are not equally motivated to perform every task. The assumption that intrinsic motivation provides utility from effort and that this utility differs across individuals has important implications for firms. First, when output is difficult to contract upon, firms can rely on intrinsic motivation to induce effort. Second, if they do so, then a firm's performance depends on its capability to attract the most intrinsically motivated workers for a task. Hence, the choice of recruitment strategy, which affects the applicant pool, becomes crucial, especially when output 
contractibility is low. We therefore argue that firms align their recruitment strategy with the choice of compensation contracts, in the sense that fixed wage contracts will be used in combination with those recruitment channels that are more likely to attract highly intrinsically motivated employees.

We define recruitment strategy as the choice between various recruitment channels—such as newspapers, the web, internal referrals, and word-of-mouth-each of which potentially results in a different pool of applicants in terms of observable and unobservable traits, including intrinsic motivation. Following the labor economics literature, we distinguish these channels into formal and informal channels based on the source of information about the potential candidate and the extent of formal procedures followed in these channels (e.g., Rees, 1966). Particularly, channels such as referrals from employees, word-of-mouth, and approaching potential candidates directly are considered informal channels because of the informal nature of the process, as well as the inward nature of sourcing information. On the other hand, channels like newspapers advertisements, employment services, and external websites are viewed as formal channels because of the formal nature of the process and the outward nature of sourcing information.

A key characteristic of recruitment channels that differentiates informal channels from formal channels are the application costs imposed on candidates, which has important consequences for the type of candidates the firm can attract. The formal nature of the recruitment process of formal channels arguably imposes higher application costs on candidates compared to informal channels. Building on the analytical model of Delfgaauw and Dur (2007), we analytically show that higher application costs result in a lower likelihood of hiring but a higher likelihood of attracting highly intrinsically motivated candidates. The economic intuition is relatively straightforward; higher application costs make the job opening less attractive, which pushes away candidates and especially those who have less intrinsic motivation for the job. Thus, compared to informal channels, formal channels induce a more favorable self-selection of candidates based on their unobservable intrinsic motivation for the job but also result in fewer candidates being interested in the job.

Since intrinsic motivation is unobservable to the firm, the effectiveness of formal channels over informal channels involves a trade-off between a more favorable self-selection and fewer interested candidates. We analytically show that output contractibility affects this trade-off. Intuitively, the greater the incentives a firm can provide, the less it cares about attracting highly intrinsically motivated candidates and in turn the more it cares about hiring per se. This triggers a preference for informal channels. Alternatively, when a firm can only provide fixed wages, then it needs to rely on the intrinsic motivation of the candidates, which triggers a preference for formal channels. Relatedly, we show that the marginal benefits of providing incentives are lower when using a formal channel compared to using an informal channel. As a result, the 
key prediction of our model is that formal channels (informal channels) and fixed wages (incentives) are complements.

Our empirical analysis is based on data from the 2011 Workplace Employment Relations Survey (WERS) for a sample of 337 unique firms. This dataset provides us with a unique opportunity to test our prediction for two reasons. First, WERS is one of the few large-scale surveys that covers a cross-section of firms with information on the recruitment channels used for hiring, as well as on employees' compensation contracts. The dataset thus contains variables for our key theoretical constructs. Second, the sampling methodology used for the WERS sample, and the provided information on sampling weights provides us with the opportunity to test for complementarity at both the sample level and the population level. This is important because Masschelein and Moers (2020) show that there is a predictable pattern in the power of different types of specifications to detect a complementarity as the level of optimality changes, and it is reasonable to expect that the population consists of "more off-equilibrium observations" (lower level of optimality). We can thus design very specific empirical tests to draw inferences about the existence of a complementarity.

We empirically test for complementarity using both the demand specification and the performance specification (Grabner \& Moers, 2013; Masschelein \& Moers, 2020). Exploiting the expected differences in the levels of optimality between the sample and the population (Masschelein \& Moers, 2020), we indeed find evidence for our key prediction that formal channels (informal channels) and fixed wages (incentives) are complements. More specifically, the demand specification, which has significant power to detect a complementarity even at lower levels of optimality, shows a significant complementarity between formal channels (informal channels) and fixed wages (incentives), irrespective of the level of optimality assumed in the observations. The performance specification, which only has significant power at lower levels of optimality, indeed shows a significant complementarity only when the level of optimality is assumed to be (relatively) lower. The empirical results are thus not only consistent with the prediction of our analytical model but also with the simulation results in Masschelein and Moers (2020) regarding the power of different specifications to detect a complementarity. Overall, our results provide support for the prediction that recruitment strategy and compensation design are complements.

While the provision of (effort) incentives is one of the most widely studied topics in both accounting and economics, much less attention has been paid to an equally relevant problem: how to attract employees who are willing to perform to the best of their abilities even when paid fixed wages. By addressing this important question, our study contributes to the literature on employee selection in two important and interrelated ways. Diverging from the related literature on employee selection that focuses on 'whom the firm selects' and implicitly takes the applicant pool as given (e.g., Abernethy et al., 2015; Grabner \& Speckbacher, 2016), we focus on that part 
of the employee selection process that has been understudied as a control mechanism, namely recruitment channels that affect 'who the firm attracts' in the first place. This has important implications for 'who the firm selects' eventually. In doing so, our study contributes to the nascent stream of research in accounting and economics on the consequences of a firm's recruitment strategy, and in particular the ability to attract highly intrinsically motivated employees. The (accounting) literature has been relatively silent about whether formal or informal channels better match with low output contractibility. An exception is Campbell (2012), who examines recruitment channels in the context of low output contractibility. He shows that hires via referrals by employees who are particularly committed to the firm strategy do better than all other hires. However, his results also show that, on average, referred hires do not do better than non-referred hires (even a bit worse). An explanation for this finding is that, while informal channels like referrals can benefit from the use of private information held by others, such channels are also troubled by issues of nepotism and favoritism, which results in worse hires (e.g., Pallais \& Sand, 2016; Beaman et al., 2018). In general, there is no consistent evidence in the literature that informal channels have, on average, an information advantage over formal channels (Pallais \& Sands, 2016). We show that a key difference between informal and formal recruitment channels that affects the attraction of highly intrinsically motivated employees is the application cost imposed on the candidate. Counter to intuition that informal recruitment channels might be better suited to identify highly intrinsically motivated employees, firms tend to rely on formal recruitment channels that pose high hurdles on their prospective employees when the provision of incentives is infeasible. Conversely, our results also imply that if firms tend to rely on formal recruitment channels for other reasons, fewer or less costly incentives would be needed to induce the same amount of effort, irrespective of their feasibility.

We further contribute to the growing stream of literature on complementarities between management control practices (Grabner \& Moers, 2013; Chapman et al., 2020) and in particular on the complementarity between personnel controls and results controls. While prior research has addressed whether employee selection and incentive contracting are complements or substitutes (e.g., Campbell, 2012; Abernethy et al., 2015), we show that such interdependence (also) depends on the recruitment channels underlying the employee selection process. That is, we find that formal recruitment channels and incentives are substitutes, while informal recruitment channels and incentives are complements. These results highlight the importance of examining management control practices at a less aggregated level, as also echoed in Grabner and Moers (2013).

The remainder of this study is structured as follows. In Section 2.2, we discuss related literature, followed by our analytical model in Section 2.3. In Section 2.4, we discuss our data and empirical models and we present the empirical results in Section 2.5. We conclude the study in Section 2.6. 


\subsection{Related Literature}

Employee selection processes can help in finding an employee with high intrinsic motivation for a task. ${ }^{8}$ Importantly, employee selection plays an even more crucial role in situations where output-based controls (such as explicit incentives) and behavior controls (such as monitoring) become difficult or costly to implement (Prendergast, 2008; Campbell, 2012; Abernethy et al., 2015). In general, output-contracting or monitoring activities direct employees' efforts to fulfilling the firms' goals (Merchant $\&$ Van der Stede, 2012). When such controls become difficult or costly to implement, selecting agents who have strong intrinsic motivation for the task serves well in mitigating agency problems.

The importance of intrinsic motivation in exerting effort has been discussed widely across multiple disciplines (e.g., Kunz \& Pfaff, 2002; Benabou \& Tirole, 2003; Prendergast, 2008; Kadous \& Zhou, 2018). When alternate forms of controls are absent/low, studies have shown that there is a higher reliance on the intrinsic motivation of employees. Most importantly, the role of employee selection in attracting highly motivated employees has been highlighted. Holzer (1987) in his seminal work takes note of the role of recruitment strategy in achieving this goal. He shows that firms that care more about the intrinsic motivation of the workers tend to give more attention to the recruitment process. In support of this argument, Grabner and Speckbacher (2016) show that firms rely more on costly selection procedures when there is greater importance placed on intrinsic motivation of employees.

Most of the prior literature on employee selection focuses on that part of the process that affects selection of an employee by examining the rigor and extensiveness of selection processes (e.g., Abernethy et al., 2015; Grabner \& Speckbacher, 2016). These studies thus primarily focus on "whom the firm selects" from the applicant pool. In contrast, little attention has been given to the part of the employee selection process that affects "whom the firm attracts" into the applicant pool from which the firm selects in subsequent stages. To fill this gap, our study focuses on that part of the employee selection process that affects "whom the firm attracts". We define recruitment strategy as those channels used for recruitment that affect the pool of candidates from whom new employees will be selected. ${ }^{9}$ Hence, recruitment strategy, in this study, refers to the choice between various recruitment channels, such as newspapers, the web, internal referrals, and word-of-mouth, each of which would potentially result in a different pool of applicants.

8 We acknowledge that every job entails a bundle of smaller tasks to be performed, however, every job has a particular task that dominates over all other tasks. Hence, we assume that intrinsic motivation for a task is equivalent to intrinsic motivation for a job that entails that task as the main task.

9 We follow Orlitzky's (2007) broad definition of recruitment strategy as all those human resource practices that affect the applicant pool. However, we narrow our focus to recruitment channels (not the entire set of human resource practices) that affect the applicant pool. 
Prior studies distinguish these channels into formal and informal channels based on the source of information about the potential applicant and the extent of formal procedures followed in these channels (Rees, 1966; Ullman, 1966; Kirnan et al., 1989; Atkinson \& Meager, 1994; Zotolli \& Wanous, 2000). Particularly, channels such as referrals from employees, word-of-mouth, approaching potential candidates directly, and internal notices are considered informal channels because of the informal nature of the process, as well as the inward nature of sourcing information. On the other hand, channels like state employment services, external websites, and newspapers advertisements are viewed as formal channels because of the formal nature of the process, and the outward nature of sourcing information.

A number of studies have examined the effectiveness of informal channels versus formal channels from the perspective of the nature of sourcing information (e.g., Blau, 1990; Castilla, 2005; Campbell, 2012; Burks et al., 2015). The assumption often made is that informal channels have an information advantage when identifying highly quality candidates. However, the empirical evidence is mixed, even within studies. For example, Campbell (2012) examines recruitment channels in the context of low output contractibility. He shows that hires via referrals by employees who are particularly committed to the firm strategy do better than all other hires. However, his results also show that, on average, referred hires do not do better than non-referred hires (even a bit worse). An explanation for this finding is that, while informal channels like referrals can benefit from the use of private information held by others, such channels are also troubled by issues of nepotism and favoritism, which results in worse hires (e.g., Pallais \& Sands, 2016; Beaman et al., 2018). In general, there is no consistent evidence in the literature that informal channels have, on average, an information advantage over formal channels (Pallais \& Sands, 2016).

Another key difference, owing to the formal versus informal nature of the recruitment process, that has received less attention in the literature are application costs, even though a more formal recruitment process generally imposes higher application costs on applicants. The importance of application costs in sorting applicants has been emphasized by a few early studies and anecdotal evidence on the significant effect of these costs on the composition of the applicant pool. Gerson (1976) reports a decrease in applicant pool size after implementing a more burdensome (in terms of both time and cost) application process. Rynes and Lawler (1983) find that candidates may also be discouraged from applying to organizations when they, rather than the employer, bear the recruitment costs. In the same light, Breaugh $(1981,2013)$ summarizes that out of the many explanations that have been given for post-hire outcomes of using different recruitment channels, the "individual difference hypothesis", originally proposed by Schwab (1982) and Taylor and Schmidt (1983), seems to be very compelling. According to the individual difference hypothesis, different recruitment methods attract individuals who are systematically different on personal attributes, such as intrinsic motivation-it 
has, for example, been suggested that applicants seem to have greater motivation to work for an employer if they had to put forward more effort to both search and apply for a job. This hypothesis, too, hints at the role of application costs as a sorting mechanism to sort candidates on unobserved intrinsic motivation. In an analytical study, Delfgaauw and Dur (2007) examine this role of application costs and show that a positive cost can act as a strong mechanism in sorting candidates based on intrinsic motivation at the time of application. In the next section, we build on the analytical model of Delfgaauw and Dur (2007) to show (i) how the differential application cost for candidates between channels make certain channels more effective than others in attracting highly motivated candidates and (ii) how the choices of recruitment channel and incentives versus fixed wages are related.

\subsection{Analytical Model}

Our model combines the basic setup of Baker et al.'s (1994) principal-agent model with Delfgaauw and Dur's (2007) modeling of intrinsic motivation and application costs. Assume a worker's effort $a$ affects firm output $y$. In particular, $y$ is either 1 or 0 with $\operatorname{Prob}(y=1 \mid a)=a$. The firm's output is non-contractible. There is, however, a performance measure $p$ available, which is also either 1 or 0 with $\operatorname{Prob}(p=1 \mid \mathrm{a})=\mu a$, where $\mu>0$ is private pre-decision (post-contract) information of the worker and relates to the difference between the effect of the worker's effort on $y$ and its effect on $p \cdot{ }^{10}$ The employer only knows that $\mathrm{E}[\mu]=1 .{ }^{11}$ The worker is compensated via the contract $w(a)=\alpha+\beta p$, where $\alpha$ is a fixed wage and $\beta$ is the incentive weight on performance measure $p$. The worker's cost of effort $C(a)$ equals $\frac{1}{2} a^{2}$.

Other than the incentives from the compensation contract, a worker has intrinsic motivation $y$ for the firm's output $y$ and we assume that this intrinsic motivation equals $\gamma y(a) .{ }^{12}$ The intrinsic motivation $y$ is private (pre-contract) information of the worker; the firm only knows that $y$ is uniformly distributed with $\gamma \in[0,1]$. The worker's expected utility when being hired but before working equals:

$\mathrm{E}_{\mu}[w(a)+\gamma y(a)-C(a)]$

10 The interpretation of $\mu$ can be as follows: $\mu$ around 1 means on those events large actions increases both $y$ and $p, \mu$ around 0 means on those events large actions increases $y$ but not $p$ and $\mu$ above 1 means on those events small actions increases $p$ and not $y$.

11 In other words, the performance measure $p$ is an unbiased estimate of $y$, on average.

12 Note that, in our setup, this is identical to assuming that the worker has intrinsic motivation $\gamma$ for the task. Akin to the assumption that cost of effort is convex, the positive benefits of intrinsic motivation is also on the margin (for that extra unit of effort). See Lazear (2009) for a discussion on the topic. 
The problem of interest is that the firm can only hire a worker when there is a nonempty applicant pool. The traditional setup of the principal-agent model ignores this 'application problem' because it assumes that there is always somebody to hire, i.e., the likelihood of not being able to fill the position is zero. An important first step in contracting with a worker is, however, the recruitment of candidates. This is the focus of our model.

A firm can recruit via an informal channel or a formal channel. When using informal channels, a firm creates an applicant pool by directly approaching potential candidates, while when using formal channels, a firm creates an applicant pool by posting a vacancy to which potential candidates need to formally apply. The key difference between these channels is that the formal channel imposes higher application costs on the candidate compared to the informal channel. For simplicity, we set the application costs for applicants in the informal channel to zero. ${ }^{13}$

When the firm uses an informal channel, the worker's participation constraint becomes

$p\left(\gamma_{i}\right)\left[E_{\mu}\left[w\left(a_{\mathrm{i}}^{*}\right)+\gamma_{i} y\left(a_{\mathrm{i}}^{*}\right)-C\left(a_{\mathrm{i}}^{*}\right)\right]-U^{\text {out }}\right] \geq 0$

where $U^{o u t}$ is the worker's outside opportunity, $a_{\mathrm{i}}^{*}$ is the optimal effort of worker $i$, and $p\left(\gamma_{i}\right)$ is the probability that worker $i$ gets selected from the applicant pool, which is given by (see Appendix 3 of Delfgaauw and Dur 2007): ${ }^{14}$

$p\left(\gamma_{i}\right)=\sum_{v=0}^{\mathrm{N}_{\gamma_{\min }}{ }^{-1}}\left[\frac{1}{(1+v)}\left(\mathrm{N}_{\gamma_{\min }}^{-1}\right) \rho^{v}(1-\rho) \mathrm{N}_{\gamma_{\min }}^{-1-v}\right.$

where $\mathrm{N}_{\gamma_{\text {min }}}$ is the total number of workers (in the labor market) for which equation (2) is satisfied, with $\gamma_{\min }$ being the lower bound on intrinsic motivation, $v$ is the number of applicants other than worker $i$ ( $v$ is a random variable that follows a binomial distribution), and $\rho<1$ is the likelihood that all $\mathrm{N}_{\gamma \min }$ workers have been approached by the firm. Further, $p\left(\gamma_{i}\right)=p\left(\gamma_{j}\right)=p(\gamma)$ for all , $\gamma \geq \gamma_{\min }$ since $\gamma$ is uniformly distributed. Given that $\gamma$ is unobservable by the firm, the firm selects a worker randomly (with respect to $\gamma$ ) from the applicant pool. The firm's maximization problem is therefore:

$\max \sum_{\gamma \geq \gamma_{\min }} P(\gamma) \mathrm{E}_{\mu}\left[\gamma\left(a_{\mathrm{i}}^{*}\right)-w_{\min }\left(a_{\mathrm{i}}^{*}\right)\right]$

13 In other words, the application cost when using formal channels reflects the differential application costs between formal and informal channels.

14 We assume that labor market conditions (tight or slack) will be reflected in the individual outside opportunities $U^{o u t}$. Hence, with changing market conditions, for example, tightening of the market, the outside opportunities might decrease, but the results of the model remain unchanged unless market conditions approach negative infinity. Hence, wages are assumed to reflect labor market conditions. 
subject to

$p(\gamma)\left[\mathrm{E}_{\mu}\left[w_{\min }\left(a_{\gamma_{\text {min }}}^{*}\right)+\gamma_{\min } y\left(a_{\gamma_{\text {min }}}^{*}\right)-\left(a_{\gamma_{\text {min }}}^{*}\right)\right]-U^{\text {out }}\right]=0$

$a_{\mathrm{i}}^{*}=\beta \mu+\gamma_{i}$

where $w_{\text {min }}$ is the minimum payment that binds the participation constraint for a worker with $\gamma=\gamma_{\min }$ and equation (6) is worker $i$ 's optimal response when being selected for the job, given the compensation contract and intrinsic motivation $\gamma_{i}{ }^{15}$ It is trivial to show that, if $w_{\text {min }}$ binds the participation constraint for $\gamma_{\text {min }}$, then $w_{\text {min }}$ satisfies the participation constraint for all $\gamma>\gamma_{\text {min }} . P(\gamma)$ is the probability that the firm selects a worker with motivation $\gamma$ and is given by (see Appendix 3 of Delfgaauw and Dur, 2007):

$P(\gamma)=\sum_{s=1}^{n} \sum_{z=0}^{\mathrm{N}_{\gamma_{\text {min }}-n}} \frac{s}{s+z}\left(\begin{array}{l}n \\ S\end{array}\right) \rho^{s}(1-\rho)^{n-s}\left(\begin{array}{c}\mathrm{N}_{\min ^{-1}} \\ \mathrm{z}\end{array}\right) \rho^{z}(1-\rho)^{\mathrm{N}_{\min }{ }^{-n-z}}$

with $n$ the total number of workers of type $\gamma$ (in the labor market), which is the same for each type (given the uniform distribution), $s$ the number of applicants of type $\gamma$, and $z$ the number of applicants of a type other than $\gamma .{ }^{16}$ It follows from the above that $p\left(\gamma_{i}\right)$ $=p\left(\gamma_{j}\right)$ for all $\gamma \geq \gamma_{\min }$ and $\sum_{\gamma \geq \gamma_{\min }} P(\gamma)<1$, the latter being the likelihood of filling the vacancy.

The optimal incentive weight that results from the firm's maximization problem is

$\beta^{*}=\frac{\mathrm{E}[\mu]}{\mathrm{E}\left[\mu^{2}\right]}=\frac{1}{1+\operatorname{var}[\mu]}$

This incentive weight is identical to the optimal incentive weight in the absence of any intrinsic motivation and application problems (see equation 8 of Baker et al., 1994). ${ }^{17}$ Thus, although the firm is now (also) concerned with being able to fill the vacancy, the optimal incentive weight is unaffected. That is, optimal incentives are independent of the application problem and fully determined by the extent to which the performance measure $p$ captures the worker's contribution to firm output $y .{ }^{18}$ The application problem centers on having a minimum fixed wage $\alpha_{\min }$ that provides at least one type

15 Upon selection and after observing $\mu$, the worker maximizes $\left[w\left(a_{i}\right)+\gamma_{i} \gamma\left(a_{i}\right)-C\left(a_{i}\right)-U^{o u t}\right]$ over $a$. That is, the worker maximizes $\left[\alpha+\beta \mu a+\gamma_{i} a-\frac{1}{2} a^{2}-U^{o u t}\right]$ over $a$. Taking the first derivative and solving for $a$ gives equation (6).

16 Both the variables $s$ and $z$ follow a binomial distribution and are independently distributed.

17 Note that $\mu$ and $\gamma$ are by construction uncorrelated because the former is post-contract private information while the latter is pre-contract private information.

18 Hence, wages are assumed to be independent of the recruitment channels used. 
the incentive to accept the contract. ${ }^{19}$ This can be seen from the firm's expected profit, which is given by:

$$
V_{\gamma}=\sum_{\gamma \geq \gamma_{\text {min }}} P(\gamma)=\left[\frac{1}{2} \beta^{*}-U^{o u t}+E_{\gamma \geq \gamma_{\text {min }}}[\gamma]+\frac{1}{2} \gamma_{\text {min }}^{2}\right]
$$

If no type has an incentive to accept the contract, i.e., $\gamma_{\text {min }}>1$, then $\sum_{\gamma \geq \gamma_{\min }} P(\gamma)=0$ and the firm shuts down. The firm might be able to change the minimum fixed wage to adjust $\sum_{\gamma \geq \gamma_{\min }} P(\gamma)$. However, wages are often tied to jobs and as such more or less given, similar to the optimal incentives being "jobspecific", as reflected by the fact that equation (8) is also the optimal solution to the maximization problem in the absence of intrinsic motivation and application problems. Rather, the question of interest here is whether a firm can increase its expected profit by using an alternative recruitment channel, given a certain $\alpha_{\text {min }}$ and $\beta^{*}$.

Let us assume that $w_{\min }$ in equation (5) is such that at least two types have an incentive to accept the contract when being approached by the firm. Following the optimal solution, $\alpha_{\min }$ is the fixed wage that binds equation (5), given the optimal incentive weight $\left(\beta^{*}\right)$ and the optimal effort of a worker with $\gamma$ $=\gamma_{\text {min }}\left(\left(a_{\gamma_{\text {min }}}^{*}\right)\right.$. The question now is what the firm's expected profit is when using a formal recruitment channel while offering the contract $w_{\min }(a)=\alpha_{\min }+\beta^{*} p$. The formal channel differs from the informal channel in two ways. First, and more technically, when the firm posts a vacancy, it discloses the compensation contract. This disclosure acts as a commitment, which is necessary because otherwise nobody will apply (see Delfgaauw and Dur, 2007). Second, and more fundamentally, the formal channel puts the application burden on the candidate and as such there are (additional) application costs for the candidate compared to when being approached via the informal channel. Assume a candidate needs to incur an application cost $A$ when the firm uses a formal channel..$^{20}$ As a result, the worker's participation constraint becomes:

$p^{\prime}\left(\gamma_{i}\right)\left[\mathrm{E}_{\mu}\left[w_{\min }\left(a_{\mathrm{i}}^{*}\right)+\gamma_{i} y\left(a_{\mathrm{i}}^{*}\right)\right]-U^{o u t}\right]-A \geq 0$

with

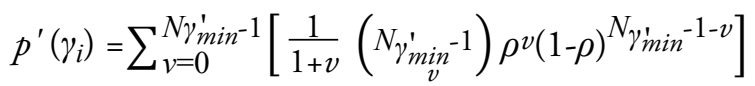

19 Technically, the application problem affects the participation (individual rationality) constraint but leaves the incentive compatibility constraint unaffected.

20 This cost can be interpreted as both explicit costs of applying as well as implicit costs of searching for the job vacancy. 
where $\mathrm{N}_{\gamma_{\text {min }}^{\prime}}$ is the total number of workers (in the labor market) for which equation (10) is satisfied. It is trivial to show that the $\gamma_{\text {min }}^{\prime}$ for which equation (10) binds is larger than $\gamma_{\text {min }}$ (and thus $\mathrm{N}_{\gamma_{\text {min }}^{\prime}}<\mathrm{N}_{\gamma_{\text {min }} \text { ) }}$. Assume that the formal channel can attract one type less than the informal channel. The expected profit when using the formal channel then equals

$$
V_{\gamma}^{\prime}=\sum_{\gamma \geq \gamma_{\min }} P^{\prime}(\gamma)\left[\frac{1}{2} \beta^{*}-U^{o u t}+E_{\gamma>\gamma_{\text {min }}}[\gamma]+\frac{1}{2} \gamma_{\text {min }}^{2}\right]
$$

with

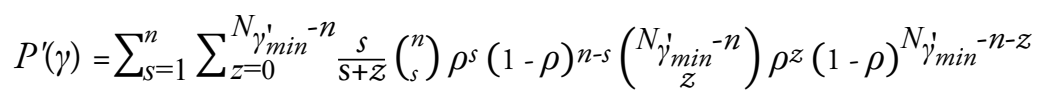

where $P^{\prime}(\gamma)>P(\gamma)$ for all $\gamma=\gamma_{\text {min }}$ (since $N_{\gamma_{\text {min }}}<N_{\gamma_{\text {min }}}$ ) and $\sum_{\gamma>\gamma_{\min }} P^{\prime}(\gamma)<$ $\sum_{\gamma \geq \gamma_{\min }} P(\gamma)$. That is, the likelihood of hiring a worker of type $\gamma=\gamma_{\min }$ is higher when using the formal channel compared to using the informal channel, but the likelihood of hiring per se is lower when using the formal channel compared to using the informal channel.

The difference in expected profits between the informal channel $\left(V_{\gamma}\right)$ and the formal channel $\left(V_{\gamma}^{\prime}\right)$ consists of two parts and is equal to: ${ }^{21}$

$$
\begin{aligned}
& \Delta V_{\gamma}=V_{\gamma}-V_{\gamma}^{\prime}=\sum \gamma \geq \gamma_{\min }\left[P(\gamma)-P^{\prime}(\gamma)\right]\left[\frac{1}{2} \beta^{*}-U^{o u t}+\frac{1}{2} \gamma_{\min }+\frac{P(\gamma) \gamma_{\min }}{\sum_{\gamma \geq \gamma_{\min }}\left[P(\gamma)-P^{\prime}(\gamma)\right]}\right]+ \\
& \sum_{\gamma>\gamma_{\min }}\left[P(\gamma)-P^{\prime}(\gamma)\right]\left[\mathrm{E}_{\gamma>\gamma_{\text {min }}}[\gamma]\right]
\end{aligned}
$$

The first part reflects the potential benefit of informal channels over formal channels. This benefit relates to a higher likelihood of hiring. The second part is negative and reflects the benefit of formal channels over informal channels. This benefit relates to formal channels having a higher likelihood of hiring more intrinsically motivated workers.

While $\Delta V_{\gamma}$ can have any sign, what is important is that the level of incentives triggers a shift in the relative benefits of the two channels. That is,

$$
\frac{\partial \Delta V_{\gamma}}{\partial \beta^{*}}=\frac{1}{2} \sum_{\gamma>\gamma_{\text {min }}}\left[P(\gamma)-P^{\prime}(\gamma)\right]>0
$$

In words, the greater the explicit incentives, the higher the expected profit when using informal channels compared to when using formal channels. Intuitively, the greater the incentives a firm can provide, the less it cares about the intrinsic motivation of the worker and the more it cares about hiring per se. In essence, the

21 Note that $\sum_{\gamma>\gamma_{\text {min }}} P^{\prime}(\gamma)=\sum_{\gamma \geq y_{\text {min }}} P^{\prime}(\gamma)$, since $P^{\prime}\left(\gamma_{\text {min }}\right)=0$. 
firm relies on the compensation contract to solve motivational problems. Given that the benefit of informal channels is a higher likelihood of hiring, explicit incentives trigger a preference for informal channels. Alternatively, when a firm can only provide fixed wages, i.e., $\beta^{*}=0$, then it needs to rely on the intrinsic motivation of the worker, which triggers a preference for formal channels. Finally, the marginal benefits of providing incentives are lower when using a formal channel compared to when using an informal channel. As a result, the key prediction of our model is that formal (informal) channels and fixed wages (incentives) are complements, which we summarize in the following hypothesis.

Нуротнеsis: Formal recruitment channels (informal recruitment channels) and fixed-pay contracts (incentive pay contracts) are complements.

\subsection{Empirical Method}

\section{Sample and data}

We use data from the 2011 Workplace Employment Relations Study (WERS) survey, which is a survey on employment relations for a sample of workplaces (hereafter referred to as firms) with five or more employees in Britain. ${ }^{22}$ We use this dataset mainly because of the availability of information on recruitment channels for a large cross-section of firms, which is particularly unique to this dataset. Specifically, the survey has information on all relevant variables for our study, including hiring practices, establishment characteristics such as total number of employees, industry, occupation of the largest group of employees, total assets, and sales on goods and services at the firm level. The survey also has a matched employee-based survey, which covers a representative group of workers from these firms and contains information on the type of contracts and their education levels, among other information. Hence, the dataset allows us to address our research question on a cross-section of firms.

The sampling methodology used for the WERS sample is a stratified design with unequal selection probabilities per firm. In particular, there is an above-average probability of selection of larger firms and those from less populated industries. As a result, the sample is not representative of the population at large. However, the dataset contains sampling weights that bring the profiles of the samples of firms in line with the profiles of the population. This allows us to provide statistics at both the sample level and the population level, which we exploit in our complementarity tests. After dropping all missing values for the relevant variables, our sample consists of 337 firms.

22 See https://www.wers2011.info/ for more information about WERS. 


\section{Key test variables}

Formal Recruitment Channel. The formal recruitment channel variable (Formal Channel) is constructed from the response to the following question asked at the firm-level: What are the three most common channels used when trying to fill [these] vacancies? Following prior literature (Rees, 1966; Atkinson \& Meager, 1994; Kirnan et al., 1989; Simon \& Warner, 1992), we consider all formal channels, such as newspaper-ads, as formal, high cost recruitment channels as the cost for a worker, in terms of time and effort spent on looking for a vacancy, writing an application, and sending the application, is relatively high compared to the informal channels such as referrals. Among the list of recruitment channels in the survey, we categorize the following as formal channels: Local or regional newspaper; trade, professional and specialist press; career services in college; job-center or employment service office; internet or external website; notice in office or shop window; and replying to speculative applications. Following the same argument, the following channels are informal and are expected to have relatively lower application costs: Internal notices; direct approach to potential recruit; recommendation or enquiry by existing employees; word of mouth; intranet or own website; and fee charging, private employment or recruiters. ${ }^{23}$

Given that each firm generally uses more than one recruitment channel, firms have multiple responses to the survey question in point. Hence, to arrive at our variable Formal Channel, we compare the share of formal channels used relative to the share of informal channels used and construct a binary variable for adoption of formal channels if the former exceeds the latter for a firm. ${ }^{24}$ Since the two types of channels are not mutually exclusive within a firm, what this categorization implies is that, when the variable takes the value one for a firm, the firm relies more on formal channels than on informal channels while recruiting.

Share of Fixed-Pay Contracts. For each workplace, we calculate the share of employees with fixed-pay contracts for the representative group of workers in a firm. These are contracts with no variable-pay based on individual output. The measure reflects the extent to which the firm relies on fixed wages versus incentives. In order to make the interpretation of the results easier, we construct a normative variable by subtracting the population average share of employees with fixed contracts and dividing the difference by the standard deviation (yielding a measure with mean zero and standard deviation one). ${ }^{25}$ When the value is positive, the workplace has a higher share of employees with fixed-pay contracts, compared to the population average, zero when it is the same as the population average, and negative when it is lower than the population average.

23 Although the latter channel is, in essence, a formal channel, it is expected to have a lower cost for applicants as the private recruiters generally approach applicants when there are vacancies, akin to the case of 'direct approach to potential recruit'. We expect that the firm (or private recruiters) bear the cost and hence, the costs are lower for applicants compared to channels like newspaper ads where the applicant needs to search and apply by himself. In addition, Simon and Warner (1992) treat search firms as another source of employee referrals.

24 We place equal weights to all channels and exclude the 'Others' category from calculation of shares because it is difficult to ascertain the exact channels used under this 'Others'category.

25 Note that this standardization neither affects the sign nor the significance level of this variable in any analysis. 


\section{Model specification}

Empirically, we test whether there is a complementary relationship between higher reliance on formal recruitment channels and higher share of fixed-pay contracts, at the firm level. The two typical specifications for testing such complementarity are (i) the demand specification, which tests for a conditional correlation between two practices, and (ii) the performance specification, which tests for the performance effects of the combined use of two practices (see Grabner \& Moers, 2013). Conceptually, the demand specification relies on the assumption of optimality (on average), while the performance specification relies on the assumption of significant deviations from optimality. Masschelein and Moers (2020), however, show that, empirically, the demand specification is much more robust to different levels of optimality in a sample than the performance specification. In addition, while both specifications are subject to the same correlated omitted variable problem (Masschelein \& Moers, 2020), it is easier to control for observed confounding factors, as well as test for the impact of unobserved confounding factors when using the demand specification. We nevertheless use both approaches because the survey design allows us to test the complementarity in both the sample and the population, and we expect that these differ in terms of the level of optimality, which we explain in detail in the next section.

According to the conditional correlation test (demand specification), if there is complementarity between two practices, then there should be a positive correlation between these practices after controlling for other firm-specific observable factors. This can be estimated by the following equation

\section{Formal Channel $l_{i}=\alpha_{0}+\alpha_{1}$ Share(Fixed-Pay Contracts) ${ }_{i}+\sum_{j} \alpha_{j}$ Controls $_{i}+\varepsilon_{i}$}

where complementarity will be revealed by a positive and significant $\alpha_{1}{ }^{26}$ To estimate the performance specification, we are restricted (by the data) to use sales as the productivity measure and thus run the following regression

$\ln \left(\right.$ Sales $_{i}=\beta_{0}+\beta_{1}$ Formal Channel $_{i}+\beta_{2}$ Share $\left(\text { Fixed }^{\prime}-" \text { Pay Contracts }\right)_{i}+$
$\beta_{3}$ Formal Channel $_{i} \times$ Share $(\text { Fixed }- \text { Pay Contracts })_{i}+\sum_{j} \beta_{j i}$ Controls $_{i}+\vartheta_{i}$

where complementarity is revealed by a positive and significant coefficient on the two-way interaction term, $\beta_{3} .{ }^{27}$

26 Note that this test is equivalent to (i) regressing Formal Channels on the controls, (ii) regressing Share(Fixed-Pay Contracts) on controls, and (iii) correlating the residuals of the these two regressions (see Masschelein \& Moers, 2020). It therefore also does not matter which of the two practices is used as a dependent variable.

27 Note that, because Formal Channel is a binary variable and Share(Fixed-Pay Contracts) is a standardized variable, we cannot include quadratic terms for these practices to control for diminishing returns (see Masschelein \& Moers, 2020). Including the non-standardized version of Share(Fixed-Pay Contracts) and its quadratic term does not change any of our results. 
In both tests, we control for various firm-specific factors that previous research has shown to be correlated with the use of formal recruitment channels and might also be associated with the use of fixed wages versus incentives. First, we control for firmsize, captured by both total number of employees $(L)$ and total assets $(K)$. Atkinson and Meager (1994) show that smaller firms tend to favor informal channels. Second, we control for the use of temporary workers (Share(Temporary Workers)) because Russo et al. (2000) show that firms tend to rely more on formal channels to fill up permanent positions than temporary positions. Third, some studies have found that informal channels are used more often when there is a higher presence of trade-unions (Kennedy \& Widener, 2019), which is why we control for the percentage of workers who are part of a trade union (Share(Workers in TU)). Fourth, Atkinson and Meager (1994) also find that certain channels are used more often to hire people for certain occupations. For example, referrals or word-of-mouth are more often used for managerial and manual labor employees, while newspapers and external websites are more often used for clerical and technical employees. We therefore include indicators for the occupation with the largest number of employees within the firm. Fifth, Aldrich and Langton (1997) and Leung (2003) find that the age of the firm can be a determinant for the choice of certain recruitment channels - younger firms preferring to go for informal channels over formal channels. We therefore control for the number of years the firm has been in operation (Firm Age). Sixth, we include industry dummies because Scott et al. (1989) find industry level variation in the use of recruitment channels-traditional manufacturing and service sectors use channels like referrals and word-of-mouth, while high-technology sectors use newspapers and external websites. Finally, in model (M2), we control for the share of female workers (Share(Females)) and certain ethnic groups (Share(Non-White)). ${ }^{28}$ All variables are defined in detail in the Appendix.

The difficulty of including the above controls in the performance specification is that, strictly speaking, all the controls should also be interacted with each of the two practices (Masschelein \& Moers, 2020). Given the large number of control variables, this leads to overfitting the model. We address this problem in the following way. We first run the performance specification without interactions between the control variables and the two practices. Subsequently we add interactions between one control variable and the two practices, and do this for all control variables sequentially, and check whether the results of the first regression hold.

28 We do not include these latter two controls in model (M1) because studies have shown that such shares might be an outcome of using particular recruitment channels (see e.g., Beaman et al., 2018). 


\section{Variation in the level of optimality}

The presence of sampling weights in the dataset allows us to test for complementarity at both the sample level and the population level. That is, estimation of models (M1) and (M2) without sampling weights results in sample (unweighted) estimates, while estimation with sampling weights results in population (weighted) estimates. While differences between unweighted and weighted estimates are typically interpreted as reflecting a bias or misspecification, we exploit the use of sampling weights to get estimates in settings with higher versus lower levels of optimality (in relative terms). In particular, we expect larger firms, which are oversampled, to exhibit higher levels of optimality than smaller firms because of their access to more resources that allow for experimentation. The expectation regarding oversampling of less populated industries is more ambiguous. On the one hand, less populated industries often have lower competition, which provides more room to experiment. In addition, a firm is more likely to "know" its peers in the industry and what they are doing, which allows for knowledge spillovers. On the other hand, the potentially lower competition in less populated industries provides less incentives to be optimal and there is also less knowledge in total compared to more populated industries. Taken together, however, we expect the selection bias to result in the sample having a higher level of optimality compared to the population.

Masschelein and Moers (2020) show that, while the performance specification suffers from elevated Type I errors in general, the power of this specification significantly decreases when the level of optimality increases. If it is indeed the case that the population has a lower level of optimality compared to the sample and there is a complementarity between the two practices, then the performance specification with sampling weights (population) will do a better job in estimating this complementarity than the performance specification without sampling weights (sample). We thus focus on the difference in the weighted and unweighted estimate of $\beta_{3}$ in model (M2), expecting the weighted estimate to be higher and more significant. ${ }^{29}$ The demand specification, on the other hand, should be more robust to these differences in the level of optimality (Masschelein \& Moers, 2020), which implies that estimation with or without sampling weights should produce fairly similar results.

29 Note that, in contrast to the recommendation of Masschelein and Moers (2020), we do not adjust the standard errors of the performance specification to correct for Type I errors. The reason for this is twofold. First, such an adjustment is not applicable when using sampling weights to estimate the population parameters. Second, and related, the focus is on a comparison between sample estimates and population estimates, so we need to hold the estimation method constant. 


\subsection{Empirical Results}

Table 2.1 provides the descriptive statistics for the sample. Panel A provides the population statistics based on the sample and using sampling weights, whereas Panel B provides the population statistics for firms who adopt more of formal channels versus those who adopt more of informal channels. Panel A shows that around 54\% of firms are Formal Channel adopters. The average share of fixed-pay contracts in a firm is around $87 \%$. The average share of workers covered by unions is around $6.7 \%$ and the average share of temporary contracts in a firm is around $6.6 \%$. The average age of a firm in the sample is 22 years. For all these variables, we use a log-normal transformation for our analysis to address the skewness in the distribution (seen from the median values of these variables compared to the mean values). Panel B shows that, on average, firms with formal channels are smaller in terms of number of employees and total assets, but more productive in terms of sales performance compared to informal channel firms. Further, the formal channel firms have a higher share of fixed-pay contracts and share of union workers than informal channel firms, and lower share of temporary contracts. Although, none of these differences are statistically significant. We do find a significant difference between the share of female workers between formal channel firms and informal channel firms, consistent with females being disadvantaged by informal channels (Beaman et al., 2018). 
Table 2.1: Population Statistics

\begin{tabular}{lccc}
\hline Panel A & Mean & Median & Std.dev \\
\hline Variable & 54 & 100 & 49.9 \\
\hline Share of formal channel firms (\%) & 87 & 100 & 21.5 \\
Share of fixed-pay contracts in a firm (\%) & 32 & 13 & 158 \\
Number of employees & 6841 & 103 & 105000 \\
Capital ('000 GBP) & 6.7 & 0 & 14.6 \\
Share of workers in Trade Unions (\%) & 6.6 & 0 & 19.8 \\
Share of temporary contracts in a firm (\%) & 21.7 & 14.0 & 24.9 \\
Firm-age (years) & 655000 & 950 & 7960000 \\
Sales ('000 GBP) & 4.6 & 0.0 & 11.1 \\
Share of non-white workers in a firm (\%) & 51.5 & 52.0 & 27.2 \\
Share of female workers in a firm (\%) & 337 & & \\
Number of Observations & & & \\
\hline Panel B & Formal & Informal & \\
\hline & Channel & Channel & Diff \\
Variable & 89.4 & 84.6 & 4.8 \\
\hline Share of fixed-pay contracts in a firm (\%) & 29.6 & 33.7 & -4.2 \\
Number of employees & 6014 & 7809 & -1795 \\
Capital ('000 GBP) & 6.8 & 6.6 & 0.2 \\
Share of workers in Trade Unions (\%) & 5.1 & 8.3 & -3.2 \\
Share of temporary contracts in a firm (\%) & 20.9 & 22.6 & -1.7 \\
Firm-age (years) & 1190000 & 33400 & 1156600 \\
Sales ('000 GBP) & 4.6 & 4.7 & -0.1 \\
Share of non-white workers in a firm (\%) & 57.7 & 44.1 & $13.6 * * *$ \\
Share of female workers in a firm (\%) & 175 & 162 & \\
Number of Observations & & & \\
\hline
\end{tabular}

${ }^{* * *} \mathrm{p}<$ 0:01 (Two-tailed)

The following table provides the pair-wise correlation between the key variables (using sampling weights). 


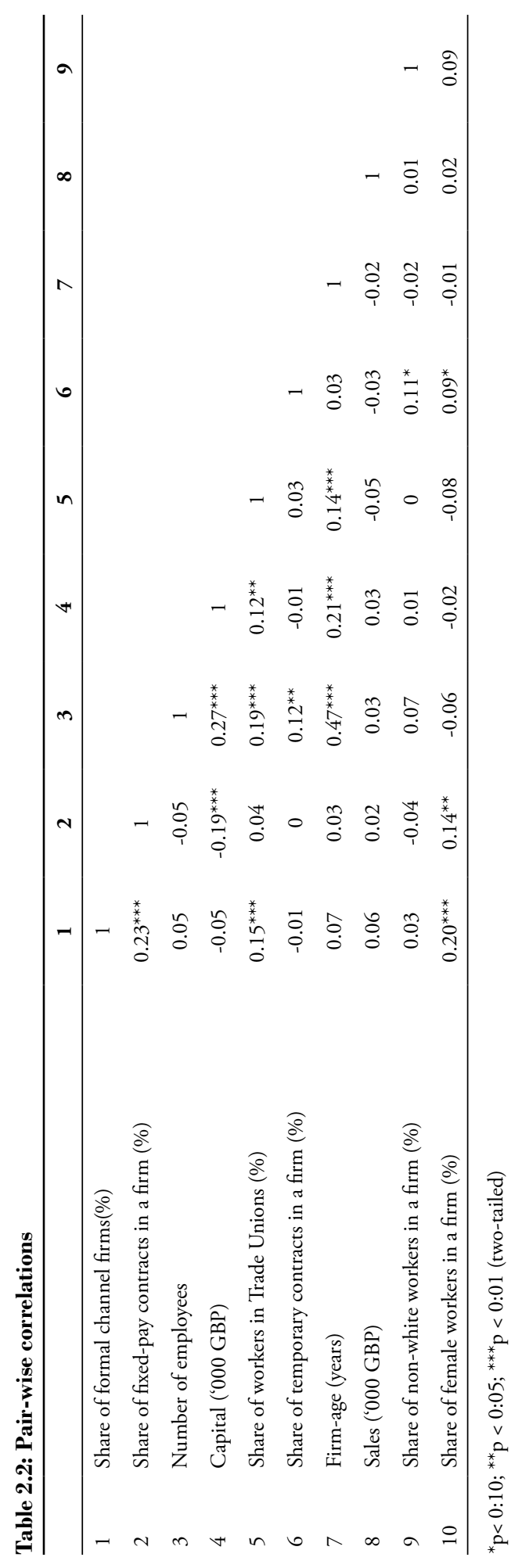




\section{Testing for complementarity}

Demand specification: conditional correlation test

Table 2.3 shows the results for the conditional correlation test by estimating model (M1) using an OLS regression with robust standard errors. Column (I) provides the weighted estimates (population) and column (II) the unweighted estimates (sample). We observe that the coefficient for Share(Fixed-Pay Contracts) is significant and positive in both column (I) and (II) (two-tailed $\mathrm{p}<0.10$ and $\mathrm{p}<0.05$, respectively). That is, both the population estimate and the sample estimate provide evidence of a positive, conditional correlation between Formal Channel and Share(Fixed-Pay Contracts). In addition, the coefficient estimates between both columns are fairly similar (0.097 vs. 0.077).

Table 2.3: Results for the demand specification using OLS

(I)

\begin{tabular}{lcc} 
Dependent Variable: Formal Channel & Population estimates & Sample estimates \\
\hline Share(Fixed-Pay Contracts) & $0.097^{*}$ & $0.077^{* *}$ \\
& $(0.050)$ & $(0.034)$ \\
$\log (\mathrm{L})$ & -0.011 & 0.003 \\
& $(0.040)$ & $(0.018)$ \\
$\log (\mathrm{K})$ & -0.003 & -0.006 \\
& $(0.007)$ & $(0.004)$ \\
$\log ($ Share(Workers in TU)) & 0.101 & $0.411^{* *}$ \\
& $(0.348)$ & $(0.163)$ \\
$\log ($ Share(Temporary Workers)) & $-0.461^{* *}$ & -0.270 \\
& $(0.210)$ & $(0.207)$ \\
$\log ($ Firm Age) & $-0.071^{*}$ & -0.037 \\
& $(0.041)$ & $(0.028)$ \\
Occupation Controls & Yes & Yes \\
Industry Controls & Yes & Yes \\
Observations & 337 & 337 \\
R-squared & 0.175 & 0.191 \\
\hline
\end{tabular}

${ }^{*} \mathrm{p}<0: 10 ;{ }^{* *} \mathrm{p}<0: 05$ (two-tailed), Robust standard errors are reported in parenthesis. All variables are defined in the Appendix. 
A key concern with these results is the potential existence of correlated omitted variables. That is, the association between the two practices might exist only because some confounding factors have not been included in the model (because they are unobservable). To examine how robust the results in Table 2.3 are to unobservable confounding factors, we use two partial identification strategies. First, we apply the technique developed by Oster (2019) and estimate the so-called coefficient of proportionality, which we label "Oster $\delta$ ". The Oster $\delta$ captures the degree of selection on unobservables relative to observables needed to explain away the result, i.e., produce a regression coefficient of zero. ${ }^{30}$ For example, an Oster $\delta$ of 2 implies that the unobservables need to be twice as important as the observables to produce a zero effect. The recommended cut-off for labeling a result as robust is an Oster $\delta$ larger than 1 (Oster, 2019). When estimating the Oster $\delta$ for Share (Fixed-Pay Contracts), we find that it is 2.93 when using weighted estimates and 2.40 when using unweighted estimates. This implies that, to overturn our results, the unobservables need to be almost three times as important as the observables to produce a zero effect in the weighted sample and almost 2.5 times more important in the unweighted sample. Such magnitudes are unlikely to be plausible, which implies that the results in Table 2.3 are robust to unobservable confounding factors.

While the previous partial identification strategy focuses on the regression coefficient, a second, alternative strategy is to focus on the t-statistic. That is, how much of an impact should an unobservable confounding factor have before the association of interest becomes (borderline) statistically insignificant (two-tailed p > 0.10). We apply the technique developed by Frank (2000) and estimate the necessary impact of a correlated omitted variable that would invalidate the inference based on the results in Table 2.3, which is labeled Impact Threshold for a Confounding Variable (ITCV). ITCV is defined as the correlation between the key predictor variable and the unobservable confounding factor ("correlated") times the correlation between the outcome variable and the unobservable confounding factor ("omitted"), conditioning the correlations on the observed covariates. This ITCV can then be benchmarked against the impact of each of the observed covariates to evaluate the robustness of the results. For example, if the $I T C V$ is lower than the impact of most of the covariates, then the results are not robust.

When we estimate the ITCV for Share(Fixed-Pay Contracts), we find that it is 0.0184 in the weighted sample, which implies that an omitted variable would have to be correlated at 0.136 with Formal Channel and at 0.136 with Share(Fixed-Pay Contracts) (conditioning on observed covariates) to invalidate our inference. Using the partial correlations for the observed covariates as a benchmark, we find that for all but two of the covariates the impact is less than the ITCV and for the vast majority it is

30 To estimate the Oster $\delta$, an assumption has to be made about what the $R^{2}$ would be when estimating the full equation, i.e., the equation including both observable and unobservable covariates, which is labelled $R_{\max }$. Based on simulations, Oster (2019) recommends to use $R_{\max }=\min [1.3 R, 1]$, where $R$ is the $R^{2}$ of the regression with observable covariates. See Oster (2019) for details. 
less than $0.01 .^{31}$ The two covariates that have an impact higher than the ITCV (Firm Age and one of the industry indicators) are only slightly higher (0.0199 and 0.0187, respectively). Results are even stronger in the weighted sample. In that case, the ITCV is 0.0373 , which implies that an omitted variable would have to be correlated at 0.193 with Formal Channel and at 0.193 with Share(Fixed-Pay Contracts) (conditioning on observed covariates) to invalidate our inference. All of the observed covariates have an impact lower than the ITCV, all but two are less than 0.01, and the highest impact is 0.0246 . Given the size of the $I T C V$, it is highly unlikely that there exists an unobservable confounding factor that, after including it in the model, would make the association between Formal Channel and Share(Fixed-Pay Contracts) insignificant in both the weighted and unweighted sample. ${ }^{32}$ In sum, both partial identification strategies reveal that the results in Table 2.3 are robust to unobservable confounding factors and the demand specification thus provides empirical evidence in support of the prediction that formal recruitment channels (informal recruitment channels) and fixed-pay contracts (incentive pay contracts) are complements.

\section{Performance specification: productivity test}

Table 2.4 shows the results from the performance specification. Column (I) provides the weighted estimates (population) and column (II) the unweighted estimates (sample). Complementarity in the performance specification is revealed by a positive and significant coefficient on the interaction between Formal Channel and Share(Fixed-Pay Contracts). Note again, however, that we are particularly interested in the difference between the weighted estimate and the unweighted estimate, expecting the former to be larger. We find that the interaction between Formal Channel and Share(Fixed-Pay Contracts) is positive and significant in column (I) $(\beta=0.772$, two-tailed $\mathrm{p}<0.01)$ and positive but not significant in column (II) $\beta=0.289$, two-tailed $\mathrm{p}=0.224$ ). These results show that there is evidence in support of a complementarity between Formal Channel and Share(Fixed-Pay Contracts) when using the weighted estimates but not when using the unweighted estimates; the difference between these estimates is marginally significant (one-tailed $\mathrm{p}<0.10$ ).

31 Similar results are observed when using the raw correlations for the observed covariates.

32 Note that, for a confounding factor to explain away our results, it should have an impact higher than the ITCV in both the weighted sample and the unweighted sample. 


\begin{tabular}{lcc} 
Dependent Variable: $\log ($ Sales) & $\begin{array}{c}\text { Population } \\
\text { estimates }\end{array}$ & Sample estimates \\
\hline Formal Channel & -0.168 & 0.060 \\
Share(Fixed-Pay Contracts) & $(0.263)$ & $(0.240)$ \\
Formal Channel x Share(Fixed-Pay Contracts) & $-0.834^{* * *}$ & $-0.495^{* * *}$ \\
& $(0.248)$ & $(0.187)$ \\
Log(L) & $0.772^{* * *}$ & 0.288 \\
& $(0.272)$ & $(0.236)$ \\
Log(K) & $1.234^{* * *}$ & $0.991^{* * *}$ \\
Log(Share(Workers in TU)) & $(0.129)$ & $(0.101)$ \\
& 0.012 & $0.039^{*}$ \\
Log(Share(Temporary Workers)) & $(0.023)$ & $(0.020)$ \\
& 0.766 & -0.027 \\
Log(Firm Age) & $(0.855)$ & $(0.719)$ \\
Log(Share(Non-white Workers)) & -0.465 & -0.641 \\
Share(Female Workers) & $(0.654)$ & $(0.664)$ \\
Occupation Controls & -0.105 & 0.017 \\
Observations & $(0.110)$ & $(0.142)$ \\
& 0.739 & -0.116 \\
& $(0.931)$ & $(0.946)$ \\
& $-1.086^{* *}$ & -0.985 \\
& $(0.490)$ & $(0.611)$ \\
Yes & $Y e s$ & 337 \\
& Yes & 0.563 \\
\hline
\end{tabular}

${ }^{*} \mathrm{p}<0: 10 ;{ }^{* *} \mathrm{p}<0: 05 ;{ }^{* * *} \mathrm{p}<0: 01$ (two-tailed), Robust standard errors are reported in parenthesis. All variables are defined in the Appendix. 
In other words, we find evidence that suggests that, in the population, formal recruitment channels and fixed-pay contracts are more productive when used jointly than when used separately, but we do not find such evidence in the sample. This is in line with the expectation that the population consists of "more off-equilibrium observations" (lower level of optimality) compared to the sample and a researcher is therefore more likely to empirically observe a complementarity when using the performance specification in the population. Taken together, the results for the performance specification are therefore also consistent with the prediction that formal recruitment channels (informal recruitment channels) and fixed-pay contracts (incentive pay contracts) are complements.

To examine to what extent the results in Table 2.4 are robust to including the interactions between the control variable and the two practices, we add these interactions for one control variable at a time, for all control variables sequentially. The (untabulated) results show that, in the weighted sample, the interaction between Formal Channel and Share(Fixed-Pay Contracts) in all cases are positive and significant at the two-tailed $10 \%$ level or higher, except for one case. When including the interactions between the two practices and the industry indicator for "Hotels and Restaurants", the two-tailed p-value for the (positive) interaction between Formal Channel and Share(Fixed-Pay Contracts) becomes 0.107 , borderline insignificant at conventional levels. However, the interactions between the two practices and the industry indicator are far from significant $(\mathrm{p}=0.680$ for Formal Channel and $\mathrm{p}=0.306$ for Share(Fixed-Pay Contracts)), which suggests that the borderline insignificance is more due to overfitting the model than due to the inclusion of relevant interaction terms. In the unweighted sample, the (positive) interaction between Formal Channel and Share (Fixed-Pay Contracts) remains insignificant in all cases. Finally, in all cases, the weighted estimate is larger than the unweighted estimate. All in all, we find that our results in Table 2.4 are robust to controlling for the observed covariates via the addition of interactions between these covariates and the two practices. $^{33}$

In addition, we also conduct robustness tests by estimating both M1 and M2 with the share of Formal Channels in a firm, in place of the dummy variable. We estimate M1 and M2 by using both the unstandardized variable of share of formal channels in a firm as well as a standardized variable (with respect to the industry average and standard deviation) and find that our results are robust to these specifications of the Formal Channel variable.

33 Note that the partial identification strategies that we apply to the demand specification cannot be applied to the performance specification because the variable of interest in the latter case is a construction of two separate variables that are themselves also included in the model. Applying a partial identification strategy in this case therefore requires an examination of all three variables as a set, which is not possible with the techniques developed by Frank (2000) and Oster (2019). 


\section{Discussion of empirical evidence of complementarity}

Our analytical model predicts that formal recruitment channels (informal recruitment channels) and fixed-pay contracts (incentive pay contracts) are complements, while the simulation results in Masschelein and Moers (2020) show that there is a predictable pattern in the power of different types of specifications to detect such complementarity. In particular, if the two practices of interest are complements, as our theory predicts, then (i) the demand specification has significant power to detect such complementarity, irrespective of the level of optimality present in the observations, while (ii) the performance specification only has significant power at lower levels of optimality. The empirical results that we present in Table 2.3 and Table 2.4 are fully consistent with these predictions. The demand specification shows a significant and robust association between Formal Channel and Share(Fixed-Pay Contracts), irrespective of the level of optimality assumed when estimating this association. The performance specification, on the other hand, only shows a significant interaction between Formal Channel and Share(Fixed-Pay Contracts) when the level of optimality is assumed to be (relatively) lower.

One caveat is our assumption that the sample has higher levels of optimality compared to the population, which might be false. However, even if this were the case, the inferences do not change. That is, the preferred analysis would then be to either rely on the weighted estimates or on the unweighted estimates. In case of the weighted estimates, both the demand and performance specification provide evidence of complementarity. In case of the unweighted estimates, the more robust demand specification provides evidence of complementarity, also after imposing stricter requirements about what is labeled significant to avoid increased Type I errors (see Masschelein \& Moers, 2020). ${ }^{34}$ In sum, the results in Table 2.3 and Table 2.4 jointly provide strong empirical support for our hypothesis that formal recruitment channels (informal recruitment channels) and fixed-pay contracts (incentive pay contracts) are complements. ${ }^{35}$

\section{Additional analysis: nature of sourcing information}

Although the empirical results are consistent with the prediction from our analytical model, the assumption underlying our model is that, on average, informal channels do not have an information advantage over formal channels, at least not with respect to intrinsic motivation. This assumption is not only consistent with the empirical results

34 Masschelein and Moers (2020) show that the probability of a Type I error when using the demand specification is independent of the probability of a Type I error when using the performance specification. As a result, running both specifications but relying on only one for inferences requires the cut-off for significance to be divided by two. That is, a result is labeled significant if the two-tailed p-value is less than 0.05 , which holds for the unweighted estimate in the demand specification.

35 In addition, we also test our theoretical assumption of wages remaining unaffected by the choice of the channels by comparing the difference in the mean level of wages (industry adjusted) between Formal and Informal Channels. We find that there is no statistical difference in the wages between the two types of channels (for both the sample and population estimates). Thus, it shows that the empirical results are consistent with our theoretical assumptions. 
in Campbell (2012) but also with the mixed empirical evidence in the broader labor economics literature regarding productivity differences between channels. We nevertheless validate our assumption by examining whether applicants are differentially exposed to job testing depending on whether they were recruited via formal channels or informal channels. Job testing exposes applicants to tests that have the potential to improve the information available to the firm with respect to worker quality (Autor \& Scarborough, 2008; Hoffman et al., 2018). Typical examples of such tests are performance assessment tests, cognitive tests, and personality tests. If our assumption is incorrect and informal channels do have an information advantage over formal channels, on average, then we expect that job testing occurs more often with formal channels compared to informal channels to (partly) offset such a disadvantage.

Our dataset contains information about the use of two different job tests, i.e., a personality/attitude test and a performance/competency test. We construct three indicator variables based on these two items: (i) Personality-Test (presence versus absence), (ii) Competency-Test (presence versus absence), and (iii) Job-Test (presence of either test versus absence). We find that the mean difference in the population between Formal Channel 1 and Formal Channel $=0$ equals $-0.12(\mathrm{p}<0.10)$ for Personality-Test, $0.06(\mathrm{p}=0.51)$ for Competency-Test, and $0.02(\mathrm{p}=0.87)$ for Job-Test. This indicates that, in the population, personality tests occur less often with formal channels compared to informal channels, while there is no difference in the occurrence of competency tests or job tests per se. We find no significant differences for any of the three indicators in the sample. ${ }^{36}$ Overall, job testing does not occur more often with formal channels compared to informal channels (if anything, the opposite), which is consistent with our assumption that, on average, informal channels do not have an information advantage over formal channels.

\subsection{Conclusion}

The need for having intrinsically motivated workers is the most when output contractibility is low or absent (Beasley \& Ghatak, 2005; Delfgaauw \& Dur, 2007; Prendergast, 2008). Hence, in this situation, input-based control in the form of recruitment strategy that optimizes the attraction capacity of the firm and increases the average level of intrinsic motivation of the applicant pool is crucial. We show that, due to higher application costs for candidates, formal recruitment channels succeed in attracting more motivated workers than informal recruitment channels, and that this is especially valuable when attracting workers into fixed-pay contracts. At the same time, firms benefit from offering fixed-pay contracts when they can select highly motivated workers. Thus, we show

36 The mean difference in the sample between Formal Channel=1 and Formal Channel=0 equals $-0.05(\mathrm{p}=0.31)$ for Personality-Test, $0.06(\mathrm{p}=0.30)$ for Competency-Test, and $0.03(\mathrm{p}=0.59)$ for Job-Test. 
that fixed-pay and formal recruitment channels are complements-implying that the benefits of using fixed-pay contracts increase by using these recruitment channels and vice-versa. Our study therefore provides important insights into the interrelation of input-based and output-based controls and has important implications for the design of recruitment strategies and compensation contracts in practice. In particular, firms that successfully align these practices can reap a productivity premium due to a more efficient match between their recruitment and compensation practices. Our results also inform practice how firms can deal efficiently with the incentive problem in the absence of monetary incentives.

Our study, however, must be interpreted in light of its limitations. Although we maintain in our theory that intrinsic motivation refers to a particular task, empirically it is difficult to distinguish whether the self-selection is based on intrinsic motivation for a task or for a particular firm. It is also possible that the intrinsic motivation derived is because of the combination of the task and the firm (Dixit, 2002; Delfgaauw \& Dur, 2007). This does not take away the main findings of the model, which hinges on the assumption that there is positive utility from effort regardless of whether that positive utility is derived from working on the task or from working in the firm or a combination of both. As a result, the complementarity between formal recruitment channels and fixed wages is unaffected. However, this distinction may have some bearing on the level of the optimal wages. That is, if intrinsic motivation is firm-specific, it increases the firm's monopsony power and allows it to extract more motivational rents compared to when intrinsic motivation is task-specific. Examining these differences is, however, beyond the scope of our study. In addition, intrinsic motivation, in this study, is a latent construct that has not been measured and tested empirically, as is the case with most cross-sectional firm-level studies on intrinsic motivation in the (accounting) literature. This is a limitation in the literature that merits research efforts in the future. 


\section{Appendix: Variable Description}

\begin{tabular}{ll}
\hline \multicolumn{1}{c}{ Variable } & \multicolumn{1}{c}{ Description } \\
\hline Formal Channel & The formal recruitment channel variable is constructed from the response to the \\
following question asked at the firm-level: What are the three most common channels \\
used when trying to fill (these) vacancies? All channels that use formal procedures and \\
entail a cost for applicants, in terms of time and effort spent on looking and applying \\
for a vacancy are categorized as formal channels: Local or regional newspaper; trade, \\
professional and specialist press; career services in college; job-center or employment \\
service office; internet or external website; notice in office, or shop window; and replying \\
to speculative applications. The following channels are categorized as informal channels: \\
Internal notices; direct approach to potential recruit; recommendation or enquiry by \\
existing employees; word of mouth; intranet or own website; and fee charging, private \\
employment or recruiters. Formal Channel is a binary variable with value 1 when the \\
share of formal channels exceeds the share of informal channel within a firm.
\end{tabular}

\section{Share(Fixed-Pay \\ Contracts)}

Total employees (L)

Total capital (K)

Share(Workers in TU)

Share(Temporary

Workers)

Firm Age

Sales

\section{Share(Non-white \\ Workers)}

Share(Female Workers)
We calculate the share of workers with fixed-pay contracts within a firm. Then, we construct a normative variable by subtracting the population mean and dividing it by the standard deviation, such that the mean of the normative variable is zero and standard deviation is one. A positive value for the variable would imply a share higher than the average, a negative value would imply a share lower than the average, and zero would imply a share equal to the average share.

Total number of employees in a firm.

Approximate value of owned and rented assets.

(Number of workers who are part of Trade Union) divided by (Total Number of employees) within a firm.

(Number of workers on temporary or fixed-term contracts) divided by (Total Number of employees) within a firm.

Number of years the workplace has been in operations.

Total value received for sales of goods and services.

(Number of non-white workers) divided by (Total Number of employees) within a firm.

(Number of female workers) divided by (Total Number of employees) within a firm.

Non-managerial occupation with the most employees. There are 7 dummies for 8 categories: Professional, Associate Professional and Technical, Administrative and Secretarial, Skilled Trades, Caring, Leisure and Other Service, Sales and Customer Service, Process, Plant and Machine Operatives, and Elementary Occupations. 


\begin{tabular}{ll}
\hline \multicolumn{1}{c}{ Variable } & \multicolumn{1}{c}{ Description } \\
\hline Industry & The primary industry in which the workplace operates. There are 11 dummies for 12 \\
& Industries: Manufacturing, Electricity, gas and water, Construction, Wholesale and \\
& retail, Hotels and restaurants, Transport and communication, Financial services, Other \\
& business services, Public administration, Education, Health, and Other community \\
& services.
\end{tabular}





\section{Chapter 3}

Sorting and the use of stock-based compensation: evidence from CEO contracts 


\section{Abstract}

A Chief Executive Officer (CEO) is a distinct employee within a firm because of her critical role in affecting the firm's value and hence, appointments of CEOs are critical turning points for organizations. The study examines the variation in the share of stock-based pay in compensation across CEOs and links it to the varying degree of informational asymmetry around the CEO's fit in a firm, at the time of appointment. The study examines contracts of CEOs in the S\&P 500 companies in USA between the period 2011-2017 and finds that the share of stock-based pay in salary (and in total compensation) increases with the severity of informational asymmetry around the CEO's fit at the time of appointment. The study discusses the possibility of firms using stock-based pay to sort CEOs, over and above serving the usual incentive purpose. In addition, the study examines the subsequent adjustments made to the contracts in the subsequent years and finds that the difference in the share of stock-based pay observed, across the different types of hiring conditions (severe versus less informational asymmetry), at the time of appointment disappears over tenure, hinting at the reducing level of information content in contracts over tenure. The study aims to provide empirical evidence to the topic of using compensation for sorting CEOs which has been dominated by theoretical studies till date. In addition, the study contributes to the ongoing discussion on the justification of the structure of executive compensationthat is mostly from an incentive perspective or a rent-seeking perspective- by offering an additional perspective, namely, the sorting perspective.

Keywords: compensation contracts, employee selection, executives, stocks and options. 


\subsection{Introduction}

A Chief Executive Officer (CEO) is a distinct employee within a firm because of her critical role in affecting the firm's value and hence, appointments of CEOs are critical turning points for organizations (Berns \& Klarner, 2017). For the same reason, the compensation contracts offered to CEOs have attracted a lot of attention in both academia and practice. Most literature on CEO compensation focuses on either a moralhazard perspective or a governance perspective to justify the significant variation in CEO compensations observed across CEOs. However, there is limited empirical research on examining the role of compensation contracts from an adverse-selection perspective among CEOs. Most of the research linking compensation to adverse-selection concerns have been theoretical in nature, while the few empirical research on this topic have focused on lower-level employees. Hence, this study aims to provide empirical evidence to an understudied topic of the role of compensation in addressing adverse-selection concerns among CEOs, with a focus on the stock-based component in compensation. In doing so, the study attempts at providing an additional perspective to the on-going debate on the justification of the increasing use of stock-based compensation in CEO contracts.

The literature on CEO compensation has been long debating over the justification and efficacy of the increasing levels of total pay (and also the increasing use of stock-based pay) because the theoretical incentive models about compensations seem to be far from explaining the empirical evidence on the structure and level of pay observed in practice. ${ }^{37}$ Most of the debate seems to oscillate between the traditional views' of claims of managerial rent-seeking due to weak governance (Bebchuk et al., 2002; Abowd \& Kaplan, 1999; Bebchuk et al., 2011) and the modern 'shareholder value' view which necessitates the use of stock-based incentives to induce effort in an increasing risk-environment (Murphy,1999; Conyon et al., 2011; Fernandes et al., 2012; Edmans $\&$ Gabaix, 2016)..$^{38}$ To date, the debate around the efficacy of CEO compensation has been more dominated by an incentive story (a moral-hazard) perspective (Jensen \& Meckling, 1976; Prendergast, 1999; Guay, 1999; Murphy, 1999; Core \& Guay, 2002; Merchant et al., 2003; Coles et al., 2006; Edmans et al., 2009; Edmans \& Gabaix, 2009,

37 The share of stock-based performance-pay for Chief Executive Officers (CEOs) of the U.S firms increased from 17 percent in 2009 to around 40 percent in 2018, according to a recent Harvard study on U.S. Executive Compensation Trends. (https://corpgov.law.harvard.edu/2019/04/16/2019-u-s-executive-compensation-trends/)

38 Inevitably, this debate has led to many regulatory changes around the CEO pay. In the United States in 2006, the Securities and Exchange Commission (SEC) mandated increased disclosure of executive compensation and introduced say-on-pay legislation through Dodd-Frank Act in 2010. The SEC further mandated disclosure of the ratio of Chief Executive Officer (CEO) pay to median employee pay in 2013. In Europe, the European Union imposed caps on bonuses for executives in the banking sector in 2013, and Switzerland attempted (although unsuccessfully) to limit CEO pay to not more than twelve times the pay of the lowest worker. See Murphy and Jensen (2018) for a discussion on regulations around executive compensation. 
2011, 2016; Frydman \& Jenter, 2010; Conyon et al., 2011; Armstrong \& Vashishtha, 2012; Fernandes et al., 2012; Murphy, 2013; Gormley et al., 2013; Garrett \& Pavan, 2015) than by a sorting story (an adverse selection) perspective (Harris \& Holmstrom, 1982; Gibbons \& Murphy, 1992; Hermalin \& Weisbach, 1998, 2012; Holmstrom, 1999; Hall \& Murphy, 2003; Lazear, 2005; Cadenillas et al., 2005; Oyer \& Schaefer, 2005; Moen \& Rosen, 2005; Garrett \& Pavan, 2012; Palomino \& Peyrache, 2013; Taylor, 2013; Bénabou \& Tirole, 2016). In addition, the literature that focuses on the sorting (adverse selection) perspective has been mostly dominated by theoretical studies, resulting in limited empirical evidence to support these theoretical underpinnings. This study, thus, aims to provide some empirical evidence to the understudied, but compelling, sorting explanation for the variation observed in a CEO's compensations at the time of appointment, with special attention to the share of stock-based component in it. The study explains how stock-based compensation might be used for sorting CEOs in the presence of informational asymmetry about the CEO's fit in the firm.

By invoking self-selection into a contract (or out of a contract), termed as sorting, the firm implements a mechanism that ensures that an applicant truthfully reveals her fit by self-selecting into the contract (Lazear, 2000, 2005; Banker. et al., 2010). ${ }^{39}$ The general idea behind using stock-based compensation to induce selfselection of the 'right fit' CEO (into a contract) is that a CEO who is willing to accept a contract that ties a high share of her wealth to the firm's future value (stock returns) in lieu of fixed-salary must believe that she is a 'right fit' in the firm. Sorting works only when the same contract is valued differently by different applicants depending on their private knowledge about their fit in the firm, which largely depends on their privately known competence for the job. ${ }^{40}$ The $\mathrm{CEO}$ must believe that she is the right person to directly affect the firm's future value favorably and in turn, reap all the upside potentials offered by such a contract (Lazear, 2005). ${ }^{41}$ Palomino and Peyrache (2013), in their theoretical study, explain how stock-based compensation is necessary to induce sorting of candidates into the $\mathrm{CEO}$ positions, when their fit is unobservable. ${ }^{42}$ Cadenillas et

39 The process of self-selection into a contract need not be restricted to a take-it-or-leave it scenario (or a menu-list scenario) and can also include a sophisticated process of bargaining from both sides. However, to accept a contract with a high share of stock-based component in both these scenarios reveal the manager's willingness to accept the riskiness inherent in the contract, which indirectly reflects the manager's perception about her fit in the firm.

40 Most of the literature on CEO skills term this competence as 'talent'(Lazear, 2005; Gabaix \& Landier, 2008; Frydman, 2019), which is generally a multi-dimensional construct of skills - encompassing general managerial skills (including leadership skills), CEO-job specific skills (risk-taking abilities), expertise in a particular industry (including firm-specific skills), innate ability, among other things. The higher the competencies for a particular firm, the higher the fit.

41 This ability to affect the firm's value directly is the crucial assumption that makes stock-based pay an effective sorting tool for employees such as a CEO.

42 They argue that effective sorting is achieved because a stock-based component discourages the low-fit candidates to select herself into the contract, which is otherwise not possible with a purely salary- based flat compensation. Obviously, within the menu of all contracts with a stock-based component the optimal one will depend on the firm's risk profile (current and anticipated). 
al. (2005) also show with their theoretical model that stock-based pay is a good sorting tool in inducing executives to self-select into a firm, based on their private information about their competence for the specific firm. Oyer and Schaefer (2005) and Hall and Murphy (2003), in their empirical studies, examine the sorting role of stock-based compensation for lower-level employees and find that these contracts sort employees on their level of optimism about the firm's future performance, but not necessarily on their productive abilities. Although their studies were at the lower-level employees, they hinted that for stock-based compensation to sort employees on their productive abilities, these employees need to have a direct effect on the firm-value through their actionsindicating the need to examine this sorting capacity of stock-based compensation at the top executive level.

Hence, the use of stock-based pay in solving adverse selection problems has been discussed in the economics literature before but mostly using theoretical models, and there is paucity of empirical work on this topic, especially at the CEO level. This study attempts to bring empirical evidence to this stream of literature by showing that stock-based pay is not only used for incentive purposes, but also to solve adverseselection problems among CEOs. However, the study argues that the relative benefit of using stock-based pay for sorting is higher when the need for sorting is higher. This is crucial because using additional stock-based pay for sorting needs imposes additional firm-risk on the risk-averse CEO affecting her actions sub-optimally, which can be viewed as implicit costs of using stock-based pay for sorting (Moen \& Rosen, 2005; Lazear, 2005; Bénabou \& Tirole, 2016). Hence, going beyond the existing studies that only focus on the benefits of using stock-based pay for sorting, this study argues that for firms to use stock-based pay for sorting profitably the need (or benefit) of using it should outweigh the associated costs (both implicit and explicit). In particular, the study examines if the use of stock-based pay (in lieu of fixed-salary) is positively linked to the severity of informational asymmetry around the CEO's fit in the firm. The argument being that with severity of informational asymmetry the need of using stock-based pay for sorting exceeds the associated costs. Thus, the study examines if the share of stockbased pay offered at the time of appointment increases with the severity of informational asymmetry around the CEO's fit at the time of appointment.

The literature on CEO succession (Vancil, 1987; Sebora \& Kesner, 1996; Rajagopalan \& Zhang, 2003) reveals that there are varying degrees of informational asymmetry around hiring a CEO, ranging from promoting an internal candidate to a CEO or hiring a CEO from outside the firm and immediately appointing as CEO. Hence, there is varying need for sorting depending on the difference in the informational asymmetry around the CEO-firm match (Lazear, 2005; Banker et al., 2010; Cadman et al., 2020). I draw upon the 'learning theory' literature in economics (Waldman, 1984, 1990; Gibbons \& Katz, 1991; Farber \& Gibbons, 1996; Altonji \& Pierret, 2001; Pinkston, 2009) and hypothesize that the variation in the stock-based component in a 
CEO's compensation at the time of appointment is associated with the varying degree of informational asymmetry around the CEO's fit in the firm-the higher the severity in the informational asymmetry, the higher the share of stock-based pay in compensation at the time of appointment. However, over the CEO's tenure, the firm is expected to learn more about the CEO's fit in the firm (Lazear, 1986; Murphy, 1986; Milbourn, 2003; Pinkston, 2009) and hence the variation in the informational asymmetry across all types of CEO-firm appointments decreases with tenure, all else equal. Thus, I hypothesize that the difference in the share of stock-based compensation in total compensation observed at the time of appointment across CEOs reduces with tenure, all else equal.

As an empirical strategy, I, first, distinguish between CEOs who are appointed from within the firm, termed as Internal CEO, and those who are appointed from outside the firm as External CEO. It is expected that the informational asymmetry around the CEO-firm match quality is more severe for the latter case than for the former. To test the hypothesis that a higher stock-based compensation is used when there is a higher degree of informational asymmetry, I test the share of stock-based compensation in salary (and in total compensation) between Internal CEO and External CEO at the time of appointment as a CEO. In addition, I test if the difference in the share of stockbased compensation in salary (and in total compensation) disappears with tenure and whether this difference is reduced by a declining share of stock-based compensation for the External CEO (for which the informational asymmetry was higher at the time of appointment) over tenure. Second, I examine the share of stock-based pay across CEOs in the smaller sub-sample of only externally hired CEOs. I compare contracts between those External CEOs with prior experience as CEO and those External CEOs with no prior experience as CEO. The assumption is that for those CEOs with previous experience serving as CEO's there will be more market information about their competence (albeit in a different firm) compared to those with no prior experience as CEOs. Third, I compare the share of stock-based pay between CEOs who have moved from a different industry to those who have moved from similar industries, assuming that there will be more severe informational asymmetry for those who moved from a different industry. To support the sorting explanation behind the use of stock-based compensation, I expect a higher share of stock-based pay for CEOs who had no prior experience as CEOs (and those who moved from different industries) compared to CEOs who had prior experience as CEOs (and those who moved from similar industries). In addition, I also hypothesize that there will be convergence in the share of stock-based pay across these different types of CEOs (or a decline in the variation) if the initial variation was driven by variation in informational asymmetry.

The sample consists of Standard and Poor's 500 US firms collected from Execucomp, Compustat matched with CRSP datasets, Boardex, and hand-collected CEO specific information from public sources (SEC website, LinkedIn public profiles). The sample consists of a pooled cross-section of firms with 3,162 firm-year observations 
for the period 2011-2017. The following are the key findings of the study. (i) At the time of appointment as a CEO, externally hired CEOs have contracts with a higher share of stock-based pay with respect to both the fixed-component (salary) and total compensation than do internally appointed CEOs. (ii) Within the externally hired CEOs, CEOs who have not served as CEOs in previous firms have higher share of stock-based pay relative to salary and total compensation compared to those who have prior experience as a CEO, at the time of appointment. Also, CEOs who have moved from a different industry have slightly higher share of stock-based pay than do CEOs who have moved from similar industries. (iii) There is a significant decline in the ratio of stock-based pay to salary over tenure for the External CEOs, while there is no significant change in the ratio of stock-based pay to salary (and to total compensation) for the Internal CEOs. Likewise, there is a significant decline in the ratio of stock-based pay to salary (and to total compensation) over tenure for those externally hired CEOs who had no prior experience as CEOs before joining the firm, while there is no significant change in the ratio of ratio of stock-based pay to salary (and to total compensation) over tenure for those CEOs who had prior experience as CEOs before joining the firm. Interestingly, for the analysis comparing these ratios between CEOs who moved from a different industry and those who moved from a similar industry, there is a decline for the former over tenure, as expected, but there is also a rise for the latter group over tenure, especially in the ratio of stock-based pay to salary. As a result, the difference in the share of stock-based pay relative to salary and total compensation at the time of appointment disappear over tenure between the External CEOs and Internal CEOs. Similar convergence is observed for CEOs with no prior CEO experience and those with prior experience as well for the CEOs who move from a different industry and those who moved from similar industries.

To conclude, this study shows that the variation in stock-based performance pay component of contracts across CEOs at the time of appointment might be serving objectives of adverse-selection, over and above the objectives of moral hazards. Most importantly, the observation that the mix of stocks and options are associated with the degree of informational asymmetry around the CEO's fit at the time of appointment suggests that the use of stock-based pay in a CEO's compensation to sort CEOs depends on the increasing need for sorting, which in this setting depends on the increasing severity of informational asymmetry.

This study makes several contributions. First, the study provides empirical evidence to the topic of using stock-based compensation for sorting executives that has been largely dominated by theoretical studies (Moen \& Rosen, 2005; Lazear, 2005; Cadenillas et al., 2005; Palomino \& Peyrache , 2013; Bénabou \& Tirole, 2016). The findings of this study make a significant contribution to the broader literature on sorting (personnel control) using pay-for-performance contracts (Hall \& Murphy, 2003; Lazear, 2005). However, it is one of the few empirical studies to bring empirical 
evidence at the CEO level. Second, the study also contributes to the widely discussed topic of CEO compensation by focusing on an understudied yet compelling perspective of sorting and deviates from the extant literature that focuses mostly on the incentive perspective (Jensen \& Meckling, 1976; Prendergast, 1999; Guay, 1999; Core \& Guay, 2002; Merchant et al., 2003; Coles. et al., 2006; Gabaix \& Landier, 2008; Edmans \& Gabaix, 2009, 2011, 2016; Armstrong \& Vashishtha, 2012; Gormley et al., 2013). By doing so, the study aims to also lend an additional perspective to the ongoing debate on the justification and efficacy in the varying mix of stock-based compensations (in lieu of fixed salary) across CEOs (Abowd \& Kaplan, 1999; Murphy, 1999; Bebchuk et al., 2002; Conyon et al., 2011; Fernandes et al., 2012). Third, this study adds to the recent and growing literature that explores into the various roles of compensation practices other than incentives (Ittner et al., 2003; Gerakos et al., 2018). Finally, the study also contributes to literature that studies the dynamic evolution of contracts over time (Murphy, 1986; Hill \& Phan, 1991; Gibbons \& Murphy, 1992; Lippert \& Porter, 1997; Cremers \& Palia, 2010; Edmans et al., 2012; Edmans \& Gabaix, 2016).

The next section of this study discusses the relevant prior literature and develops the hypotheses. Section 3.3 describes the research design. Section 3.4 lists out the results of the main analysis. Section 3.5 shows results of some additional analysis. Section 3.6 concludes the study.

\subsection{Prior Literature and Hypothesis Development}

\section{Relevance of CEO-firm match quality}

In order to answer questions on how firms hire, studies have developed theoretical models of the broad economic forces-matching with costly search and bilateral asymmetric information - that could explain the various hiring practices across firms (Oyer \& Schaefer, 2011). Typically, there is heterogeneity in both sides of the labor market—job seekers are heterogeneous in aptitude, skill, and motivation and firms are heterogeneous in their varying needs for these attributes that complement their size, risk-profile, technology, governance structure etc. (Gabaix \& Landier, 2008; Acharya et al., 2010; Edmans \& Gabaix, 2011; Oyer \& Schaefer, 2011). More importantly, there is incomplete information about the other side of the market and hence, agents on both sides need to incur costly search (including costly sorting tools) to get information about their potential match. This is even more important for firms because there is the possibility that employees may have an incentive to un-truthfully signal their attributes. Truthful information at the time of hiring is very important because a productive worker-firm match is not only stable but also profitable for both the firm and the worker (Jovanovic, 1979). On the other hand, the more severe the informational asymmetry the higher the risk of forming an unproductive worker-firm match. Because a CEO is a 
distinct employee within a firm—due to his critical role in affecting the firm's value—it is often the case that there are internal disruptions within a firm and a significant market reaction around the appointment of a new CEO or the replacement of an incumbent CEO (Chan, 1996; Berns \& Klarner, 2017; Cadman et al., 2020). Hence, it is even more important for a firm to ensure that the new CEO is the 'right' one. Hence, a firm's optimal hiring strategy should be one that alleviates this informational asymmetry around the CEO-firm fit through some learning process and/or incentivizing employees to reveal their true attribute (through self-selection) that meets the needs of the firms. ${ }^{43}$

Notably, studies emphasize that when it comes to appointing a CEO, firms tend to demand for a 'right fit' which has both a CEO-specific component (such as individual ability, skill, knowledge, risk-appetite) and a firm-CEO match component (such as the relevance of the CEO's ability, skill, knowledge, and risk-appetite in the firm's operations). This is because studies find that a CEO's performance is not only dependent on her individual (transferrable across firms) skills but also dependent on the CEO-firm fit component (that is not transferrable across firms). In fact, studies seem to suggest that the latter component might be more crucial than the former when evaluating the productivity of a CEO (Cadenillas et al., 2005; Oyer \& Schaefer, 2011; Palomino \& Peyrache, 2013; Guay et al., 2015). In line with this argument, Guay et al. (2015) argue how CEO turnover is a result of a CEO no longer having a good fit in the firm because of changing risk-profiles (due to exogenous shocks) and not necessarily because of the CEO's individual skills/ability. ${ }^{44}$ Palomino and Peyrache (2013), in their theoretical study, also suggest that sorting of CEOs' should be based on their fit and not on their general level of skills. ${ }^{45}$ Similarly, Cadenillas et al. (2005), in their theoretical study, also model the high versus low 'type' of executives as a proxy for fit, and not in an absolute level of skill or ability. From the CEO's perspective, it can be argued that the same contract can be valued by CEOs differently based on their privately-observed fit (and hence productivity) in a particular firm which results from privately-observed skills/knowledge/risk-appetite that complement the observed firm's characteristicsinducing the better fit CEO to self-select into the contract (or alternatively, induce the

43 In theory there is bilateral informational asymmetry, however, in practice, the informational asymmetry around the CEO is relatively higher than the informational asymmetry around the firm's characteristics (especially riskstrategy), mostly because firms (at least the publicly listed ones) are required by regulations to disclose its financial and operational characteristics (including board composition) publicly.

44 In fact, they show that even a well-performing CEO can get terminated if he fails to adapt to the changing needs of the firm and fit in the new firm profile, emphasizing the constant need for a good CEO-firm fit.

45 They term this 'fit' as having firm-specific skills as opposed to generic skills that are transferable across all firms and emphasize the non-transferrable CEO-firm match quality. 
worse-fit CEO to select out of the contract) ${ }^{46},{ }^{47}$

\section{Use of Compensation for Sorting}

Salop and Salop (1976) is one of the earliest studies to examine the use of compensation contracts as a tool for inducing self-selection of the desired type of workers. The general idea of these self-selection models is that firms will want to offer forms of compensation that are most valuable to the type of employee the firm wishes to attract (Oyer \& Schaefer, 2011). For example, if firms wish to attract workers who can be trained and retained, then using retention bonuses as a component of compensation contract can be useful (Salop \& Salop, 1976). Xu and Yang (2016), also, find that firms use executive signing bonuses to sort on CEOs intention to stay with the hiring firm (for retention motives). Alternately, Lazear (1979) show that some firms design their compensation in such a way that workers are overpaid (relative to their productivity) late in their careers to attract only those workers who are willing to stay with the firm for a long period of time.

Similarly, if the primary objective of the firm is to attract high-ability workers, pay-for-performance is one of the most used components of compensation policy to sort workers on their unobserved ability (Lazear, 1986, 2005; Hall \& Murphy, 2003; Ittner et al., 2003; Oyer \& Schaefer, 2005; Gerakos et al., 2018). Lazear (1986) notes that payfor-performance induces self-selection of only those workers who believe themselves to be productive (based on their private information about their competence/ability) since they expect to earn larger payments in a pay-for-performance contract than what they could earn in a compensation contract with no performance-based component. Later in his Safelite study, Lazear (2000) shows that a switch from fixed-pay to performancepay for an automobile windshield installers induced self-selection of more productive workers into the new compensation policy, leading to a productivity rise of around twenty percentage points. ${ }^{48}$ In recent times, the use of stock-based performance pay has risen for both lower-level employees and top-management. Oyer and Schaefer (2005) argue that inducing self-selection is one of the main possible explanations for the use of stock-based pay. Their study focuses on the lower-level workers and finds that those who self-select themselves into these contracts are (i) less risk-averse and (ii) more optimistic regarding the firm's prospect. They note that these employees have

46 To note, this worker-firm fit quality sensitivity is not unique to CEO performance and may be present in lowerlevel employees too. However, as suggested by studies (Cadenillas et al., 2005; Oyer \& Schaefer, 2011; Palomino \& Peyrache, 2013; Guay et al., 2015) this component is most important for CEOs, given the nature of their jobs and their strong ability to directly affect firm-value with their actions.

47 This valuation may be imperfect given that there is imperfect information about the firm in the market, however, it can be imagined that the market information about the firm is uniformly accessible to all CEO applicants at the time of appointment.

48 The productivity rise of the switch from fixed-pay to performance-based pay is estimated at forty percentage points, of which twenty percentage points is attributed to the self-selection induced by the switch where highproductive workers joined the company and low-productive workers left the company after the switch from fixed to performance-based pay. 
limited power to directly affect the firm's stock prices and hence, stock-based contracts have limited role in sorting them on ability. Hall and Murphy (2003) second their view and state that stock options in lieu of cash compensation would attract highly motivated and entrepreneurial employees only at top management level, and sometimes engineering or technical employees who can directly affect the company's stock-prices favorably. Thus, it can be argued that for stock-based pay to induce self-selection on ability, the employee's actions need to have a direct and significant impact on the firm's stock price. Hence, stock-based compensation (in lieu of fixed salary) might have more sorting capabilities at the CEO level than at the lower-level employees, especially on the unobserved productivity.

The general idea behind using stock-based performance pay to induce selfselection of the 'right-fit' CEO is that a CEO who is willing to accept a contract that ties a higher share of her wealth to a specific firm's future value (stock returns) in lieu of fixed-salary must believe that he or she is a 'right-fit' in that particular firm. The CEO must believe that he or she possesses the right kind of firm-specific skills to directly affect the firm's future value favorably and in turn, reap all the upside potentials offered by such a contract (Lazear, 2005). ${ }^{49}$ Alternately, the CEO's expected benefits from the upside potential of a stock-based contract in a firm largely depends on the CEO's private information about her knowledge needed to identify all positive net positive value (NPV) projects in the industry in which the firm operates, the optimal level of risk-aversion to be able to invest in high risk-high return projects given the firm's resource constraints, and the relevant skills (and/or effort) to affect the cash flows from the chosen projects. ${ }^{50}$ With the same idea, Palimo and Peyrache (2013), in their theoretical study, show that when there are sorting needs over and above incentive objectives, firms should use stockbased compensation to sort the 'right-fit' CEO from the 'wrong-fit' one. Bénabou and Tirole (2016) and Cadenillas et al. (2005), with their theoretical models, find similar results in favor of using stock-based compensation for sorting CEOs.

49 Stock-based variable pay is considered to be a better tool for attracting talent, especially CEO talent, compared to other non-equity (accounting) performance- based pay because of the long-run nature of the stock- based pay compared to accounting-based pay that has a short-run nature. Accounting based pay are usually redeemable annually, as opposed to stock-based pay that usually have a lock-in period of at least three years before they are redeemable (Hemmer et al., 1994). Generally, firms want to hire CEOs that can make strategic choices with highreturns (and hence increase firm-value) that are sustained over the long-run, sometimes even if it comes at the cost of short-term accounting profits. As such, using accounting profit-based variable pay in lieu of fixed salary could potentially attract workers who might prove to be productive to the firm only in the short-run and not necessarily in the long-run.

50 It may be possible that these three dimensions are highly correlated. For example, an in-depth knowledge about a particular sector makes the CEO skilled in affecting the profitability of a project in that sector and therefore, make him or her less risk-averse in investing in high risk-high returns projects. In addition, his disutility from effort might also be minimized if he or she works in projects in the sector in which he is well-informed. The discussion on their possible correlation is beyond the scope of this study and is left for future research. 


\section{Hypothesis Development}

Thus, it has been widely accepted that like most performance pay, stock-based compensation has some sorting capabilities, especially to sort CEOs on their fit in the firm. However, akin to any other control mechanism, the use of stock-based pay for sorting will depend on benefits outweighing the costs. As discussed, the existing literature focuses mainly on the benefits of using stock-based pay for sorting, without weighing it against the costs. On the other hand, a few studies have argued that when a part of the stock-based pay is used for sorting purposes, it results in transferring additional firmrisk on the CEO, over and above what is necessary for purely incentive purposes (Moen \& Rosen, 2005; Lazear, 2005; Bénabou \& Tirole, 2016). Thus, the cost associated with using stock-based pay for sorting purposes includes imposing additional risk on the risk-averse CEO than is necessary for motivation (in addition to the explicit costs of the stock-based compensation). Thus, for firms to use stock-based pay for sorting profitably, the benefits must outweigh the cost. One such situation where benefits could outweigh the costs is when there is severe informational asymmetry. There have a few studies that have linked the use of various compensation components to the degree of the informational asymmetry, but there is no study that links stock-based pay for CEOs and the severity of the informational asymmetry and examines it from a sorting perspective (Gillian et al., 2009; Banker et al., 2010; Xu \& Yang, 2016; Cadman et al., 2020) ${ }^{51}$ Banker et al. (2010) find that for executives whose observable ability was high, firms offered lower pay-for-performance contracts, without making any conclusive observations about sorting objectives. Cadman et al. (2020) find that firms tend to use more stock-based inducement grants, to sort 'good-reputation' CEOs, when the degree of informational asymmetry is higher. However, their study focuses on market information as a measure of informational asymmetry, whereas this study hypothesizes informational asymmetry arising out of boards' (private) imperfect information on the CEO's fit (not just reputation). ${ }^{52},{ }^{53}$ Hence, although the link between the severity of informational asymmetry and use of different components of contracts has been established in the literature, evidence of using stock-based to sort CEOs on their fit is limited.

Thus, given that stock-based pay can serve as effective tools for sorting CEOs, firms are expected to use a compensation that has a higher stock-based pay component relative to other components (especially fixed salary) in sorting the 'right-fit' CEO when there is more severity in the informational asymmetry around the CEO-firm match.

51 Xu and Yang (2016) find that the use of signing bonus is higher with more severe informational asymmetry. Whereas, Gillian et al. (2009) find that with more severe informational asymmetry firms prefer explicit contracts over implicit ones. Hence, the link between informational asymmetry and use of different components of contracts has been established in the literature.

52 With respect to other components of compensation, Xu and Yang (2016) find that the use of signing bonus is higher with more severe informational asymmetry. Whereas, Gillian et al. (2009) find that with more severe informational asymmetry firms prefer explicit contracts over implicit ones.

53 Milbourn (2003) shows argue that markets and boards might have different information. This can have a bearing on what the firm desires to sort the CEOs on, namely, reputation versus fit. 
Hence, I expect that the ratio of stock-based performance-pay to fixed salary (and in total compensation) increases in the degree of informational asymmetry around the CEO-firm fit at the time of appointment. Hence, the following hypothesis:

Hypothesis 1 (H1): The ratio of stock-based pay to fixed salary (and in total compensation) increases in the degree of informational asymmetry around the CEO-firm match at the time of appointment.

Models and empirical evidence on asymmetric information and learning (Waldman, 1984, 1990; Gibbons \& Katz, 1991; Farber \& Gibbons, 1996; Altonji $\&$ Pierret, 2001; Pinkston, 2009) show that information about a particular worker is often accumulated through (i) a public learning process where learning takes place by accumulating publicly available information about a worker, for example, her labor market experience and reputation (most commonly found in publicly available resume (Altonji \& Pierret, 2001; Falato et al., 2015) and the noisy performance measure of the firms they have worked in during their entire labor market experience); and/or (ii) a private employer learning process where the employer firm (board) learns (more than other firms) about its employees over the employees tenure with the firm. In addition, Lazear (1986) and Pinkston (2009) show that a firm keeps accumulating private information about their employees over their tenure and keeps updating its belief about the employee's fit in the firm. Similarly, a firm keeps accumulating precise information about the CEO's fit by observing the CEO's actions and strategic choices (Murphy, 1986; Milbourn, 2003)..$^{54}$ Murphy (1986), further, argues that the information content in a contract about the CEO's fit keeps reducing over tenure. As a result, the severity in informational asymmetry about the CEO's fit decreases over tenure across CEOs. Hence, I argue that if the initial difference in the share of stock-based performance pay (relative to salary and total compensation) across CEOs is reflective of the difference in the informational asymmetry around the CEO-firm fit at the time of appointment, then this difference should progressively decrease with tenure as the firm accumulates private knowledge about the CEO's fit for all CEOs. Hence, the following hypothesis:

Hypothesis 2 (H2): The ratio of stock-based pay to fixed salary (and in total compensation) decreases over tenure for CEOs with higher informational asymmetry than for those with lower informational asymmetry.

54 This is the reason why some studies (Shemesh, 2017) view CEO tenure as an indicator for good-fit (retention decision). 


\subsection{Empirical Method}

\section{Sample}

My sample is constructed from five data sources and hand-collected data from public sources. First, I obtain data on CEO appointment, CEO compensation and equity portfolio holdings from the ExecuComp database. Second, I obtain data on the segments in which the sample firms operate from the Compustat Industry Segment Database. Third, I gather stock return and Treasury bond yield data from Center for Research in Security Prices (CRSP). I gather financial statement information from Compustat (FUNDA) and Boardex. ${ }^{55}$ Finally, I hand-collect data on CEO's prior work experience (outside the Compustat environment). Consistent with prior literature, I exclude financial service firms and utilities and drop observations with missing values for the relevant variables. I also drop all interim CEOs for my analysis.

In general, there are several types of CEO successions with different origins of successors, from within or outside the firm. At the same time there could be different succession process-from relay succession where the successor is groomed by the incumbent $\mathrm{CEO}$ for a period before appointing as the CEO to a situation where the successor immediately replaces the predecessor following his or her dismissal (Vancil, 1987; Sebora \& Kesner, 1996; Rajagopalan \& Zhang, 2003). However, all these different types of CEO successions can be categorized, prima facie, in three distinct categories with respect to the informational asymmetry around the CEO-firm match, in decreasing order of asymmetry: (i) CEOs that are promoted from within the firm (whether groomed by the incumbent CEO or following the incumbent CEO's dismissal), (ii) CEOs that are hired from outside the firm, one or two years prior to being appointed as a CEO, and (iii) CEOs that are hired and immediately appointed as a CEO in the same year. Thus, the three types of CEO succession differ in the degree of information asymmetry about the CEO's fit in the firm-the last case having the highest degree of information asymmetry since there is relatively limited opportunity for private learning compared to the other two cases. I categorize the first categories as Internal CEO and the last category as External CEO and exclude the second category from the main sample. The reason being that it is not clear to what extent there is any informational asymmetry around these candidates' fit (compared to either the first category) and what has been communicated to these CEOs at the time of appointment to the board, for example, if their appointments as $\mathrm{CEO}$ are dependent on their performance as members on the board or if they are based on other considerations (for example, outcome of a tournament). Likewise, they cannot be categorized as External CEOs because the firm has had some opportunity to learn about these candidates' fit in the firm before appointing them as CEOs. Also, it is difficult to ascertain if these candidates are always

55 For survey description, refer to https://wrds-www.wharton.upenn.edu/ 
hired with the purpose of appointing them as $\mathrm{CEO}$ at some later date. Hence, I exclude them from the main sample. ${ }^{56}$ Hence, I expect that hiring the External CEO is associated with a higher severity of informational asymmetry than is hiring Internal CEO. ${ }^{57}$

In addition, for the main analysis, I exclude all those CEOs who were previously employed as CEOs by their former employers (referred to as 'CEO-CEO jumps'). The reason for doing so is three-fold: First, the information asymmetry about an ExternalCEO's fit in the firm might be lower for these group of CEOs who have served as CEOs before. The public (or market) information about these CEOs' performance in the former firm measured by the firm's stock performance, albeit noisy, could contain valuable information for the new employer. This exclusion is done to ensure that there is no additional public (or market) information for some externally hired candidates (who served as CEOs in previous firms) and not for others (who have never served as CEOs). ${ }^{58}$ Second, CEOs who had previous experience as CEOs in other firms might have CEO-job-specific skills and the compensation might represent some premium for these skills [as observed by Bragaw and Mysangyi (2017)]. Hence, the results from comparing this group of CEOs to those who have been promoted from within the firm and have never served as a CEO might get confounded by the skills-premium argument. Last, some studies have conjectured (Fee \& Hadlock, 2003; Lazear, 2005) that when currently serving CEOs are hired by other firms, the hiring firm tries to compensate the $\mathrm{CEO}$ for the stock-based compensation that he is willing to forego in his current firm if he decides to join the new firm. Hence, with such 'CEO-CEO jumps' it is difficult to exclude these possible explanations behind a higher stock and option mix. Hence, I exclude these cases for my analysis. The final sample consists of 3,162 firm-year observations for the period, 2011-2017.

\section{Methodology}

To test Hypothesis 1, I compare the ratio of stocks and options at the time of appointment as a $\mathrm{CEO}$ between External $\mathrm{CEO}$ and Internal CEO. I estimate the following equation (1) using ordinary least square estimation for the first-year CEO contracts for all CEOfirm observations:

Ratio $(\text { Stock-based pay })_{i}=\alpha_{0}+\alpha_{1}$ External CEO+ $\sum_{i} \alpha_{i}$ Controls $_{i}+\varepsilon_{i}$

56 As a robustness check, I later include the second category of CEOs for the analysis.

57 Although, most firms are known to hire intermediate executive search firms who screen external candidates from the spot market, that could serve as an effective sorting mechanism, although costly. However, there is little evidence showing that these search firms are substitutes to the contracts as sorting mechanisms in the spot market Hamori (2010) and Khurana (2002) show that the role of these executive search firms is more in facilitating effective communication between the firm and the candidate, not necessarily affecting the compensation package mix that the $\mathrm{CEO}$ is willing to accept.

58 A few studies examining the role of CEO's reputation in hiring decisions view this market information as a valuable source of information for boards (Cadman et al., 2020). 
The first hypothesis (H1) states that ratio of stock-based pay to fixed salary (and in total compensation) is higher for External CEOs compared to Internal CEOs (the base category in equation 1) for the first year (year of appointment). Thus, $\alpha_{1}>0$ will support H1. Stocks and Options are measured using grant-date stock and option values based on ExecuComp's Black-Scholes' calculations for the fiscal year. I test H1 with the ratio of stock-based performance pay component to the non-performance based salary (risk-free pay) as the sum of the value of stocks and options divided by salary. I do so to capture the stock-based pay relative to the non-performance based component of total compensation (total compensation is composed of other non-equity performance-pay). I also test $\mathrm{H} 1$ for the share of stock-based performance pay in total compensation as measured by the ratio of stocks and options to total compensation (in value). This takes care of the situation when one type of CEO (external or internal) receives higher total compensation than the other (albeit, with components that are tied to other accountingbased performance driven compensation).

To test H2, I estimate the following equations (2) and (3) using ordinary least square estimation for all CEO-firm observations. The standard errors are corrected for heteroscedasticity and are clustered by firms.

Ratio $(\text { Stock-based pay })_{i}=\beta_{0}+\beta_{1}{\text { Tenure }+\sum_{i} \beta_{i} \text { Controls }_{i}+\vartheta_{i}}$

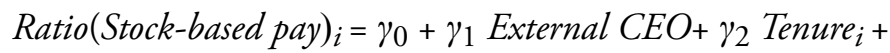
$\gamma_{3}$ External CEO $\times$ Tenure $+\sum_{i} \gamma_{i}$ Controls $_{i}+\mu_{i}$

The second hypothesis (H2) predicts that the coefficient on tenure in equation (2), $\beta_{1}<0$ for External CEOs and $\beta_{1}=0$ for Internal CEOs or alternately, if its declining for both, then the decline for External CEOs should be (significantly) larger than that for Internal CEOs. In short, if the initial ratio of stock-based to fixed-salary was to serve an additional purpose of sorting, once there is learning about the CEO's fit, subsequent adjustments should be such that the ratio of stock-based to fixed-salary for both Internal and External CEOs would converge over tenure as the variation in the informational asymmetry reduces over tenure (i.e., after controlling for the observable firm characteristics). This will be supported when the coefficient on the interaction term in equation (3) is negative, namely, $\gamma_{3}<0$.

The choice of control variables for equations (1), (2) and (3) is primarily based on prior accounting and finance literature (Jensen, 1986; Stulz, 1990; Garvey, 1997; Friend \& Lang, 1998; Leland, 1998; Core \& Guay, 1999; Guay, 1999; Rajagopalan \& Zhang, 2003; Coles. et al., 2006; Lewellen, 2006; Fernandes et al., 2012; Armstrong \& Vashishtha, 2012). They include (i) firmsize, measured as natural log of sales, and prior literature has found a positive relationship between size and higher incentives; (ii) investment-opportunity sets and growth options, measured by book-to-market ratio, 
prior period's sales growth, and net investment in property, plant and equipment (PPE) scaled by total assets and prior literature only states that larger investment-opportunity sets and more growth options are associated with more risk-taking (Guay, 1999) but makes no predictions for these individual empirical constructs. (iii) Leverage, measured as the ratio of long-term debt to total assets and literature has been divided in its prediction about its effect on firm risk and hence on incentives. For example, more risky firms face a higher probability of financial distress and therefore should have less leverage (Friend \& Lang, 1998; Lewellen, 2006) or higher leverage provides managers with greater incentives to transfer wealth from debtors to shareholder (Leland, 1998); (iv) cash and short-term investments scaled by assets which proxies for the short-term availability of cash to make compensation payments. Core and Guay (1999) find that cash-constrained firms tend to use restricted stock and stock options as substitutes for cash compensation. Alternatively, firms with greater cash balances are more likely to have greater agency problems (Jensen, 1986; Stulz, 1990) which equity incentives can mitigate (Garvey, 1997); (v) measures based on the firm's past performance, proxied by the firm's marginal tax rate with an indicator that is equal to one if a firm has a tax-loss carry-forward in any of the past three years and zero (Taxloss), the cumulative stock returns, the return on assets (ROA) (Armstrong \& Vashishtha, 2012), and the Altman Z-Score that captures the firm's performance and its likelihood of going bankrupt (Coles et al., 2006); (vi) Governance measures including a CEO-duality dummy, Board size and ratio of independent directors (Rajagopalan \& Zhang, 2003; Fernandes et al., 2012); (vii) Risk measure, captured by stock return volatility over the last sixty months (Lazear, 2005; Edmans \& Gabaix, 2011); and (viii) Age of the CEO, to proxy for experience (Armstrong \& Vashishtha, 2012). Finally, I use year and industry fixed effects. Refer to Appendix A for the description of the key variables.

Table 3.1 (Column I) presents descriptive statistics for the main variables for the full sample. To ensure that outliers do not drive the results, I winsorize leverage, book-to-market ratio, cash compensation (sum of salary and bonus), and PPE at the first and ninety-ninth percentiles, following prior studies (Coles et al., 2006; Armstrong $\&$ Vashishtha, 2012). The values for most variables are in-line with most prior studies. Table 3.1 also presents the descriptive statistics by firms who have hired Internal and External CEOs (Columns II, III and IV). Prima facie, firms that hire External CEOs tend to offer higher mix of stocks and options, than those that hire Internal CEOs. With respect to other financial characteristics, the firms do seem to be very different; hence the need to control for these firm characteristics in the regression analysis is justified. The average length of tenure (as a CEO) for External CEOs and Internal CEOs is also significantly different. ${ }^{59}$ Hence, as a robustness check, I also perform the regression analysis in (1-3) using entropy balancing, especially for $\mathrm{H} 2$ in the next sub-section.

59 This is partly because of the sample. The frequency of appointment of External CEOs increased over time, especially post 2014. The frequency was less than 1 percent in 2011 and increased to over 4 percent in 2018 in this sample (which excludes excluding all CEO-CEO jumps). 


\begin{tabular}{|c|c|c|c|c|}
\hline & $\begin{array}{c}\text { I } \\
\text { Full Sample }\end{array}$ & $\begin{array}{c}\text { II } \\
\text { External }\end{array}$ & $\begin{array}{c}\text { III } \\
\text { Internal }\end{array}$ & $\begin{array}{c}\text { IV } \\
\text { Diff. }\end{array}$ \\
\hline \multicolumn{5}{|l|}{ CEO contract } \\
\hline Total annual compensation ( $\$ 000)$ & 5779.3 & 7490.7 & 5736.6 & $1754.1^{* * *}$ \\
\hline Stocks and Options, annual ( $\$$ '000) & 3545.5 & 4738.3 & 3515.7 & $1222.5^{* *}$ \\
\hline Salary, annual (\$`000) & 819.6 & 857.0 & 818.6 & 38.3 \\
\hline Cash-based Salary and Bonus, annual (\$ ‘000) & 914.1 & 1053.4 & 910.6 & $142.8^{* * *}$ \\
\hline (Stocks and Options)/Total compensation & 0.52 & 0.57 & 0.52 & $0.05^{* *}$ \\
\hline (Stocks and Options)/Salary & 4.16 & 5.77 & 4.12 & $1.65^{* *}$ \\
\hline Options/Salary & 1.29 & 2.07 & 1.27 & $0.80^{* *}$ \\
\hline Stocks/ Salary & 2.87 & 3.70 & 2.85 & 0.85 \\
\hline Options/Total Compensation & 0.16 & 0.22 & 0.16 & $0.06^{* * *}$ \\
\hline Stocks/Total Compensation & 0.36 & 0.35 & 0.36 & -0.01 \\
\hline \multicolumn{5}{|l|}{ Firm characteristics } \\
\hline Cash & 0.12 & 0.12 & 0.12 & -0.01 \\
\hline ROA & 0.05 & 0.02 & 0.05 & $-0.032^{* * *}$ \\
\hline Taxloss & -0.02 & -0.02 & -0.02 & 0.003 \\
\hline Return & 5495.8 & 6674.6 & 5466.4 & 1208.2 \\
\hline Z-score & 0.18 & 0.25 & 0.18 & $0.07^{* * *}$ \\
\hline Sales $(\$ 000)$ & 0.50 & 0.57 & 0.50 & 0.07 \\
\hline Leverage & 0.84 & 0.83 & 0.84 & -0.01 \\
\hline Growth & 0.07 & 0.05 & 0.07 & -0.03 \\
\hline BTM & 0.24 & 0.27 & 0.24 & 0.03 \\
\hline PP\&E & 7.15 & 6.70 & 7.17 & -0.47 \\
\hline CEO dismissal (\%) & 15.87 & 16 & 15.86 & 0.48 \\
\hline Board size & 0.14 & 0.05 & 0.15 & $-0.09^{* * *}$ \\
\hline CEO-duality (\%) & 0.81 & 0.85 & 0.81 & $.045^{* * *}$ \\
\hline Independent Board & 0.35 & 0.43 & 0.35 & 0.08 \\
\hline Stock-volatility (annualized) & 0.35 & 0.355 & 0.35 & 0.01 \\
\hline CEO tenure & 9.3 & 2.0 & 9.4 & $-7.4^{* * *}$ \\
\hline CEO age & 58 & 54 & 58 & $-3.5^{* * *}$ \\
\hline \#Firm-year Observation & 3,162 & 77 & 3,085 & \\
\hline
\end{tabular}

${ }^{* *} \mathrm{p}<0.05 ;{ }^{* * *} \mathrm{p}<0.01$ (Two-sided); For detailed description on the key variables refer to Appendix.

The following table shows the pair-wise correlation between the key variables. 


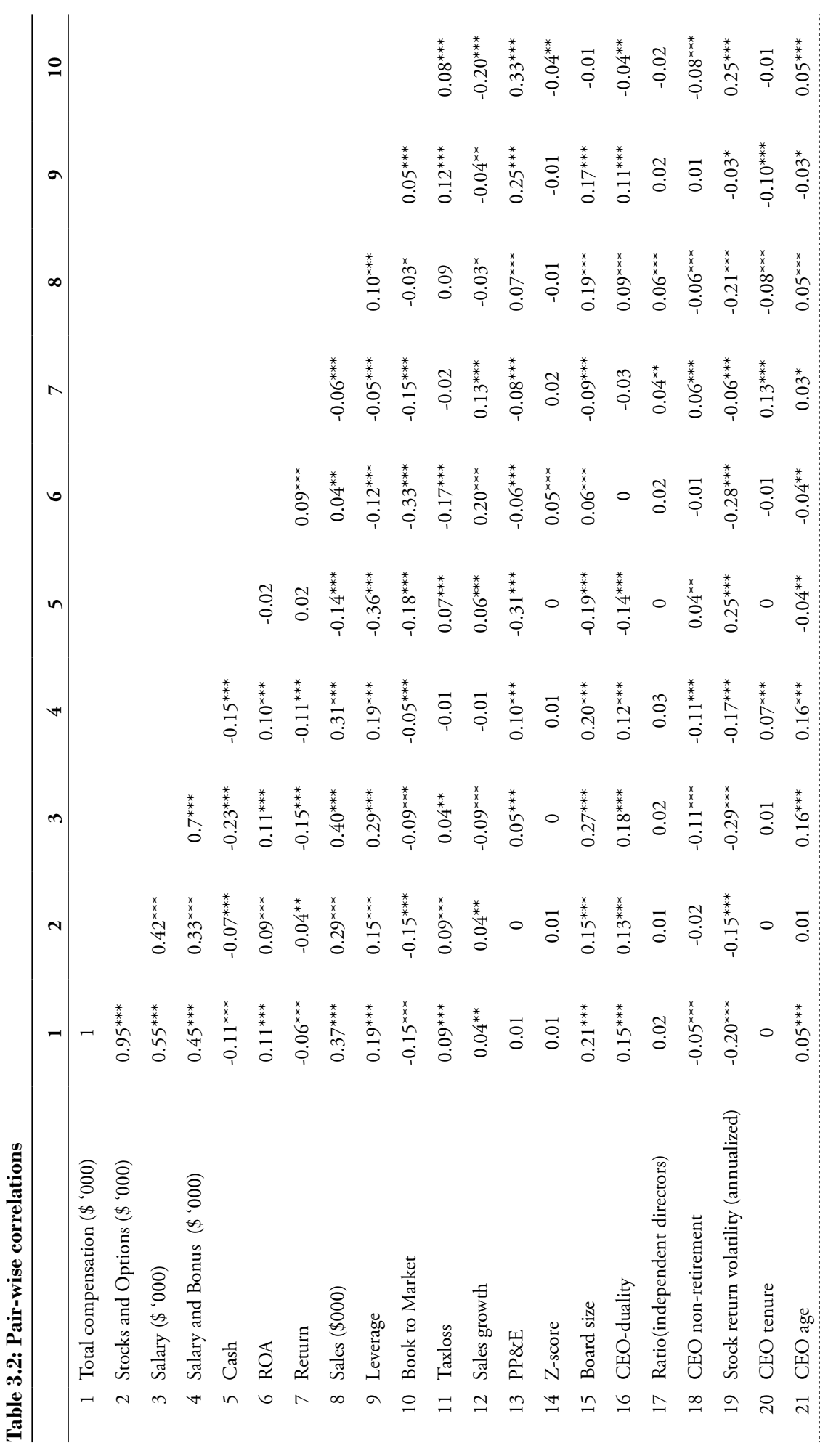




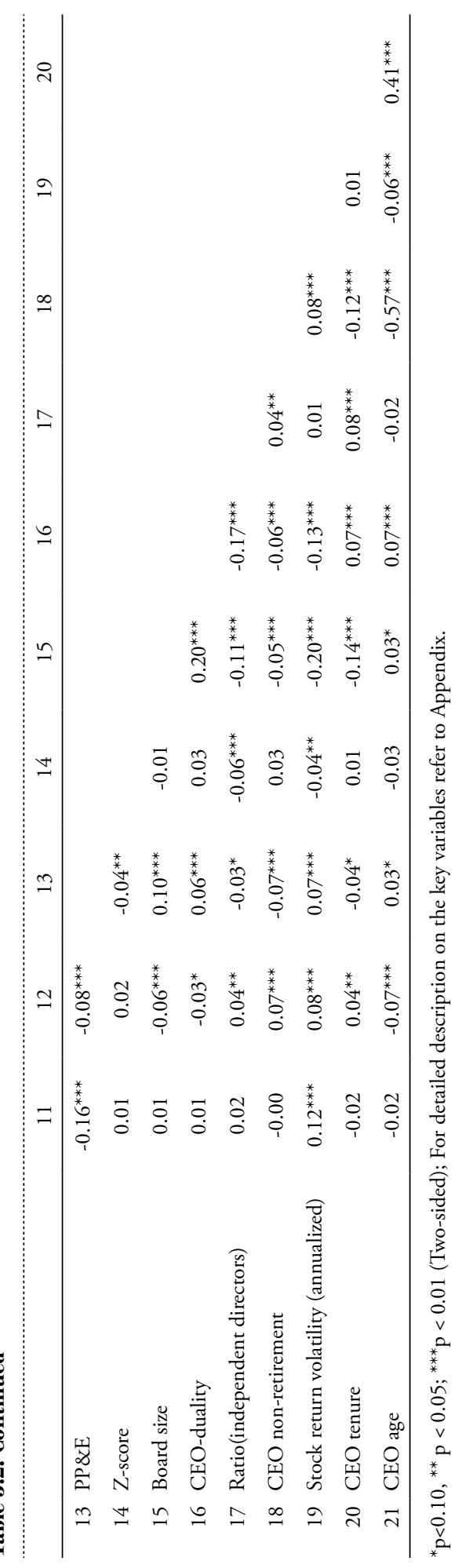




\subsection{Empirical Results}

\section{Testing H1}

The results, from ordinary least square estimation of equation (1), for testing H1 are presented in Table 3.3 Column (I) shows ratio of sum of stocks and options to salary; Column (II) and Column (III) show the individual ratios of stocks to salary and options to salary respectively for the first year as a CEO. Column (IV)- Column (VI) show the ratio of the sum of stocks and options to total compensation, ratios of stocks to salary, and ratios of options to salary respectively for the first year as a CEO. These ratios are compared between External CEO and Internal CEO (base category in the regression). In order to support $\mathrm{H} 1, \alpha_{1}>0$ needs to be satisfied. We see from Table 3.3 that indeed this condition is satisfied as the coefficient on External CEO $\left(\alpha_{1}\right)$ is both positive and statistically significant (at 1 percent level of significance) for the ratio of the sum of stocks and options, relative to fixed salary (As well as the individual ratios). These findings support $\mathrm{H} 1$ that External CEOs are, indeed, offered a higher mix of stock-based pay in lieu of fixed salary compared to Internal CEO at the time of appointment. I find that the ratio of the sum of stocks and options to total compensation is also significantly higher for External CEOs, compared to that for Internal CEOs. However, the individual ratios of stocks to total compensation and options to total compensation are not statistically different for the two types of CEOs. 
Table 3.3: Results from OLS estimation of equation (1) to test $\mathrm{Hl}$

(I)

(II)

(III)

(IV)

(V)

(VI)

(Stocks

$\begin{array}{cc}\text { (Stocks } & \text { Stocks/ } \\ \text { \&Options)/ } & \text { Salary } \\ \text { Salary } & \end{array}$

External CEO

$7.552^{* * *}$

(2.156)

$5.628^{* *}$

$(2.331)$

Cash

$7.732^{*}$

4.654

(4.403)

(3.384)

$R O A$

$-4.722$

$-3.837$

(5.071)

(4.417)

Return

0.427

(2.096)

1.398

(1.908)

$\ln$ (Sales)

$1.618^{* * *}$

$1.096^{* * *}$

(0.372)

(0.421)

Leverage

1.248

(3.041)

0.633

(2.633)

BTM

$-1.789$

$-1.883$

(1.381)

(1.408)

Taxloss

$2.376^{*}$

$3.321^{* * *}$

(1.422)

(1.096)

Growth

0.652

(1.967)

1.809

(1.889)

PP\&E

4.205

(4.038)

5.157

(4.290)

Z-Score

$-0.023$

(0.028)

$-0.015$

(0.026)

Board size

0.011

0.000

(0.037)

(0.035)

CEO duality

$-1.735^{* *}$

(0.833)

$-0.474$

(0.974)

Independent Board

0.015

(2.746)

1.138

(2.187)

Stock-volatility

$$
1.536
$$

(2.973)

1.304

(2.690)

CEO age

$-0.012$

0.005

(0.038)

(0.042)

Industry effects

Yes

Year effects

Observations

Yes

208

0.519
Yes

Yes

208

0.434

Options/
Salary

$1.924^{*}$

(1.094)

3.078

(3.316)

$-0.885$

(4.332)

$-0.971$

(1.422)

$0.521^{*}$

(0.283)

0.615

(1.449)

0.094

$(0.798)$

$-0.945$

(0.874)

$-1.158$

(1.936)

$-0.952$

(1.617)

$-0.008$

(0.012)

0.011

(0.030)

$-1.261^{*}$

(0.716)

$-1.123$

(2.202)

0.232

(1.835)

$-0.016$

(0.025)

\begin{abstract}
Yes
\end{abstract}
Yes

208

0.293

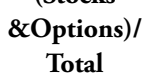

compensation

$0.161^{* *}$

(0.069)

0.294

(0.198)

$-0.105$

(0.273)

0.013

(0.102)

$0.036^{* * *}$

(0.012)

0.074

(0.106)

$-0.051$

(0.056)

$0.128^{* *}$

(0.060)

0.136

(0.089)

0.098

(0.117)

0.001

(0.001)

$0.003^{*}$

(0.002)

$-0.067$

(0.057)

$0.260^{*}$

(0.141)

$-0.072$

(0.165)

$-0.001$

(0.003)

Yes

Yes

208

0.414

${ }^{*} \mathrm{p}<0.10 ;{ }^{* *} \mathrm{p}<0.05 ;{ }^{* * *} \mathrm{p}<0.01$ (Tw
on the key variables refer to Appendix. 


\section{Testing H2}

Table 3.4 shows results for estimating equation (2) to test H2. I see that the coefficient on tenure in equation (2) for External CEOs is negative at 10\% level of significance for the ratio of stock-based pay to total compensation whereas there is no significant change for the Internal CEO. I do not find support for $\mathrm{H} 2$ for the ratio of stock-based pay to salary (it is only weakly significant at $10 \%$ level of significance, one sided t-test).

Table 3.5 shows the results for estimation of equation (3). The coefficient on the interaction term between External CEO and tenure (as a CEO) in equation (3) is indeed negative and significantly different from zero for both the ratios of stockbased pay to salary (and to total compensation) which is also driven by a convergence in stocks to salary (and stocks to total compensation), indicating a narrowing of the gap in the ratio of stocks to salary between External CEOs and Internal CEOs. There is no evidence for convergence of option-based ratios. Interestingly, I see that there is convergence of the ratio of stocks to total compensation over tenure between the two types of CEOs, although I do not find any significant decline in this ratio for the External CEOs, neither do I find any significant increase in the ratio for the Internal CEOs.

However, given the significant difference in the average level of tenure between External and Internal CEOs in the sample, I would interpret these results with caution and refer to the section where I re-estimate (and report) these equations using entropybalancing. 
Table 3.4: Results from OLS estimation of equation (2) to test H2

(I)

(II)

(III)

(Stocks \&Options)/

Salary Stocks/
Salary

\section{Options/} Salary

IV)

(V)

(VI)

(Stocks

\&Options)/

Total

Stocks/ Tota

Options/ Total compensation

\section{External CEO}

\begin{tabular}{|c|c|c|c|c|c|c|}
\hline Tenure & $\begin{array}{c}-1.734 \# \\
(1.113)\end{array}$ & $\begin{array}{c}-1.832 \# \\
(1.129)\end{array}$ & $\begin{array}{c}0.098 \\
(0.273)\end{array}$ & $\begin{array}{c}-0.057^{*} \\
(0.029)\end{array}$ & $\begin{array}{l}-0.048 \\
(0.045)\end{array}$ & $\begin{array}{l}-0.009 \\
(0.035)\end{array}$ \\
\hline Cash & $\begin{array}{c}-8.742 \\
(11.118)\end{array}$ & $\begin{array}{l}-10.947 \\
(11.768)\end{array}$ & $\begin{array}{c}2.205 \\
(4.649)\end{array}$ & $\begin{array}{c}0.007 \\
(0.231)\end{array}$ & $\begin{array}{l}-0.113 \\
(0.367)\end{array}$ & $\begin{array}{c}0.120 \\
(0.340)\end{array}$ \\
\hline$R O A$ & $\begin{array}{l}-38.260 \\
(26.067)\end{array}$ & $\begin{array}{l}-17.110 \\
(26.970)\end{array}$ & $\begin{array}{l}-21.150 \\
(15.312)\end{array}$ & $\begin{array}{l}-0.300 \\
(0.289)\end{array}$ & $\begin{array}{c}0.464 \\
(0.346)\end{array}$ & $\begin{array}{c}-0.763^{* *} \\
(0.314)\end{array}$ \\
\hline Return & $\begin{array}{c}4.278 \\
(3.868)\end{array}$ & $\begin{array}{c}0.064 \\
(3.010)\end{array}$ & $\begin{array}{c}4.214^{* * *} \\
(1.525)\end{array}$ & $\begin{array}{c}0.390^{* * *} \\
(0.141)\end{array}$ & $\begin{array}{l}-0.003 \\
(0.148)\end{array}$ & $\begin{array}{l}0.393^{*} \\
(0.218)\end{array}$ \\
\hline $\ln ($ Sales $)$ & $\begin{array}{c}0.127 \\
(2.253)\end{array}$ & $\begin{array}{l}-0.690 \\
(2.039)\end{array}$ & $\begin{array}{c}0.817 \\
(0.897)\end{array}$ & $\begin{array}{c}0.046 \\
(0.050)\end{array}$ & $\begin{array}{l}-0.019 \\
(0.081)\end{array}$ & $\begin{array}{c}0.065 \\
(0.072)\end{array}$ \\
\hline Leverage & $\begin{array}{c}1.165 \\
(5.212)\end{array}$ & $\begin{array}{c}3.699 \\
(3.947)\end{array}$ & $\begin{array}{l}-2.534 \\
(2.704)\end{array}$ & $\begin{array}{l}-0.016 \\
(0.233)\end{array}$ & $\begin{array}{c}0.084 \\
(0.178)\end{array}$ & $\begin{array}{l}-0.100 \\
(0.283)\end{array}$ \\
\hline$B T M$ & $\begin{array}{l}-1.855 \\
(3.158)\end{array}$ & $\begin{array}{l}-0.772 \\
(2.511)\end{array}$ & $\begin{array}{l}-1.083 \\
(1.012)\end{array}$ & $\begin{array}{l}-0.040 \\
(0.088)\end{array}$ & $\begin{array}{l}0.146^{*} \\
(0.083)\end{array}$ & $\begin{array}{c}-0.187^{* *} \\
(0.075)\end{array}$ \\
\hline Taxloss & $\begin{array}{c}7.703 \\
(4.548)\end{array}$ & $\begin{array}{l}9.098^{*} \\
(4.720)\end{array}$ & $\begin{array}{l}-1.395 \\
(1.457)\end{array}$ & $\begin{array}{c}0.453^{* * *} \\
(0.118)\end{array}$ & $\begin{array}{c}0.483^{* *} \\
(0.198)\end{array}$ & $\begin{array}{l}-0.030 \\
(0.152)\end{array}$ \\
\hline Growth & $\begin{array}{c}2.236 \\
(3.227)\end{array}$ & $\begin{array}{c}2.188 \\
(2.966)\end{array}$ & $\begin{array}{c}0.048 \\
(0.960)\end{array}$ & $\begin{array}{l}-0.057 \\
(0.091)\end{array}$ & $\begin{array}{l}-0.013 \\
(0.109)\end{array}$ & $\begin{array}{l}-0.044 \\
(0.086)\end{array}$ \\
\hline PP\&E & $\begin{array}{l}11.917 \\
(9.509)\end{array}$ & $\begin{array}{l}-2.059 \\
(9.095)\end{array}$ & $\begin{array}{c}13.976^{* * *} \\
(3.013)\end{array}$ & $\begin{array}{l}0.495^{*} \\
(0.279)\end{array}$ & $\begin{array}{l}-0.031 \\
(0.307)\end{array}$ & $\begin{array}{l}0.525^{* *} \\
(0.236)\end{array}$ \\
\hline Z-Score & $\begin{array}{c}0.054 \\
(0.041)\end{array}$ & $\begin{array}{l}-0.034 \\
(0.028)\end{array}$ & $\begin{array}{c}0.088^{* * *} \\
(0.025)\end{array}$ & $\begin{array}{l}0.003^{* *} \\
(0.001)\end{array}$ & $\begin{array}{l}-0.003^{*} \\
(0.002)\end{array}$ & $\begin{array}{c}0.006^{* * *} \\
(0.002)\end{array}$ \\
\hline Board size & $\begin{array}{l}-0.026 \\
(0.127)\end{array}$ & $\begin{array}{l}0.176^{*} \\
(0.099)\end{array}$ & $\begin{array}{c}-0.202^{* *} \\
(0.080)\end{array}$ & $\begin{array}{l}-0.001 \\
(0.004)\end{array}$ & $\begin{array}{l}0.008^{*} \\
(0.005)\end{array}$ & $\begin{array}{c}-0.009^{* *} \\
(0.003)\end{array}$ \\
\hline CEO duality & $\begin{array}{l}4.324^{*} \\
(2.415)\end{array}$ & $\begin{array}{l}3.302 \\
(2.531)\end{array}$ & $\begin{array}{c}1.022 \\
(1.017)\end{array}$ & $\begin{array}{c}0.034 \\
(0.046)\end{array}$ & $\begin{array}{c}0.019 \\
(0.069)\end{array}$ & $\begin{array}{c}0.016 \\
(0.079)\end{array}$ \\
\hline Independent Board & $\begin{array}{c}11.472 \\
(15.566)\end{array}$ & $\begin{array}{c}12.245 \\
(16.291)\end{array}$ & $\begin{array}{l}-0.773 \\
(3.432)\end{array}$ & $\begin{array}{l}0.199 \\
(0.269)\end{array}$ & $\begin{array}{c}0.020 \\
(0.319)\end{array}$ & $\begin{array}{c}0.179 \\
(0.257)\end{array}$ \\
\hline Stock-volatility & $\begin{array}{l}-7.335 \\
(13.169)\end{array}$ & $\begin{array}{l}-7.367 \\
(12.090)\end{array}$ & $\begin{array}{c}0.033 \\
(4.814)\end{array}$ & $\begin{array}{l}-0.039 \\
(0.340)\end{array}$ & $\begin{array}{l}-0.197 \\
(0.503)\end{array}$ & $\begin{array}{c}0.158 \\
(0.339)\end{array}$ \\
\hline CEO age & $\begin{array}{c}0.198 \\
(0.243)\end{array}$ & $\begin{array}{l}-0.029 \\
(0.232)\end{array}$ & $\begin{array}{c}0.228 \\
(0.151)\end{array}$ & $\begin{array}{c}0.015 \\
(0.012)\end{array}$ & $\begin{array}{l}-0.006 \\
(0.012)\end{array}$ & $\begin{array}{l}0.021^{*} \\
(0.011)\end{array}$ \\
\hline Industry effects & Yes & Yes & Yes & Yes & Yes & Yes \\
\hline Year effects & Yes & Yes & Yes & Yes & Yes & Yes \\
\hline Observations & 77 & 77 & 77 & 77 & 77 & 77 \\
\hline R-squared & 0.615 & 0.645 & 0.649 & 0.646 & 0.772 & 0.711 \\
\hline
\end{tabular}




\begin{tabular}{|c|c|c|c|c|c|}
\hline $\begin{array}{c}\text { (I) } \\
\text { (Stocks } \\
\text { \&Options)/ } \\
\text { Salary }\end{array}$ & $\begin{array}{c}\text { Stocks/ } \\
\text { Salary }\end{array}$ & $\begin{array}{l}\text { Options/ } \\
\text { Salary }\end{array}$ & $\begin{array}{c}\text { (IV) } \\
\text { (Stocks } \\
\text { \&Options)/ } \\
\text { Total } \\
\text { compensation }\end{array}$ & $\begin{array}{l}\text { Stocks/ Total } \\
\text { compensation }\end{array}$ & $\begin{array}{c}\text { (VI) } \\
\text { Options/ } \\
\text { Total } \\
\text { compensation }\end{array}$ \\
\hline \multicolumn{6}{|c|}{ Internal CEO } \\
\hline-0.002 & -0.001 & -0.000 & 0.052 & 0.018 & 0.034 \\
\hline$(0.001)$ & $(0.001)$ & $(0.001)$ & $(0.034)$ & $(0.025)$ & $(0.026)$ \\
\hline 0.041 & -0.024 & 0.064 & 5.511 & 0.802 & 4.709 \\
\hline$(0.061)$ & $(0.064)$ & $(0.061)$ & (4.175) & (1.067) & (4.128) \\
\hline$-0.221^{* * *}$ & $-0.101^{*}$ & $-0.120^{* *}$ & $-3.368^{* *}$ & $-2.300^{* *}$ & -1.068 \\
\hline$(0.054)$ & $(0.058)$ & $(0.056)$ & (1.559) & $(0.916)$ & (1.261) \\
\hline 0.006 & -0.003 & 0.009 & 0.890 & 0.417 & 0.472 \\
\hline$(0.037)$ & (0.041) & (0.039) & (1.190) & $(0.524)$ & (1.152) \\
\hline $0.042^{* * *}$ & $0.029^{* * *}$ & $0.012^{* *}$ & $1.181^{* * *}$ & $0.701^{* * *}$ & $0.480^{* * *}$ \\
\hline$(0.005)$ & (0.007) & $(0.006)$ & $(0.158)$ & (0.092) & $(0.145)$ \\
\hline-0.044 & 0.071 & $-0.115^{* * *}$ & -1.227 & -0.096 & $-1.131^{*}$ \\
\hline (0.043) & $(0.051)$ & $(0.041)$ & (1.119) & (0.978) & $(0.602)$ \\
\hline$-0.081^{* * *}$ & -0.029 & $-0.052^{* * *}$ & $-1.664^{* * *}$ & $-0.992^{* * *}$ & $-0.672^{* * *}$ \\
\hline$(0.019)$ & $(0.022)$ & (0.018) & $(0.364)$ & $(0.314)$ & (0.219) \\
\hline $0.058^{* * *}$ & $0.042^{* *}$ & 0.017 & $0.768^{* * *}$ & $0.561^{* *}$ & 0.207 \\
\hline (0.019) & $(0.021)$ & $(0.016)$ & $(0.295)$ & $(0.220)$ & (0.193) \\
\hline 0.031 & -0.011 & $0.042^{*}$ & $2.281^{* * *}$ & $1.010^{* *}$ & $1.271^{*}$ \\
\hline$(0.020)$ & $(0.025)$ & $(0.023)$ & (0.818) & (0.392) & $(0.687)$ \\
\hline 0.010 & 0.075 & -0.065 & 0.483 & 0.155 & 0.328 \\
\hline$(0.051)$ & $(0.060)$ & $(0.040)$ & $(1.050)$ & $(0.815)$ & $(0.720)$ \\
\hline-0.000 & -0.000 & 0.000 & 0.004 & -0.001 & 0.005 \\
\hline$(0.000)$ & $(0.000)$ & $(0.000)$ & $(0.004)$ & $(0.001)$ & $(0.004)$ \\
\hline-0.000 & -0.001 & 0.000 & -0.014 & $-0.020^{*}$ & 0.006 \\
\hline (0.001) & $(0.001)$ & $(0.001)$ & (0.012) & (0.011) & (0.007) \\
\hline 0.023 & 0.030 & -0.007 & 0.809 & $0.954^{* *}$ & -0.145 \\
\hline$(0.017)$ & $(0.021)$ & $(0.016)$ & (0.492) & $(0.468)$ & $(0.256)$ \\
\hline 0.076 & 0.053 & 0.023 & 0.789 & 1.058 & -0.269 \\
\hline (0.047) & (0.052) & $(0.040)$ & (0.888) & $(0.674)$ & $(0.652)$ \\
\hline 0.023 & -0.025 & 0.048 & $2.792^{* *}$ & 0.747 & $2.045^{*}$ \\
\hline$(0.054)$ & (0.067) & $(0.052)$ & (1.225) & $(0.769)$ & (1.076) \\
\hline$-0.003^{* * *}$ & -0.001 & $-0.002 *$ & $-0.069^{*}$ & -0.014 & -0.055 \\
\hline$(0.001)$ & $(0.001)$ & $(0.001)$ & $(0.040)$ & $(0.021)$ & $(0.036)$ \\
\hline Yes & Yes & Yes & Yes & Yes & Yes \\
\hline Yes & Yes & Yes & Yes & Yes & Yes \\
\hline 3,085 & 3,085 & 3,085 & 3,085 & 3,085 & 3,085 \\
\hline 0.194 & 0.166 & 0.124 & 0.115 & 0.118 & 0.055 \\
\hline
\end{tabular}

${ }^{*} \mathrm{p}<0.10 ;{ }^{* *} \mathrm{p}<0.05 ;{ }^{* * *} \mathrm{p}<0.01$ (Two-sided); \# $\mathrm{p}<0.10$ (One-sided), Robust standard errors clustered at firmlevel. For detailed description on the key variables refer to Appendix. 
Table 3.5: Results from OLS estimation of equation (3) to test H2

\begin{tabular}{|c|c|c|c|c|c|c|}
\hline & $\begin{array}{c}\text { (I) } \\
\text { (Stocks } \\
\text { \&Options)/ } \\
\text { Salary }\end{array}$ & $\begin{array}{c}\text { Stocks/ } \\
\text { Salary }\end{array}$ & $\begin{array}{c}\text { Options/ } \\
\text { Salary }\end{array}$ & $\begin{array}{c}\text { (IV) } \\
(\text { Stocks } \\
\text { \&Options)/ } \\
\text { Total } \\
\text { compensation }\end{array}$ & $\begin{array}{c}\text { (V) } \\
\text { Stocks/ } \\
\text { Total } \\
\text { compensation }\end{array}$ & $\begin{array}{c}\text { (VI) } \\
\text { Options/ } \\
\text { Total } \\
\text { compensation }\end{array}$ \\
\hline \multirow[t]{2}{*}{ External CEO } & $3.618^{* * *}$ & $2.453^{*}$ & 1.165 & 0.068 & 0.008 & 0.060 \\
\hline & $(1.288)$ & $(1.351)$ & $(0.877)$ & $(0.042)$ & $(0.056)$ & $(0.050)$ \\
\hline \multirow[t]{2}{*}{ Tenure } & 0.053 & 0.019 & 0.033 & -0.002 & -0.001 & -0.000 \\
\hline & $(0.034)$ & $(0.025)$ & $(0.026)$ & $(0.001)$ & $(0.001)$ & $(0.001)$ \\
\hline \multirow[t]{2}{*}{ External CEO x Tenure } & $-1.155^{* * *}$ & $-0.974^{* * *}$ & -0.181 & $-0.038^{* * *}$ & $-0.035^{* *}$ & -0.003 \\
\hline & $(0.388)$ & $(0.377)$ & $(0.185)$ & $(0.012)$ & $(0.017)$ & $(0.011)$ \\
\hline \multirow[t]{2}{*}{ Cash } & 5.481 & 0.748 & 4.733 & 0.049 & -0.022 & 0.071 \\
\hline & $(4.059)$ & $(1.037)$ & $(4.015)$ & $(0.059)$ & $(0.063)$ & $(0.060)$ \\
\hline \multirow[t]{2}{*}{$R O A$} & $-3.728^{* *}$ & $-2.428^{* * *}$ & -1.300 & $-0.222^{* * *}$ & $-0.096^{*}$ & $-0.126^{* *}$ \\
\hline & $(1.567)$ & $(0.926)$ & $(1.267)$ & $(0.053)$ & $(0.057)$ & $(0.056)$ \\
\hline \multirow[t]{2}{*}{ Return } & 0.978 & 0.515 & 0.463 & 0.012 & 0.001 & 0.011 \\
\hline & $(1.154)$ & $(0.507)$ & $(1.120)$ & $(0.036)$ & $(0.040)$ & $(0.038)$ \\
\hline \multirow[t]{2}{*}{$\ln$ (Sales) } & $1.210^{* * *}$ & $0.720^{* * *}$ & $0.490^{* * *}$ & $0.042^{* * *}$ & $0.029^{* * *}$ & $0.013^{* *}$ \\
\hline & $(0.157)$ & $(0.093)$ & $(0.144)$ & $(0.005)$ & $(0.007)$ & $(0.006)$ \\
\hline \multirow[t]{2}{*}{ Leverage } & -1.282 & -0.222 & $-1.060^{*}$ & -0.040 & 0.066 & $-0.106^{* * *}$ \\
\hline & (1.091) & $(0.956)$ & $(0.595)$ & $(0.043)$ & $(0.051)$ & $(0.041)$ \\
\hline \multirow[t]{2}{*}{$B T M$} & $-1.708^{* * *}$ & $-1.073^{* * *}$ & $-0.635^{* * *}$ & $-0.081^{* * *}$ & -0.032 & $-0.049^{* * *}$ \\
\hline & $(0.357)$ & $(0.312)$ & $(0.217)$ & $(0.019)$ & $(0.022)$ & $(0.017)$ \\
\hline \multirow[t]{2}{*}{ Taxloss } & $0.872^{* * *}$ & $0.717^{* * *}$ & 0.155 & $0.062^{* * *}$ & $0.051^{* *}$ & 0.011 \\
\hline & $(0.301)$ & $(0.231)$ & $(0.191)$ & $(0.020)$ & $(0.021)$ & $(0.017)$ \\
\hline \multirow[t]{2}{*}{ Growth } & $2.092^{* * *}$ & $0.919^{* *}$ & $1.173^{*}$ & 0.027 & -0.013 & $0.040^{*}$ \\
\hline & $(0.784)$ & $(0.376)$ & $(0.662)$ & $(0.020)$ & $(0.024)$ & $(0.023)$ \\
\hline \multirow[t]{2}{*}{$P P \mho E$} & 0.782 & 0.514 & 0.268 & 0.015 & 0.092 & $-0.077^{*}$ \\
\hline & (1.024) & $(0.807)$ & $(0.701)$ & $(0.050)$ & $(0.057)$ & $(0.040)$ \\
\hline \multirow[t]{2}{*}{ Z-Score } & 0.003 & -0.001 & 0.005 & -0.000 & -0.000 & 0.000 \\
\hline & $(0.004)$ & $(0.001)$ & $(0.004)$ & $(0.000)$ & $(0.000)$ & $(0.000)$ \\
\hline \multirow[t]{2}{*}{ Board size } & -0.014 & $-0.019^{*}$ & 0.005 & -0.000 & -0.001 & 0.000 \\
\hline & $(0.012)$ & $(0.011)$ & $(0.008)$ & $(0.001)$ & $(0.001)$ & $(0.001)$ \\
\hline \multirow[t]{2}{*}{ CEO duality } & 0.776 & $0.912^{* *}$ & -0.136 & 0.023 & 0.029 & -0.006 \\
\hline & $(0.489)$ & $(0.464)$ & $(0.255)$ & $(0.016)$ & $(0.021)$ & $(0.015)$ \\
\hline \multirow[t]{2}{*}{ Independent Board } & 0.663 & 0.920 & -0.257 & 0.073 & 0.047 & 0.026 \\
\hline & $(0.881)$ & $(0.663)$ & $(0.647)$ & $(0.046)$ & $(0.050)$ & $(0.039)$ \\
\hline \multirow[t]{2}{*}{ Stock-volatility } & $2.834^{* *}$ & 0.665 & $2.169^{* *}$ & 0.032 & -0.032 & 0.064 \\
\hline & $(1.221)$ & $(0.764)$ & $(1.078)$ & $(0.053)$ & $(0.066)$ & $(0.052)$ \\
\hline
\end{tabular}




\begin{tabular}{lcccccc} 
CEO age & $-0.068^{*}$ & -0.015 & -0.054 & $-0.003^{* * *}$ & -0.002 & $-0.002^{*}$ \\
& $(0.040)$ & $(0.021)$ & $(0.035)$ & $(0.001)$ & $(0.001)$ & $(0.001)$ \\
Industry effects & Yes & Yes & Yes & Yes & Yes & Yes \\
Year effects & Yes & Yes & Yes & Yes & Yes & Yes \\
Observations & 3,162 & 3,162 & 3,162 & 3,162 & 3,162 & 3,162 \\
R-squared & 0.118 & 0.121 & 0.053 & 0.194 & 0.164 & 0.119 \\
\hline
\end{tabular}

${ }^{*} \mathrm{p}<0.10 ; * * \mathrm{p}<0.05 ; * * \mathrm{p}<0.01$ (Two-sided). Robust standard errors clustered at firm-level.

\section{Robustness Check}

\section{Testing for Omitted Variable Bias}

A key concern with these results is the potential existence of correlated omitted variables. That is, the association between the two variables might exist only because some confounding factors have not been included in the model (because they are unobservable). To examine how robust the results in Table 3.3 are to unobservable confounding factors, I use a partial identification strategy. I apply the technique developed by Oster (2019) and estimate the so-called coefficient of proportionality (for each regression in Column I to Column VI), which I label "Oster $\delta$ ". The Oster $\delta$ captures the degree of selection on unobservables relative to observables needed to explain away the result, i.e., produce a regression coefficient of zero. ${ }^{60}$ For example, an Oster $\delta$ of 2 implies that the unobservables need to be twice as important as the observables to produce a zero effect. The recommended cut-off for labeling a result as robust is an Oster $\delta$ larger than 1 (Oster 2019). When estimating the Oster $\delta$ for External CEO, I find that $\delta$ ranges from 2.05 to 13.95 for the different regressions. ${ }^{61}$ This implies that, to overturn the results, the unobservables need to be almost atleast two times as important as the observables to produce a zero effect in the sample. Such magnitudes are unlikely to be plausible, which implies that the results in Table 3.3 are robust to unobservable confounding factors.

60 To estimate the Oster $\delta$, an assumption has to be made about what the $R^{2}$ would be when estimating the full equation, i.e., the equation including both observable and unobservable covariates, which is labelled $R_{\max }$. Based on simulations, Oster (2019) recommends to use $R_{\max }=\min [1.3 R, 1]$, where $R$ is the $R^{2}$ of the regression with observable covariates. See Oster (2019) for details.

61 The $\delta$ values for the regressions for Column I to Column VI (of Table 3.3) are respectively 4.66, 13.95, 2.64, 6.82, -3.59, and 2.05 [A negative delta means that if the observables are positively correlated with the key variable, the unobservables have to be negatively correlated with the key variable to produce a zero effect. In this case, the negative correlation has to 3.5 times more than the positive correlation to produce a zero effect]. 


\section{Entropy Balancing}

I estimate equations (1), (2) and (3) using entropy balancing to account for the difference in the distribution of firms hiring External CEOs and those hiring Internal CEOs, and to account for the significant difference in tenure between the two types of CEOs and the significant difference in the sub-sample sizes. In Table 3.6, I find that the results for $\mathrm{H} 1$ are robust to this alternate form of estimation.

Table 3.6: Results from Entropy Balancing estimation of equation (1) to test $\mathrm{HI}$

\begin{tabular}{|c|c|c|c|c|c|c|}
\hline & $\begin{array}{c}\text { (I) } \\
\text { (Stocks } \\
\text { \&Options)/ } \\
\text { Salary }\end{array}$ & $\begin{array}{c}\text { Stocks/ } \\
\text { Salary }\end{array}$ & $\begin{array}{c}\text { Options/ } \\
\text { Salary }\end{array}$ & $\begin{array}{c}\text { (IV) } \\
\text { (Stocks } \\
\text { \&Options)/ } \\
\text { Total } \\
\text { compensation }\end{array}$ & $\begin{array}{c}(\mathrm{V}) \\
\text { Stocks/ } \\
\text { Total } \\
\text { compensation }\end{array}$ & $\begin{array}{c}\text { (VI) } \\
\text { Options/ } \\
\text { Total } \\
\text { compensation }\end{array}$ \\
\hline \multirow[t]{2}{*}{ External CEO } & $7.773^{* * *}$ & $5.587^{* * *}$ & $2.187^{* *}$ & $0.115^{* *}$ & 0.015 & $0.100^{*}$ \\
\hline & (1.839) & $(1.957)$ & $(0.960)$ & $(0.055)$ & $(0.058)$ & $(0.055)$ \\
\hline Industry effects & Yes & Yes & Yes & Yes & Yes & Yes \\
\hline Year effects & Yes & Yes & Yes & Yes & Yes & Yes \\
\hline Observations & 208 & 208 & 208 & 208 & 208 & 208 \\
\hline R-squared & 0.633 & 0.578 & 0.524 & 0.410 & 0.386 & 0.378 \\
\hline
\end{tabular}

${ }^{*} \mathrm{p}<0.10 ;{ }^{* *} \mathrm{p}<0.05 ;{ }^{* * *} \mathrm{p}<0.01$ (Two-sided).

Table 3.7 and Table 3.8 shows the results for H2. We see that with entropy balancing $\mathrm{H} 2$ is supported for the ratio of stock-based pay to salary (and stocks to salary) and no significant decline for stock-based pay to total compensation for External CEOs (Table 3.7). The results for the Internal CEO remain robust to entropy balancing. The results for equation (3) are robust with entropy balancing estimation method, as seen from Table 3.8. 


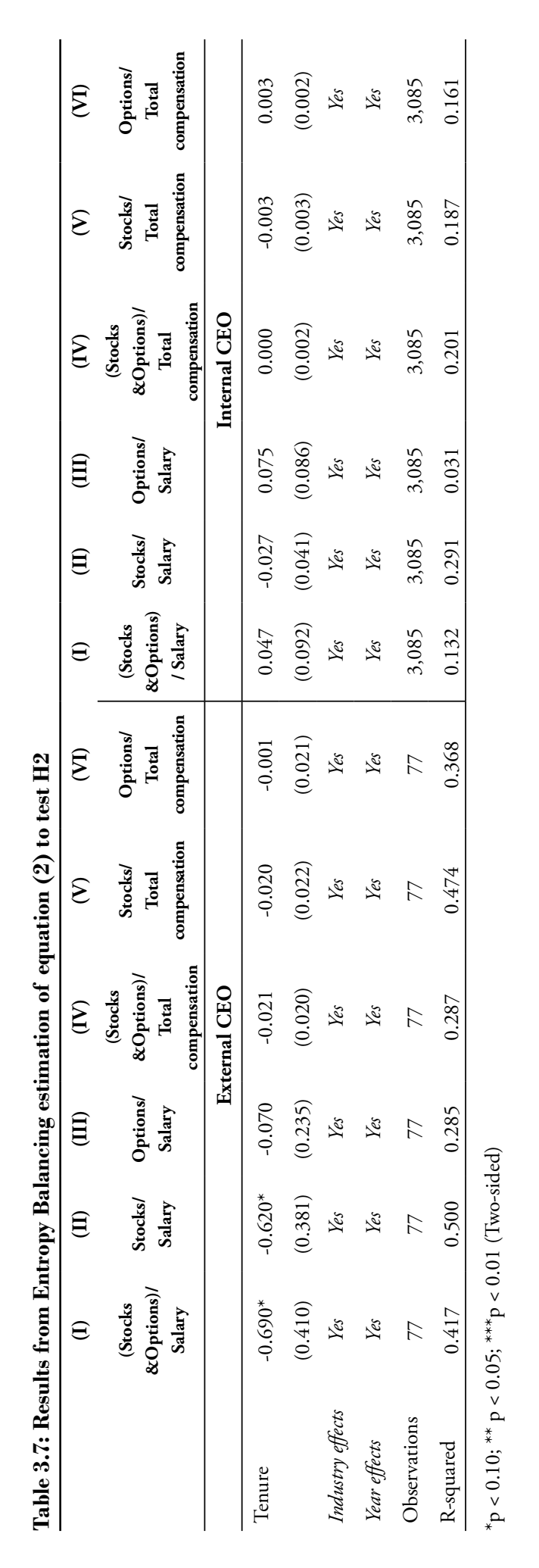

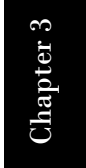


Table 3.8: Results from entropy balancing estimation of equation (3) to test $\mathrm{H2}$.

\begin{tabular}{|c|c|c|c|c|c|c|}
\hline & $\begin{array}{c}\text { (I) } \\
\text { (Stocks } \\
\text { \&Options)/ } \\
\text { Salary }\end{array}$ & $\begin{array}{l}\text { Stocks/ } \\
\text { Salary }\end{array}$ & $\begin{array}{c}\text { Options/ } \\
\text { Salary }\end{array}$ & $\begin{array}{c}\text { (IV) } \\
\text { (Stocks } \\
\text { \&Options)/ } \\
\text { Total } \\
\text { compensation }\end{array}$ & $\begin{array}{c}(\mathrm{V}) \\
\text { Stocks/ } \\
\text { Total } \\
\text { compensation }\end{array}$ & $\begin{array}{c}\text { (VI) } \\
\text { Options/ } \\
\text { Total } \\
\text { compensation }\end{array}$ \\
\hline \multirow[t]{2}{*}{ External CEO } & $3.646^{* *}$ & $2.667^{*}$ & 0.979 & $0.068^{*}$ & 0.020 & 0.048 \\
\hline & $(1.526)$ & (1.473) & $(0.706)$ & $(0.039)$ & $(0.045)$ & $(0.038)$ \\
\hline \multirow[t]{2}{*}{ Tenure } & 0.070 & 0.035 & 0.035 & 0.000 & -0.001 & 0.001 \\
\hline & $(0.101)$ & $(0.063)$ & $(0.087)$ & $(0.003)$ & $(0.003)$ & $(0.003)$ \\
\hline \multirow[t]{2}{*}{ External CEO x Tenure } & $-1.079^{* * *}$ & $-0.871^{* *}$ & -0.208 & $-0.033^{* * *}$ & $-0.029^{* *}$ & -0.004 \\
\hline & $(0.408)$ & $(0.370)$ & $(0.225)$ & $(0.012)$ & $(0.013)$ & $(0.012)$ \\
\hline Industry effects & Yes & Yes & Yes & Yes & Yes & Yes \\
\hline Year effects & Yes & Yes & Yes & Yes & Yes & Yes \\
\hline Observations & 3,162 & 3,162 & 3,162 & 3,162 & 3,162 & 3,162 \\
\hline R-squared & 0.211 & 0.294 & 0.083 & 0.194 & 0.234 & 0.189 \\
\hline
\end{tabular}

${ }^{*} \mathrm{p}<0.10 ;{ }^{* *} \mathrm{p}<0.05 ;{ }^{* * *} \mathrm{p}<0.01$ (Two-sided)

This shows that indeed the ratio of stock-based pay to fixed salary for External CEOs decreases over tenure, as expected, with the decreasing informational asymmetry around the CEO-firm match and that for the Internal CEO remains unchanged. This confirms that indeed the narrowing of the gap between the External and the Internal CEO's stock and options mix is due to the decreasing ratio for the External CEOs (and not because the ratio increases for the Internal CEOs), especially because of the decreasing ratio of stocks to salary. Although, the ratio of stock-based pay in total compensation for External CEOs remains unchanged over tenure. In sum, these findings together support the hypothesis that the difference in the stock-based pay mix at the time of appointment between the Internal CEOs and External CEOs disappears over tenure resulting in some convergence in some of the ratios between the two types of CEOs.

In general, empirical evidence on the dynamic behavior of $\mathrm{CEO}$ incentives, so far, has been mixed. Gibbons and Murphy (1992), Lippert and Porter (1997), and Cremers and Palia (2010) find that the managerial pay to performance sensitivity increases with tenure, while Murphy (1986) and Hill and Phan (1991) find the opposite evidence. In addition, theoretical studies that examined this dynamic behavior have focused mostly on either a moral-hazard perspective (Gibbons \& Murphy, 1992; Edmans et al., 2012) or a rent-seeking/ governance perspective (Hill \& Phan, 1991; Bebchuk \& Fried , 2003). ${ }^{62}$ To say that the incentive story might not be at play in

62 Murphy (1986) is one of the few theoretical studies to use a learning model to predict the dynamic behavior of CEO incentives. 
explaining the variation in compensation structure (incentives) between External and Internal CEOs is difficult (at this stage), especially because hiring an External versus an Internal CEO is a decision that is closely linked to the varying need for strategic changes within a firm and hence, could result in providing different incentives in the form of differences in stock-salary ratios. Hence, I examine this alternate explanation in detail in the subsequent section 3.5.

\section{Including those CEOs who were hired on the board one-two years before being appoint- ed as CEO}

As a robustness check, I include those CEOs who were hired on the board one or two years prior to appointment as the CEO in the categorization of Internal CEO. In untabulated results, I find that the results are robust to this inclusion. However, to keep my categorization clean in terms of strong differences in the degrees of informational asymmetry I choose to use the original sample and exclude this group of CEOs for the rest of the analysis.

\subsection{Additional Analysis}

\subsubsection{Incentive-story Argument}

\section{External versus Internal CEO hiring decisions and incentives}

Prior literature has acknowledged and discussed some antecedents to hiring External CEOs versus Internal CEOs. These studies (Boeker \& Goodstein, 1993; Cannella \& Lubatkin, 1993; Datta \& Guthrie, 1994; Guthrie Datta, 1997) have found that the likelihood of appointing an Internal CEO is higher under good pre-succession performance. Whereas, the likelihood of appointing an External CEO is higher under poor pre-succession profitability, especially under a former Internal CEO. Usually, the poor company performance is attributed to the previous CEO (Graffin et al., 2013) and hence, with the need for a strategic change, a need arises for an External CEO (Guthrie Datta, 1997). This is because often External CEOs are associated with external expertise and less commitment to the status quo making the strategic change possible (Hambrick \& Mason, 1984; Schwartz \& Menon, 1985). In short, prior literature shows that external candidates are hired over internal candidates when firms desire strategic change, especially if they have been performing poorly in the past. When firms intend to encourage CEOs risk-taking to make strategic changes, they tend to direct the CEO's actions to this purpose by giving them contracts with higher incentives (with higher sensitivity of CEO wealth to firm performance) (Jensen \& Meckling, 1976; Guay, 1999; Core \& Guay, 2002; Coles. et al., 2006; Edmans \& Gabaix, 2011; Armstrong \& Vashishtha, 2012; Gormley et al., 2013). Stock-based performance-pay could be a tool to align the firm's performance (in terms of stock returns) more strongly to the CEO's 
rewards, and consequently, direct actions to value-enhancing (long-term) investments. ${ }^{63}$ Hence, as an alternate explanation, it is possible that the higher share of stock-based performance pay observed in Table 3.3 and Table 3.6 for External CEOs could also be driven by incentive concerns and not necessarily because of sorting concerns.

I estimate the difference in effective incentives as measured by the delta and vega values generated by the stock-based components of a compensation, and not by the mere value of stocks and options, [as calculated in Core and Guay (2002)], and an incentive measure taken from Conyon et al. (2011) across both types of CEOs in their entire length of employment using equation (1) and (2) (I also control for total compensation for the analysis). ${ }^{64}$ Higher values of these measures should, in principle, reflect higher incentives. In Table 3.9 (Columns I-III), I find that delta (log linearized) is smaller (statistically significant) for External CEOs compared to Internal CEOs. The results for the Conyon et al. (2011) incentive measure and vega (log linearized) are not statistically different for the External CEOs from those for the Internal CEOs. In addition, Table 3.9 (Columns IV-VI) shows that there is convergence of incentives for the two types of CEOs over tenure. Hence, these results do not seem to support the alternate explanation of different (intended) incentives driving the difference in stockbased mix in contracts at the time of appointment as a CEO. ${ }^{65}$

Table 3.9: Effective Incentives for External CEOs vis-a-vis Internal CEOs using OLS estimation.

\begin{tabular}{|c|c|c|c|c|c|c|}
\hline & (I) & (II) & (III) & (I) & (II) & (III) \\
\hline & $\ln ($ Vega $)$ & $\ln ($ Delta $)$ & $\ln$ (Incentive) & $\ln ($ Vega $)$ & $\ln ($ Delta $)$ & $\ln$ (Incentive) \\
\hline \multirow[t]{2}{*}{ External CEO } & -0.835 & $-1.076^{* * *}$ & -0.543 & $-1.095^{* *}$ & $-1.327^{* * *}$ & $-1.204^{* *}$ \\
\hline & $(0.546)$ & $(0.243)$ & $(0.673)$ & $(0.465)$ & $(0.197)$ & $(0.570)$ \\
\hline \multirow[t]{2}{*}{ Tenure } & & & & 0.001 & $0.073^{* * *}$ & $0.057^{* * *}$ \\
\hline & & & & $(0.011)$ & $(0.006)$ & $(0.011)$ \\
\hline \multirow[t]{2}{*}{ External CEOxTenure } & & & & $0.375^{* *}$ & $0.246^{* * *}$ & $0.383^{* *}$ \\
\hline & & & & $(0.152)$ & $(0.051)$ & $(0.149)$ \\
\hline \multirow[t]{2}{*}{ Log(total compensation) } & 0.075 & $0.248^{*}$ & $1.134^{* * *}$ & $0.535^{* * *}$ & $0.352^{* * *}$ & $1.142^{* * *}$ \\
\hline & $(0.262)$ & $(0.128)$ & $(0.361)$ & $(0.100)$ & $(0.063)$ & $(0.115)$ \\
\hline
\end{tabular}

63 There are other kinds of performance pay such as cash bonuses that are linked to meeting short-term targets of earnings or other accounting measures.

64 The reason for using these measures of incentives, and not mere stock and option mix in total compensation (and salary), is because extant literature has stated that effective incentives provided by stock-based components in compensations are in the form of the sensitivity of the CEO's wealth to the change in stock-prices and stock-return volatility resulting from the contracts. These three measures capture effective incentives. For definition of these measures, refer to Appendix.

65 As a robustness check, I re-run the analysis using entropy balancing, and find that the results are robust. 
Table 3.9: Continued

\begin{tabular}{|c|c|c|c|c|c|c|}
\hline & (I) & (II) & (III) & (I) & (II) & (III) \\
\hline & $\ln ($ Vega $)$ & $\ln ($ Delta $)$ & $\ln$ (Incentive) & $\ln ($ Vega $)$ & $\ln ($ Delta $)$ & $\ln$ (Incentive) \\
\hline \multirow[t]{2}{*}{ Cash } & 0.287 & 0.612 & -1.535 & 0.644 & 0.341 & 0.618 \\
\hline & (1.848) & $(0.887)$ & $(2.490)$ & $(0.545)$ & $(0.300)$ & $(0.618)$ \\
\hline \multirow[t]{2}{*}{ Taxloss } & -0.640 & -0.166 & 2.807 & $-0.917^{* *}$ & 0.353 & -0.057 \\
\hline & $(1.875)$ & $(0.950)$ & $(2.716)$ & $(0.455)$ & $(0.294)$ & $(0.513)$ \\
\hline \multirow[t]{2}{*}{$R O A$} & 0.208 & 0.445 & -0.720 & 0.483 & $0.546^{* * *}$ & $0.847^{* * *}$ \\
\hline & $(0.927)$ & $(0.510)$ & $(1.261)$ & $(0.293)$ & $(0.182)$ & $(0.312)$ \\
\hline \multirow[t]{2}{*}{ Returns } & $0.323^{*}$ & $0.392^{* * *}$ & $0.456^{*}$ & $0.286^{* * *}$ & $0.327^{* * *}$ & $0.367^{* * *}$ \\
\hline & $(0.192)$ & $(0.089)$ & $(0.253)$ & $(0.070)$ & $(0.042)$ & $(0.084)$ \\
\hline \multirow[t]{2}{*}{$\log ($ Sales $)$} & 0.465 & -0.255 & -0.003 & -0.733 & $-0.470^{* *}$ & $-1.228^{* *}$ \\
\hline & $(1.182)$ & $(0.604)$ & $(1.483)$ & $(0.463)$ & $(0.238)$ & $(0.507)$ \\
\hline \multirow[t]{2}{*}{ Leverage } & -0.335 & $-0.743^{* * *}$ & -0.472 & $-0.291^{*}$ & $-0.958^{* * *}$ & $-1.285^{* * *}$ \\
\hline & $(0.562)$ & $(0.285)$ & $(0.796)$ & $(0.162)$ & $(0.097)$ & $(0.182)$ \\
\hline \multirow[t]{2}{*}{$B T M$} & -0.392 & $-0.616^{* *}$ & $-1.365^{* *}$ & 0.315 & $-0.191^{* *}$ & -0.107 \\
\hline & $(0.490)$ & $(0.247)$ & $(0.605)$ & $(0.196)$ & $(0.097)$ & $(0.196)$ \\
\hline \multirow[t]{2}{*}{ Growth } & -1.077 & 0.012 & -0.511 & 0.011 & $0.312^{* * *}$ & 0.179 \\
\hline & $(1.069)$ & $(0.462)$ & (1.384) & $(0.156)$ & $(0.113)$ & $(0.203)$ \\
\hline \multirow[t]{2}{*}{ PPळE } & $-2.041^{*}$ & -0.071 & -1.107 & -0.400 & 0.178 & -0.210 \\
\hline & $(1.174)$ & $(0.528)$ & $(1.405)$ & $(0.470)$ & $(0.277)$ & $(0.537)$ \\
\hline \multirow[t]{2}{*}{ Z-Score } & -0.008 & 0.001 & -0.009 & 0.000 & 0.000 & 0.001 \\
\hline & $(0.011)$ & $(0.005)$ & $(0.013)$ & $(0.001)$ & $(0.000)$ & $(0.001)$ \\
\hline \multirow[t]{2}{*}{ Board size } & $0.036^{* *}$ & 0.001 & 0.029 & 0.009 & -0.005 & 0.008 \\
\hline & $(0.017)$ & $(0.007)$ & $(0.021)$ & $(0.008)$ & $(0.004)$ & $(0.009)$ \\
\hline \multirow[t]{2}{*}{ CEO duality } & $-1.549^{* *}$ & $-0.687^{* * *}$ & $-1.664^{* *}$ & 0.043 & -0.030 & -0.022 \\
\hline & $(0.632)$ & $(0.231)$ & $(0.693)$ & $(0.185)$ & $(0.096)$ & $(0.208)$ \\
\hline \multirow[t]{2}{*}{ Independent Board } & 1.372 & 0.592 & 0.441 & 0.173 & -0.045 & 0.097 \\
\hline & (1.202) & $(0.651)$ & $(1.667)$ & $(0.391)$ & $(0.211)$ & $(0.413)$ \\
\hline \multirow[t]{2}{*}{ Stock-volatility } & -1.659 & 0.076 & -2.584 & -0.136 & -0.176 & $-1.319^{* *}$ \\
\hline & (1.619) & $(0.829)$ & $(2.188)$ & $(0.504)$ & $(0.283)$ & $(0.589)$ \\
\hline \multirow[t]{2}{*}{ CEO age } & -0.019 & -0.010 & -0.017 & -0.006 & -0.007 & $-0.020^{*}$ \\
\hline & $(0.025)$ & $(0.017)$ & $(0.034)$ & $(0.010)$ & $(0.006)$ & $(0.011)$ \\
\hline Industry effects & Yes & Yes & Yes & Yes & Yes & Yes \\
\hline Year effects & Yes & Yes & Yes & Yes & Yes & Yes \\
\hline Observations & 208 & 208 & 205 & 3,162 & 3,162 & 3,135 \\
\hline R-squared & 0.409 & 0.631 & 0.535 & 0.263 & 0.522 & 0.392 \\
\hline
\end{tabular}

${ }^{*} \mathrm{p}<0.10 ;{ }^{* *} \mathrm{p}<0.05 ;{ }^{* * *} \mathrm{p}<0.01$ (Two-sided). Robust standard errors clustered at firm-level. For detailed description on the key variables refer to Appendix. 
As a final test, I investigate if there is any differential investment behavior between External CEOs and Internal CEOs in terms of increasing the systematic and idiosyncratic risks (following the two-stage least square approach and the measures of risks calculated in Armstrong and Vashishtha, 2012) using the following equation. ${ }^{66}$

Risk $_{i}=\delta_{0}+\delta_{1}$ External CEO $+\sum_{i} \delta_{i}+\emptyset_{i}$

The controls used are the same as those used for equation (1). In addition, I also control for vega and delta. The difference in my analysis and that of Armstrong and Vashishtha (2012) are the following: (i) I use governance measures as controls in the second stage whereas they do not; and most importantly, (ii) I use the predicted probabilities of hiring the external CEOs vis-à-vis the internal CEO as an instrument in my first stage since my endogenous variable is a dummy variable, following Wooldridge (2019). The variables used to predict the likelihood of hiring an External CEO over an Internal CEO are (i) CEO non-retirement, indicator variable that the leaving CEO was younger than sixty years in age suggesting non-retirement of the leaving $\mathrm{CEO}$, which could be a proxy for CEO-dismissal (Parrino, 1997; Coles et al., 2014). Prior literature finds a link between incumbent CEO dismissal and hiring of an External CEO. Hence, I use it as an instrument because there is no reason to expect any direct effect of the non-retirement of the leaving $\mathrm{CEO}$ on the current risk profile of a firm except through the decisions on CEO hiring. I expect a positive relationship between this measure and hiring an External-CEOs; and (ii) Firm's past performance, proxied by the variable Taxloss, lagged values of ROA, Cumulative Returns and Altman Z-score. Following earlier studies (Coles et al., 2006; Armstrong \& Vashishtha, 2012) I do not expect a direct relationship between a firm's prior performance and a firm's current risk-profile, other than its effects through incentives and leverage, hence I control for these two measures in my risk-equation estimation. I also use the controls of the risk-equation to explain the hiring choice. However, I exclude tenure because the predictions are made at the time of appointment as a CEO and tenure is the same for all CEOs at the time of appointment [See Table 3.17 in Appendix for the results from the probit estimation used for the first-stage of the two-stage least square estimation]. Table 3.10 reports the results of the two-stage least-square estimation of the various types of risks taken by the two types of CEOs. There is no statistically significant difference in the risk-taking behavior

66 The main reason for using the imputed measure of risk in place of the realized stock volatility is to get around the concerns of omitted variable bias that is associated with realized stock-return volatility. A measure of risk based on realized stock-return volatility can depend on various factors apart from the CEO's risk-taking decisions, such as the firm's disclosures and other features of the information environment. It is seen that there is generally also a market reaction regarding CEO succession decisions that could reflect in stock-returns. This could lead to spurious correlation between risk-taking incentives and firm risk. On the other hand, using this imputed return ensures that the focal firm cannot influence the stock returns of that segment and the information environment of the segments in question and gets rid of the omitted variable bias (Armstrong \& Vashishtha, 2012). 
of the External CEO vis-à-vis the Internal CEO, after controlling for effective incentives (vega and delta) and all firm specific characteristics (see Panel B of Table 3.10). These results do not seem to support the argument that External CEOs are inherently different from Internal CEOs as far as risk-taking is concerned, as argued by prior literature.

Hence, to summarize: (i) the effective incentives (initially) for External CEOs are not higher than that for Internal CEOs, and (ii) After controlling for incentives and firm and CEO characteristics, there is no significant difference in the risk-taking behavior of External CEOs compared to Internal CEOs. Hence, there seems to be no strong evidence in support of the alternate explanation of (different) incentive motives behind the difference in the stock-based component in compensation at the time of appointment.

However, when comparing the share of stock-based pay between Internal and External CEOs, there is a possibility that a part of the difference in the share of stockbased pay observed at the time of appointment is driven by the fact that Internal CEOs might already have firm-related wealth from their prior appointment as an executive in the firm and that External CEOs are given a higher share of stock-based pay at the time of appointment to bring their firm-related wealth at par with those of the Internal CEOs. Hence to avoid such other possible explanations regarding Internal versus External CEO hiring, I examine only the sub-sample of externally hired CEOs (including the 'CEOCEO jump' cases) and look for variation in the degree of informational asymmetry among the externally hired CEOs and examine if there is a positive link between the severity of informational asymmetry and the use of stock-based pay at the time of appointment in the following sub-section. 
Table 3.10: 2SLS estimation of risk-taking behavior of External CEOs, compared to Internal CEOs

\begin{tabular}{|c|c|c|c|}
\hline \multirow[t]{2}{*}{ Panel A: First Stage } & \multicolumn{3}{|c|}{ Likelihood of hiring External CEO } \\
\hline & \multicolumn{2}{|c|}{ (coefficient) } & (std. errors) \\
\hline Predicted Probability & \multicolumn{2}{|c|}{$0.818^{* *}$} & $(0.418)$ \\
\hline Leverage & \multicolumn{2}{|c|}{0.079} & $(0.152)$ \\
\hline Log (Sales) & \multicolumn{2}{|c|}{-0.017} & $(0.012)$ \\
\hline$B T M$ & \multicolumn{2}{|c|}{-0.048} & $(0.099)$ \\
\hline Sales Growth & \multicolumn{2}{|c|}{-0.061} & $(0.086)$ \\
\hline PPE & \multicolumn{2}{|c|}{0.036} & $(0.051)$ \\
\hline Board size & \multicolumn{2}{|c|}{0.001} & $(0.001)$ \\
\hline CEO duality & \multicolumn{2}{|c|}{-0.011} & $(0.031)$ \\
\hline Independent Board & \multicolumn{2}{|c|}{0.136} & $(0.117)$ \\
\hline $\log (v e g a)$ & \multicolumn{2}{|c|}{-0.008} & $(0.008)$ \\
\hline $\log ($ delta $)$ & \multicolumn{2}{|c|}{0.002} & $(0.014)$ \\
\hline Log(salary \& bonus) & \multicolumn{2}{|c|}{0.005} & $(0.077)$ \\
\hline Tenure & \multicolumn{2}{|c|}{-0.022} & $(0.015)$ \\
\hline CEO age & \multicolumn{2}{|c|}{0.001} & $(0.003)$ \\
\hline $\mathrm{F}(1,75)$ & 3.82 & P-value: 0.0544 & \\
\hline Panel B: Second Stage & Total risk & Systematic Risk & Idiosyncratic Risk \\
\hline \multirow[t]{2}{*}{ External CEO } & 0.425 & -0.170 & 0.302 \\
\hline & $(0.494)$ & $(0.167)$ & $(0.506)$ \\
\hline \multirow[t]{2}{*}{ Leverage } & 0.252 & 0.018 & 0.297 \\
\hline & $(0.247)$ & $(0.034)$ & $(0.266)$ \\
\hline \multirow[t]{2}{*}{$\log ($ sale $)$} & 0.030 & 0.001 & $0.059^{* *}$ \\
\hline & $(0.028)$ & $(0.003)$ & $(0.027)$ \\
\hline \multirow[t]{2}{*}{$B T M$} & $0.311^{*}$ & -0.036 & 0.184 \\
\hline & $(0.185)$ & $(0.032)$ & $(0.187)$ \\
\hline \multirow[t]{2}{*}{ Growth } & 0.219 & 0.000 & 0.305 \\
\hline & $(0.257)$ & $(0.025)$ & $(0.287)$ \\
\hline \multirow[t]{2}{*}{$\log ($ salary \& bonus) } & 0.013 & 0.010 & -0.083 \\
\hline & $(0.149)$ & (0.019) & $(0.165)$ \\
\hline \multirow[t]{2}{*}{ Tenure } & $0.059^{*}$ & -0.006 & 0.053 \\
\hline & $(0.035)$ & $(0.006)$ & $(0.042)$ \\
\hline \multirow[t]{2}{*}{ PP\&E } & 0.251 & 0.002 & $0.728^{* * *}$ \\
\hline & $(0.187)$ & $(0.014)$ & $(0.201)$ \\
\hline \multirow[t]{2}{*}{ Board size } & $-0.011^{* *}$ & 0.000 & $-0.009^{*}$ \\
\hline & $(0.005)$ & $(0.000)$ & $(0.005)$ \\
\hline \multirow[t]{2}{*}{ CEO-duality } & -0.054 & -0.006 & 0.010 \\
\hline & $(0.142)$ & $(0.012)$ & $(0.155)$ \\
\hline
\end{tabular}




\begin{tabular}{lccc} 
Independent Board & -0.294 & 0.006 & 0.028 \\
& $(0.244)$ & $(0.031)$ & $(0.316)$ \\
CEO age & 0.001 & -0.001 & 0.007 \\
& $(0.006)$ & $(0.001)$ & $(0.008)$ \\
Log(vega $)$ & 0.019 & -0.003 & 0.000 \\
& $(0.017)$ & $(0.003)$ & $(0.020)$ \\
Log(delta) & -0.000 & -0.002 & $-0.074^{* *}$ \\
& $(0.041)$ & $(0.003)$ & $(0.032)$ \\
Year Effects & $Y e s$ & $Y e s$ & Yes \\
Observations & 180 & 180 & 180 \\
R-squared & 0.210 & 0.867 & 0.336 \\
\hline
\end{tabular}

${ }^{*} \mathrm{p}<0.10{ }^{* *} \mathrm{p}<0.05 ;{ }^{* * *} \mathrm{p}<0.01$ (Two-sided).

\subsubsection{Analysis within External CEOs}

\section{Comparing CEO-CEO jump to NonCEO-CEO jump}

In order to find support for the sorting hypothesis, I estimate equations (1) and (2) for only the External CEO (sample of 124 firm-year observations), in order to keep the incentive objectives constant across the two types of External CEO. I compare the ratio of stock-based performance to salary (and in total compensation) and salary between those External CEOs who were CEOs in their previous firm (referred to as CEO-CEO jump) to those that were not CEOs (referred to as NonCEO-CEO jump). I argue that boards might have a less severe informational asymmetry around the first category's fit of External CEOs than the second category's (Graffin et al., 2013; Falato et al., 2015). Hence, I should find that the stock-based performance pay at the time of appointment to the second category (NonCEO-CEO jumps) is higher than that given to the first category (CEO-CEO jumps). Using entropy balancing, I show in Table 3.11, that indeed the ratio of stocks and options to salary (and the ratio of stocks and options to total compensation) is significantly higher for NonCEO-CEO jump CEO's than that for CEO-CEO jump CEOs (significant at 1 percent level of significance). ${ }^{67}$ The difference in this ratio is attributable to the significant difference in the ratio of options to salary (and ratio of options in total compensation) between NonCEO-CEO jump and that for CEO-CEO jump. However, the ratio of stocks to salary (and ratio of stocks to total compensation) is not significantly different between the two groups of CEOs.

67 I do not control for industry fixed effects in this analysis because of the small sample size and to avoid the risk of over-fitting the model. 
Table 3.11: Results from entropy balancing estimation for (1) to test HI for NonCEO-CEO jumps vis-a-vis CEO-CEO jumps, within External CEOs

\begin{tabular}{|c|c|c|c|c|c|c|}
\hline & $\begin{array}{c}\text { (I) } \\
\text { (Stocks } \\
\text { \&Options)/ } \\
\text { Salary }\end{array}$ & $\begin{array}{c}\text { Stocks/ } \\
\text { Salary }\end{array}$ & $\begin{array}{c}\text { Options/ } \\
\text { Salary }\end{array}$ & $\begin{array}{c}\text { (IV) } \\
\text { (Stocks } \\
\text { \&Options)/ } \\
\text { Total } \\
\text { compensation }\end{array}$ & $\begin{array}{c}(\mathrm{V}) \\
\text { Stocks/ } \\
\text { Total } \\
\text { compensation }\end{array}$ & $\begin{array}{c}\text { (VI) } \\
\text { Options/ } \\
\text { Total } \\
\text { compensation }\end{array}$ \\
\hline \multirow[t]{2}{*}{ NonCEO-CEO jump } & $11.635^{* * *}$ & -6.492 & $18.127^{* * *}$ & $0.424^{* *}$ & -0.201 & $0.625^{* * *}$ \\
\hline & $(4.110)$ & $(4.196)$ & $(1.054)$ & $(0.164)$ & $(0.140)$ & $(0.137)$ \\
\hline Industry effects & No & No & No & No & No & No \\
\hline Year effects & Yes & Yes & Yes & Yes & Yes & Yes \\
\hline Observations & 35 & 35 & 35 & 35 & 35 & 35 \\
\hline R-squared & 0.599 & 0.533 & 0.443 & 0.423 & 0.332 & 0.410 \\
\hline
\end{tabular}

${ }^{*} \mathrm{p}<0.10 ;{ }^{* *} \mathrm{p}<0.05 ;{ }^{* * *} \mathrm{p}<0.01$ (Two-sided)

As hypothesized, the ratio of stock-based pay to salary (and ratio of stock-based pay to total compensation) remains unchanged over tenure for the CEO-CEO jump group, as seen from Table 3.12. However, interestingly, the ratio of stock to salary (and ratio of stocks to total compensation) and the ratio of options to salary (and ratio of options to total compensation) are adjusted down and up respectively over tenure for the CEO-CEO jump group, resulting in zero net change in total stock-based pay (relative to both salary and total compensation) over tenure. On the other hand, the ratio of stock-based pay to salary (and ratio of stocks to total compensation) for the NonCEOCEO jumps declines over tenure, as expected. In addition, Table 3.13 shows that there is convergence in the ratio of stock-based pay to total compensation. 


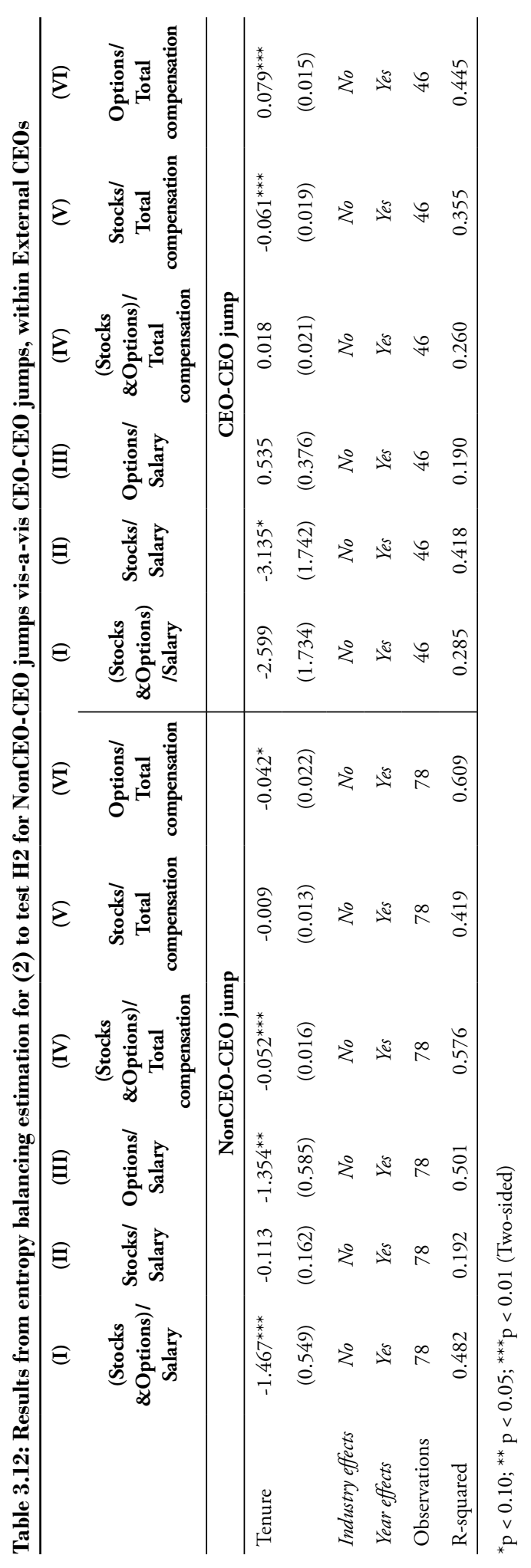


Table 3.13: Results from entropy balancing estimation for (3) to test $\mathrm{H} 2$ for NonCEO-CEO jumps vis-a-vis CEO-CEO jumps, within External CEOs.

\begin{tabular}{|c|c|c|c|c|c|c|}
\hline & $\begin{array}{c}\text { (I) } \\
\text { (Stocks } \\
\text { \&Options)/ } \\
\text { Salary }\end{array}$ & $\begin{array}{c}\text { (II) } \\
\text { Stocks/ } \\
\text { Salary }\end{array}$ & $\begin{array}{c}\text { (III) } \\
\text { Options/ } \\
\text { Salary }\end{array}$ & $\begin{array}{c}\text { (IV) } \\
\text { (Stocks } \\
\text { \&Options)/ } \\
\text { Total } \\
\text { compensation }\end{array}$ & $\begin{array}{c}(\mathrm{V}) \\
\text { Stocks/ } \\
\text { Total } \\
\text { compensation }\end{array}$ & $\begin{array}{c}\text { (VI) } \\
\text { Options/ } \\
\text { Total } \\
\text { compensation }\end{array}$ \\
\hline \multirow[t]{2}{*}{ NonCEO-CEO jump } & -0.092 & -1.227 & 1.136 & 0.067 & 0.087 & -0.020 \\
\hline & $(3.267)$ & $(1.731)$ & $(2.964)$ & $(0.077)$ & $(0.058)$ & $(0.100)$ \\
\hline \multirow[t]{2}{*}{ Tenure } & -1.940 & -2.046 & 0.105 & 0.003 & $-0.037^{* *}$ & $0.040^{*}$ \\
\hline & $(1.373)$ & (1.415) & $(0.421)$ & $(0.018)$ & $(0.019)$ & $(0.021)$ \\
\hline \multirow[t]{2}{*}{ NonCEO-CEO jump x Tenure } & 0.184 & 1.333 & -1.149 & $-0.045^{*}$ & 0.026 & $-0.071^{* *}$ \\
\hline & $(1.131)$ & $(0.932)$ & $(0.760)$ & $(0.023)$ & $(0.019)$ & $(0.028)$ \\
\hline Industry effects & No & No & No & No & No & No \\
\hline Year effects & Yes & Yes & Yes & Yes & Yes & Yes \\
\hline Observations & 124 & 124 & 124 & 124 & 124 & 124 \\
\hline R-squared & 0.230 & 0.247 & 0.223 & 0.264 & 0.297 & 0.337 \\
\hline
\end{tabular}

${ }^{*} \mathrm{p}<0.10 ;{ }^{* *} \mathrm{p}<0.05 ;{ }^{* * *} \mathrm{p}<0.01$ (Two-sided)

\section{Comparing Intra-industry jumps to Inter-industry jumps}

Finally, I categorize external CEO hiring as Intra-industry jumps if their pervious employer were in a similar industry and as Inter-industry jumps if their previous employer were in a different industry (it is a smaller sample of 88 firm-year observations). ${ }^{68} \mathrm{I}$ assume that there is more severe informational asymmetry around the Inter-industry jump than for Intra-Industry jumps and hence, the stock-based pay (relative to salary and total compensation) should be higher for the former than the latter (H1). Table 3.14 shows results for $\mathrm{H} 1$ (for entropy balancing estimation). I see that the ratio of stock-based pay to salary (and ratio of only stocks to total compensation) is significantly higher for InterIndustry jump compared to an Intra-industry jump. ${ }^{69} \mathrm{I}$ find no significant difference for the ratio of total stock-based pay to compensation. ${ }^{70}$

68 The similar industry classification will include (i) exact same 4-digit SIC code and (ii) similar industries such as Industrial Organic Chemical (2860) and Industrial Inorganic Chemicals (2810). An example of a different industry will be Surgical \& Medical Instruments \& Apparatus (3841) and Biological Products - except Diagnostic Substances (2836). I observe that the share of Similar Industry jump is around $70 \%$.

69 I also control for CEO-CEO jumps.

70 I also estimate the difference in the share of stock-based pay by considering only same industry jump (same four digit sic code) as Intra-Industry jump and do not find support for H1. The probable reason could be that this classification fails to recognize that the jump from a similar industry could still mitigate a major part of the informational asymmetry, hence the variation in the informational asymmetry between the Intra-Industry jump and the Interindustry jump is not very pronounced. 
Table 3.14: Results from entropy balancing estimation for(1) to test $\mathrm{HI}$ for Inter-industry jumps vis-a-vis Intra-industry jumps, within External CEOs

(I) (II) (III)

(IV)

(V)

(VI)

\begin{tabular}{lcccccc} 
& $\begin{array}{c}\text { (Stocks } \\
\text { \&Options)/ } \\
\text { Salary }\end{array}$ & $\begin{array}{c}\text { Stocks/ } \\
\text { Salary }\end{array}$ & $\begin{array}{c}\text { Options/ } \\
\text { Salary }\end{array}$ & $\begin{array}{c}\text { (Stocks } \\
\text { \&Options)/ } \\
\text { Total } \\
\text { compensation }\end{array}$ & $\begin{array}{c}\text { Stocks/ } \\
\text { Total } \\
\text { compensation }\end{array}$ & $\begin{array}{c}\text { Options/ } \\
\text { Total } \\
\text { compensation }\end{array}$ \\
\hline Inter-Industry Jump & $7.536^{* * *}$ & 0.318 & $7.218^{* * *}$ & 0.103 & $0.136^{*}$ & -0.034 \\
& $(2.446)$ & $(1.942)$ & $(2.226)$ & $(0.061)$ & $(0.078)$ & $(0.070)$ \\
CEO-CEO jump effect & Yes & Yes & Yes & Yes & Yes & Yes \\
Year effects & Yes & Yes & Yes & Yes & Yes & Yes \\
Observations & 35 & 35 & 35 & 35 & 35 & 35 \\
R-squared & 0.792 & 0.527 & 0.878 & 0.372 & 0.645 & 0.653 \\
\hline
\end{tabular}

${ }^{*} \mathrm{p}<0.10 ;{ }^{* *} \mathrm{p}<0.05 ;{ }^{* * *} \mathrm{p}<0.01$ (Two-sided)

For H2, I find support for the ratio of stock-based pay to salary (mainly driven by options to salary ratio) and for the ratio of options in total compensation (see Table 3.15 and Table 3.16). However, I also find that the convergence of stock-based pay to salary observed in Table 3.16 is also partly driven by an increase in the ratio of stocks to salary for the Intra-Industry jumps over tenure. 


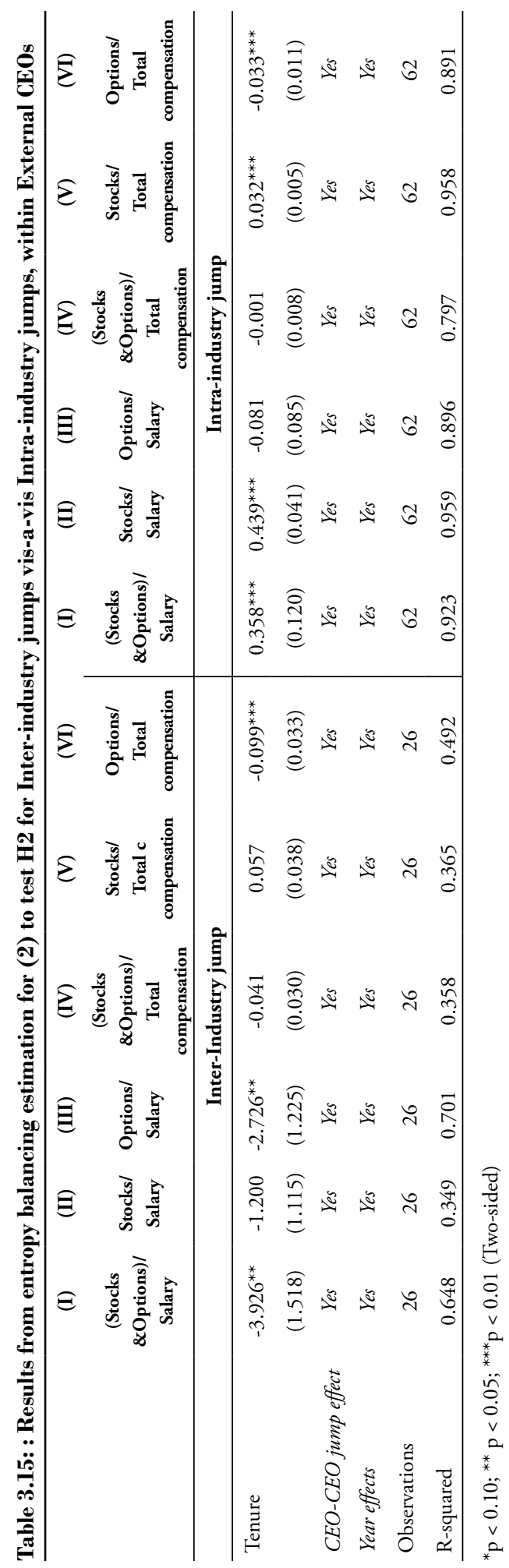


Table 3.16: Results from entropy balancing estimation for (3) to test $\mathrm{H} 2$ for Inter-industry jumps vis-a-vis Intra-industry jumps, within External CEOs

\begin{tabular}{|c|c|c|c|c|c|c|}
\hline & (I) & (II) & (III) & (IV) & $(\mathbf{V})$ & (VI) \\
\hline & $\begin{array}{c}\text { (Stocks } \\
\text { \&Options) } \\
\text { / Salary }\end{array}$ & $\begin{array}{c}\text { Stocks/ } \\
\text { Salary }\end{array}$ & $\begin{array}{c}\text { Options/ } \\
\text { Salary }\end{array}$ & $\begin{array}{c}\text { (Stocks } \\
\text { \&Options)/ } \\
\text { Total } \\
\text { compensation }\end{array}$ & $\begin{array}{c}\text { Stocks/ } \\
\text { Total } \\
\text { compensation }\end{array}$ & $\begin{array}{c}\text { Options/ } \\
\text { Total } \\
\text { compensation }\end{array}$ \\
\hline \multirow[t]{2}{*}{ Inter-Industry Jump } & $10.086^{* * *}$ & $3.746^{* *}$ & $6.340^{*}$ & 0.088 & $0.230^{* * *}$ & $-0.142^{*}$ \\
\hline & $(3.059)$ & $(1.558)$ & $(3.565)$ & $(0.075)$ & $(0.085)$ & $(0.080)$ \\
\hline \multirow[t]{2}{*}{ Tenure } & $-0.830^{*}$ & -0.015 & -0.815 & -0.006 & 0.020 & -0.026 \\
\hline & $(0.463)$ & $(0.344)$ & $(0.519)$ & $(0.017)$ & $(0.015)$ & $(0.016)$ \\
\hline \multirow[t]{2}{*}{ Inter-Industry jump x Tenure } & $-3.377^{* *}$ & -1.083 & $-2.294^{* *}$ & -0.027 & 0.041 & $-0.067^{*}$ \\
\hline & $(1.349)$ & $(0.863)$ & $(1.121)$ & $(0.028)$ & $(0.034)$ & $(0.040)$ \\
\hline CEO-CEO jump effect & Yes & Yes & Yes & Yes & Yes & Yes \\
\hline Year effects & Yes & Yes & Yes & Yes & Yes & Yes \\
\hline Observations & 88 & 88 & 88 & 88 & 88 & 88 \\
\hline R-squared & 0.645 & 0.303 & 0.595 & 0.305 & 0.402 & 0.396 \\
\hline
\end{tabular}

${ }^{*} \mathrm{p}<0.10 ;{ }^{* *} \mathrm{p}<0.05 ;{ }^{* * *} \mathrm{p}<0.01$ (Two-sided)

To conclude, it is evident that there is some support for $\mathrm{H} 1$ in this sub-sample, supporting the correlation between severity of informational asymmetry and the use of stock-based pay. The findings for $\mathrm{H} 2$ are somewhat weak in supporting our hypothesis in this sub-sample.

\subsubsection{Skills-Premium Argument}

In the previous two analyses, whether its CEO-CEO jump or the Intra-Industry jump, one can argue that there could be a skills-premium story behind the lower share of stock-based pay in their compensations. For instance, prior experience as CEO could be viewed as a valuable skill that carries a premium in the form of higher share of riskfree salary in compensation (although empirical evidence on compensation premium for CEO experience is mixed). ${ }^{71}$ Arguably, this could also be true for Intra-industry experience. However, to note, most of the existing studies do not specify if skillspremium is in the form of higher share of risk-free salary or a higher share of stock-based pay, but only find a higher level of total compensation (Harris \& Helfat, 1997; Murphy \& Zabojnik, 2007; Gabaix et al., 2014; Edmans \& Gabaix, 2016; Frydman, 2019). I argue that even if the skills-premium were to be in the form of risk-free salary (which could confound our findings for H1) that should (and does) persist over tenure for both

71 See Elsaid et al (2011), Bragaw and Misangyi (2017) for empirical evidence on the topic. Elsaid et al (2011) find no significant compensation premium for prior CEO experience, whereas, Bragaw and Misangyi (2017) do find empirical evidence of a compensation premium for prior CEO experience. 
the CEO-CEO jump and Intra-Industry jump CEOs, it still does not explain our results for $\mathrm{H} 2$ for the NonCEO-CEO jump and Inter-industry jump CEOs where we observe the convergence in the compensation structure over tenure, because of a decline in the stock-based component (relative to salary or total compensation) for the latter groups of External CEOs. ${ }^{72}$

As far as External CEOs are concerned, a few studies (Murphy \& Zabojnik, 2007; Frydman, 2019) argue that externally hired CEOs are paid higher total compensation as a form of premium for their general skills. However, if that were the case, then this premium (if in the form of risky stock-based pay) should have persisted over tenure, which is not observed. In the alternate situation where having firm-specific skills are paid a premium over general skills (Harris \& Helfat, 1997) in the form of higher riskfree salary, we will observe a lower share of stock-based pay for Internal CEOs (which also persists over tenure) than for External CEOs which could confound our findings for H1. However, it still does not explain the decrease in the stock-based pay ratio for the External CEOs over time.

Hence, although the skills-premium argument can explain a part of the findings for $\mathrm{H} 1$ in the cases of (i) NonCEO-CEO jumps versus CEO-CEO jumps and (ii) Inter-industry jumps versus Intra-Industry jumps, it does not explain the findings for $\mathrm{H} 2$ for External CEOs, NonCEO-CEO jumps and Inter-industry jumps. To conclude, there might be some skills-premium argument explaining the compensation structure for the Internal CEO, CEO-CEO jump CEO and the Intra-industry jump CEO, but it cannot explain that for the External CEO, NonCEO-CEO jump CEO, and the Interindustry jump CEO. Thus, the results seem to support the sorting story in explaining the compensation structure (in part) at the time of appointment and the dynamic changes to it over tenure.

\subsection{Conclusion}

To sum up, the following are the main findings of the study. At the time of appointment as a CEO, externally hired CEOs have contracts with higher shares of stock-based pay with respect to both the fixed-component (salary) and total compensation than do internally appointed CEOs. Within the externally hired CEOs, CEOs who have not served as CEOs in previous firms have higher shares of stock-based pay relative to salary and total compensation compared to those who have prior experience as a CEO, at the time of appointment. Also, CEOs who have moved from a different industry have

72 The same argument should hold if we are considering a case where CEO-CEO jumps are compensated by the new firm for the wealth forgone while leaving the old firm (Fee \& Hadlock, 2003; Lazear, 2005). Although, with our findings these compensations should come in the form of higher salary component, and not in the form of higher stock-based pay, as suggested by Fee and Hadlock (2003) and Lazear (2005). 
slightly higher shares of stock-based pay than do CEOs who have moved from similar industries. There is a significant decline in the ratio of stock-based pay to salary over tenure for the External CEOs, while there is no significant change in the ratio of stockbased pay to salary (and to total compensation) for the Internal CEOs. Likewise, there is a significant decline in the ratio of stock-based pay to salary (and to total compensation) over tenure for those externally hired CEOs who had no prior experience as CEOs before joining the firm, while there is no significant change in the ratio of ratio of stock-based pay to salary (and to total compensation) over tenure for those CEOs who had prior experience as CEOs before joining the firm. Interestingly, for the analysis comparing these ratios between CEOs who moved from a different industry and those who moved from a similar industry, there is a decline for the former over tenure, as expected, but there is also a rise for the latter group over tenure, especially in the ratio of stock-based pay to salary. As a result, the difference in the share of stock-based pay relative to salary and total compensation at the time of appointment disappears over tenure between the External CEOs and Internal CEOs. Similar convergence is observed for CEOs with no prior CEO experience and those with prior experience as well for the CEOs who move from a different industry and those who moved from similar industries. For the analysis comparing contracts of internally appointed versus externally hired CEOs, I do not find any strong evidence for (i) difference in incentives for the two types of CEOs, and (ii) differential strategic behavior (after controlling for all firm specific and CEO specific characteristics), thus, not supporting the incentive story behind the difference in stockbased pay.

To conclude, the findings of the study suggest that stock-based pay in a CEO's compensation can serve as a tool for sorting CEOs at the time of appointment, especially for those CEOs for whom the hiring firm has a relatively more severe informational disadvantage than for those CEOs for whom the informational asymmetry around their fit is less severe. These findings support the theoretical predictions of studies (Lazear, 2005; Cadenillas et al., 2005; Moen \& Rosen, 2005; Palomino \& Peyrache, 2013; Bénabou \& Tirole, 2016) and their conclusion that stock-based pay can help in sorting CEOs based on their unobserved ability or talent. However, this study argues that although stock-based pay can be an effective sorting tool across all firms, the need for using stock-based pay for sorting may vary across firms. Offering a higher mix of stocks and options is costly since it allocates additional risks on the risk-averse CEO, more than the necessary level for purely incentive purposes (Lazear, 2005). Hence, the study argues that the need for using stock-based pay for sorting CEOs varies with the different informational environment around a CEO's appointment. In particular, it argues that the benefit of using stock-based pay (relative to its costs) increases with the severity in informational asymmetry around the CEO's fit in the firm. The study argues that firms can vary in their needs for using stock-based compensation for sorting at the time of hiring depending on the type of hiring the firm opts for-Internal versus External CEO, 
CEOs with or without prior CEO experience, CEOs from same or different industries etc. Different hiring strategies entail potentially different informational environment around the CEO's fit in the firm. The higher the severity of informational asymmetry in the environment, the higher the benefit (relative to cost) of using stock-based pay for sorting the CEO's based on their unobserved fit.

However, one of the possible limitations of the study might be that it does not investigate the possibility of using stocks and options at the time of appointment as tools for retention (as an alternate explanation), as indicated by earlier studies (Ittner et al., 2001; Gerakos et al., 2018). My argument against this explanation, especially using stock-based pay at the time of appointment for this purpose, is as follows; (i) there is no reason why a firm would want to retain (ex-ante) the CEO for which they have the least amount of private information at the time of appointment more than the other CEOs, and (ii) if that is the case (for example, to keep stakeholders' faith intact with the hiring choice) then it still does not explain the convergence of the mix of shares and options in the compensations across the two types of CEOs over tenure. Finally, I re-iterate Lazear's (2005) argument that if retention is the objective, then there are more efficient forms of compensation, such as bonds that mature after a certain period [as observed by $\mathrm{Xu}$ and Yang (2016)], than offering risky stocks and options to risk-averse agents and allocating unnecessary risks to the CEO only for the sake of retention.

In addition, the study also does not investigate the role of board connectedness of external CEOs in determining their compensation structure at the time of appointment. Theoretically, having connections to board members of the hiring firm can have two effects: (i) allow for reducing the informational asymmetry about the CEO's fit in the firm that can affect the compensation structure and/or (ii) allowing for greater (or less) rent-extraction by the CEO which can also affect the structure of the compensation. Hence, any observation of higher share of risk-free salary in compensation could be confounded by both these arguments. However, analyzing the evolution of the compensation structure over tenure along with the evolution in the board structure could be worth exploring in the future, also as a means to distinguishing the two possible effects.

Finally, some interesting observations evolve from analyzing the dynamic evolution of stock-based components in compensation that merit more detailed discussion as future research. We see that most of the dynamic changes in the compensation structure come in the form of changes made to the share of stocks for External CEOs and in the share of options for the other two groups of CEOs (within the External CEOs). For example, Taylor (2013) note that stock-return volatility decreases over tenure. This can make options less attractive from an incentive point of view, hence, it is possible that stocks are adjusted accordingly to maintain the necessary level of incentives (although stocks and options do not induce the same kinds of risk-taking behavior because of their different linearity properties). Also, as a topic for further research, it might be interesting 
to examine (theoretically and empirically) the sorting capabilities of use of stocks versus options, especially given their different sensitivity to firm value (linear versus non-linear) and the flexibility of the exercise price in case of options. As a final note, it must be acknowledged that hiring a CEO is an extremely complex process and studies like these can, at best, only examine the outcome of the entire process (in terms of who is hired and what compensation contract is accepted by them) and attempt to draw reasonable inferences from these snapshot views at the end of the process (in this case, mainly based on the assumption of revealed preferences). 


\section{Appendix}

\begin{tabular}{|c|c|}
\hline Variables & Description \\
\hline External CEO & $\begin{array}{l}\text { Indicator variable equal to } 1 \text { if the CEO joined the focal firm in the same year as the } \\
\text { year of appointment as CEO, zero otherwise. }\end{array}$ \\
\hline NonCEO-CEO jump & $\begin{array}{l}\text { Indicator variable equal to } 1 \text { when the appointed CEO of the focal firm has no prior } \\
\text { experience as CEO in previous firms, } 0 \text { otherwise. }\end{array}$ \\
\hline Inter-industry jump & $\begin{array}{l}\text { Indicator variable equal to } 1 \text { when the appointed CEO of the focal firm has moved from } \\
\text { a firm operating in a different industry ( } 4 \text {-digit SIC code) }\end{array}$ \\
\hline Stocks & $\begin{array}{l}\text { Restricted stock awards estimated at fair-value as of the grant date (Black and Scholes } \\
\text { value) for the fiscal year. }\end{array}$ \\
\hline Options & $\begin{array}{l}\text { Options grants estimated at fair-value as of the grant date (Black and Scholes value) for } \\
\text { the fiscal year. }\end{array}$ \\
\hline Salary & Total value of cash-based salary for the fiscal year. \\
\hline Total Compensation & $\begin{array}{l}\text { Total value of cash-based salary, cash-based non-formulaic bonus, cash-based formulaic } \\
\text { non-equity incentives, options grants, stock grants, other compensation, and total } \\
\text { portion of deferred earnings, for the fiscal year. }\end{array}$ \\
\hline Cash-Compensation & $\begin{array}{l}\text { Total value of cash the CEO received during the year, which is the sum of salary and } \\
\text { cash-based bonus at the end of the fiscal year. }\end{array}$ \\
\hline Vega & $\begin{array}{l}\text { Change in the risk-neutral value of the CEO's portfolio of stock options for a } 0.01 \\
\text { change in the standard deviation of the return of the underlying stock [refer to Coles et. } \\
\text { al (2006) and Core and Guay (2002)]. }\end{array}$ \\
\hline Delta & $\begin{array}{l}\text { Change in the risk-neutral value of the CEO's equity portfolio of stock and options for } \\
\text { a } 1 \% \text { change in the price of the underlying stock [refer to Coles et. al (2006) and Core } \\
\text { and Guay (2002)] }\end{array}$ \\
\hline Incentives & $\begin{array}{l}\text { Following Conyon et. al (2011), it is equal to Share-price* (number of restricted stocks+ } \\
\text { number of performance vested restricted stock) + (share-price*Option-delta*Number of } \\
\text { options held) }\end{array}$ \\
\hline Firm Risk & $\begin{array}{l}\text { Firm-risk is measured using the imputed monthly returns based on the industry } \\
\text { segments in which the firm operates and is estimated using the three Fama and French } \\
\text { factors as described in Armstrong and Vashishtha (2012). Systematic risk is the square } \\
\text { root of the variance of firm-returns explained by the Fama-French three-factor model. } \\
\text { Idiosyncratic risk is the square root of the residual variance from the Fama- French three- } \\
\text { factor model. Total risk is the standard deviation of firm returns. }\end{array}$ \\
\hline ROA & Net income scaled by beginning-of-year book value of assets. \\
\hline Taxloss & $\begin{array}{l}\text { An indicator variable equal to one if a firm has tax-loss carry-forwards in any of the past } \\
3 \text { years and zero otherwise, following Armstrong and Vashishtha (2012). }\end{array}$ \\
\hline Return & Cummulative stock-return over the fiscal year. \\
\hline Z-score & $\begin{array}{l}\text { Score derived based on a weighted average of five financial ratios, including profitability, } \\
\text { leverage, liquidity, solvency and activity, to measure the financial health of a firm. The } \\
\text { score is calculated using the formula of Altman (1968), which was updated in } 1993 .\end{array}$ \\
\hline Cash & Firm's total cash balance and short-term investments scaled by total assets. \\
\hline Sales & Firm’s annual revenue. \\
\hline Book-to-market (BTM) & Ratio of book value to market value of total-assets. \\
\hline Leverage & Book value of total long-term debt scaled by total assets. \\
\hline Growth & Growth in annual sales over the prior year. \\
\hline PP\&E & Net plant, property, and equipment scaled by total assets. \\
\hline Stock-volatility & Standard deviation of monthly returns over the past 60 months. \\
\hline
\end{tabular}




\begin{tabular}{ll}
\hline Variables & Description \\
\hline CEO dismissal & $\begin{array}{l}\text { An indicator variable equal to } 1 \text { if the leaving CEO was younger than sixty years of age, } \\
\text { zero otherwise [following Parrino (1997)]. } \\
\text { Total number of years serving as a CEO in the focal firm. It is calculated at the } \\
\text { denure }\end{array}$ \\
$\begin{array}{l}\text { Agerence between the fiscal year and the year the executive was appointed as a CEO. } \\
\text { CEO-age }\end{array}$ & Board size is total number of directors on a board. \\
Board-size & Indicator variable equal to 1 for when CEO is also the chairman of the board. \\
CEO-duality & Ratio of independent directors on the board to total board size. \\
Independent board &
\end{tabular}


Table 3.17: Probit estimation of likelihood of hiring an External CEO.

\begin{tabular}{|c|c|}
\hline & Likelihood of hiring External CEO \\
\hline \multirow[t]{2}{*}{ CEO dismissal } & -0.006 \\
\hline & $(0.508)$ \\
\hline \multirow[t]{2}{*}{$\mathrm{ROA}(\mathrm{t}-1)$} & -0.520 \\
\hline & $(1.602)$ \\
\hline \multirow[t]{2}{*}{ Returns ( $\mathrm{t}-1)$} & -0.677 \\
\hline & $(1.161)$ \\
\hline \multirow[t]{2}{*}{ Z-Score $(\mathrm{t}-1)$} & -0.015 \\
\hline & $(0.027)$ \\
\hline \multirow[t]{2}{*}{ Taxloss $(\mathrm{t}-1)$} & -0.553 \\
\hline & $(0.440)$ \\
\hline \multirow[t]{2}{*}{ Csh } & 3.615 \\
\hline & $(2.239)$ \\
\hline \multirow[t]{2}{*}{ Stock volatility } & -0.464 \\
\hline & $(1.854)$ \\
\hline \multirow[t]{2}{*}{$\ln ($ sale $)$} & $0.289^{*}$ \\
\hline & $(0.172)$ \\
\hline \multirow[t]{2}{*}{ Leverage } & -0.810 \\
\hline & $(1.393)$ \\
\hline \multirow[t]{2}{*}{ BTM } & $-1.822^{*}$ \\
\hline & $(1.069)$ \\
\hline \multirow[t]{2}{*}{ Growth } & -0.791 \\
\hline & $(1.332)$ \\
\hline \multirow[t]{2}{*}{ PP\&E } & -0.595 \\
\hline & $(0.996)$ \\
\hline \multirow[t]{2}{*}{$\ln ($ vega $)$} & 0.083 \\
\hline & $(0.141)$ \\
\hline \multirow[t]{2}{*}{$\ln ($ delta $)$} & $-0.735^{* * *}$ \\
\hline & $(0.262)$ \\
\hline \multirow[t]{2}{*}{ Board size } & -0.002 \\
\hline & $(0.023)$ \\
\hline \multirow[t]{2}{*}{ Independent Board } & 1.227 \\
\hline & $(1.507)$ \\
\hline Year effect & Yes \\
\hline Observations & 124 \\
\hline
\end{tabular}

Note: Results reported are not marginal effects, ${ }^{*} \mathrm{p}<0.10 ;{ }^{* *} \mathrm{p}<0.05 ;{ }^{* * *} \mathrm{p}<0.01$ (Two-sided). 



\section{Chapter 4}

\section{Employee Selection and Training: A Complementarity View*}

* This chapter is a joint work with Isabella Grabner and Frank Moers. 


\begin{abstract}
In this study, we investigate the relationship between investments in employee training and investments in the employee selection process. Taking a complementarity theory perspective, we show that firms that invest highly in training will also invest highly in employee selection. In particular, we argue that the stability of the employee-firm relationship as well as the trainability of the employees (as attributes possessed by employees) affect the returns to training and are thus, demanded and selected by firms when they invest in training. We further argue and find that creativity-dependence of a firm plays a moderating (positive) role in this complementarity, especially in creative industries. The study brings new empirical evidence to a topic in the management control literature that has been otherwise studied and explained through theoretical models in the economics literature.
\end{abstract}

Keywords: employee selection, training, creativity dependence, personnel control 


\subsection{Introduction}

Firms spend a lot of resources, in the form of time and money, on training employees. According to the 2017 Training Industry Report, U.S. companies spent over 90 billion dollars on training and development activities in 2017, a year-over-year increase of $32.5 \%$ relative to the previous year. ${ }^{73}$ At the same time, companies spend almost $\$ 4,129$ per job in employee selection processes (according to Society for Human Resource Management estimates). ${ }^{74}$ Traditional human-capital theory (Abraham \& Farber, 1987; Altonji \& Shakotko, 1987; Topel, 1991; Neal, 1995; Woodcock, 2008) suggests that higher investment in the employee selection process should substitute training (and other forms of control, such as monitoring) later. However, the traditional humancapital theory seems to fall short of explaining the huge investments in both employee selection and training. Clearly, these two forms of personnel control are both viewed as very important by firms. Despite their importance, there is only a handful of studies that examine the relationship between these two forms of personnel control (Barron et al, 1985; Cohen \& Pfeffer, 1986; Barron et al., 1989; Barron et al., 1997; Burdett \& Cunningham, 1998). In this study, we examine this important, yet understudied, question of why firms tend to invest (in terms of resources and time) in both training and employee selection by proposing and testing a complementarity relationship between investment in training and employee selection.

Firms invest in training its employees on the pretext that training will improve the productivity of the employees and eventually allow the firm to reap the benefits of this enhanced productivity (Salop \& Salop, 1976; Cohen \& Pfeffer, 1986; Blinder \& Krueger, 1996; Acemoglu \& Pischke, 1998). Key to the proposed complementarity between selection and training is the expectation that the returns to training will be contingent on the employee selection process, and vice versa. Along these lines, some studies argue that returns to training might depend on the pre-acquired ability/skill of the employee, whether it is possessed in the form of innate talent or learned through prior work experience (observed and unobserved), that determines the extent of their 'trainability' (Thurow, 1975; Barron et al., 1985; Cohen \& Pfeffer, 1986; Clifton \& Harter, 2003; Gagne, 2004). Hence, investment in the employee selection process is needed to screen applicants on their pre-acquired (or innate) ability/skills. Other studies propose that it is the stability (or longevity) of the employee-firm relationship post training that affects the returns to training (Salop \& Salop, 1976; Blinder \& Krueger, 1996; Acemoglu \& Pischke, 1998; Lockwood \& Ansari, 1999). Thus, for the firm to reap the benefits of training, the employee-firm relationship needs to be stable over time to allow the firm to have some monopsony power over the enhanced productivity (Salop \& Salop, 1976; Blinder \& Krueger, 1996; Acemoglu \& Pischke, 1998). Hence,

73 https://hbr.org/2018/10/when-companies-should-invest-in-training-their-employees-and-when-they-shouldnt

74 https://hbr.org/2019/05/your-approach-to-hiring-is-all-wrong 
investment in employee selection is done to maximize the likelihood of hiring a stable (or reliable) employee that fits with the firm (Cohen \& Pfeffer, 1986; Burdett \& Cunningham, 1998). In addition, Barron et al. (1985) and Barron et al. (1989) argue that investment in the employee selection process increases the precision of the signal of the employee's attributes (whether it is ability or stability). Thus, the returns to training are expected to depend on the effectiveness of the selection process of employees, based on the desired attributes of stability and/or pre-acquired/innate technical skills (Barron et al., 1985; Cohen \& Pfeffer, 1986; Barron et al., 1989; Barron et al., 1997; Burdett \& Cunningham, 1998).

Interestingly, most of these studies use only theoretical models (for the stability and trainability argument) to explain the observed positive relationship between investment in employee selection and in training and/or focus on one of these attributes in isolation. Our study, on the other hand, tests both these arguments directly and provides the first set of empirical evidence in support of the arguments proposed by existing literature. ${ }^{75}$ In particular, we hypothesize a positive relationship between investment in employee selection and in training, in line with prior studies (H1). More importantly, we expect that there is higher demand for stability as an attribute at the time of selection when investment in training increases $(\mathrm{H} 1.1)$, and that there is higher demand for ability (as a proxy for trainability) as an attribute at the time of selection with an increasing investment in training (H1.2).

To provide a more detailed understanding of the boundary conditions regarding the proposed interdependence (Cassiman \& Veugelers, 2006; Grabner \& Moers, 2013), we also examine this complementarity in the context of varying creativity dependence. Studies on employee creativity suggest that the concerns of stability and 'trainability' of employees are of particular importance for firms that rely heavily on the creativity of their core employees for their competitive edge (Suojanen \& Brooke, 1971; Amabile, 1983, 1988; Mumford \& Gustafson, 1988; Amabile et al., 1996; Oldham \& Cummings, 1996; Fiest, 1999; Caves, 2000; Mumford et al., 2002; Shalley et al., 2004; Peterson \& Seligman, 2004; Gil \& Spiller, 2007; Biswas-Diener et al., 2011; Grabner, 2014). They argue that one of the most important control problems in creative industries is managing creative employees who seem to associate themselves with only the creative task at hand, and not share the firm's value, or display any organizational commitment at large. This makes stability of an employee-firm relationship a big concern for these firms, ex-ante, especially if they also invest in training these employees. In addition, these studies also acknowledge an innate component in the 'creative talent' that can affect the returns to any training. We therefore hypothesize that the positive relationship between training and employee selection becomes stronger with increasing creativitydependence (H2), and, in line with H1, an even higher demand for stability (H2.1) and

75 To our knowledge, Cohen and Pfeffer (1986) is the only study to test directly the demand for employees' stability at the time of selection when the firm invests in training. 
ability (H2.2) attributes with increasing creativity-dependence. ${ }^{76}$

Using rich survey data on 457 medium-sized firms operating in both creative and non-creative industries, we find a strong positive relationship between investment in training and in employee selection. Most importantly, we find that the complementarity between training and employee selection across all firms in the sample is driven by the need to select employees based on both the attributes of stability of the employee, and ability of the employee (innate or previously acquired). In addition we also find that this positive relationship between employee selection and training investment gets stronger with increasing creativity-dependence, especially in firms involved in $R \& D$ activities and those operating in the creative industries of design, new media, such as software and video games, and creative services, such as advertising. ${ }^{77}$ While such firms do not seem to put an increased emphasis on screening for trainability, we find evidence that they have a different demand for the stability of the employee-firm relationship. To shed more light on the types of attributes that firms demand, we separately examine the items forming the stability construct, namely, value congruence, team fit and stability. Interestingly, in the sub-sample of creative industries, the attribute that is prioritized when there is high creativity-dependence is the extent of value congruence between the employee and the firm, over any other attribute. On the other hand, the degree of fit in an existing team is very important in the non-creative industries.

The findings seem to support the arguments of looking for a stable and 'trainable' employee when firms are investing in training, at large. However, interestingly, 'trainability' does not seem to be a particular concern among firms operating in creative industries. We reconcile this finding to the findings of earlier literature (Kachelmeier \& Williamson, 2010) that suggest that creative employees seem to self-select into creative jobs, hence their ability (pre-acquires/innate) does not seem to be a major concern for these firms. On the other hand, studies do find that creative employees tend to care only about their specific creative tasks, sometimes, at the cost of losing the overall vision of the firm (Amabile, 1983, 1988; Mumford \& Gustafson, 1988; Amabile et al., 1996; Oldham \& Cummings, 1996; Fiest, 1999; Mumford et al., 2002; Shalley et al., 2004). This can probably explain why firms have a higher demand for value-congruence in their employees before they are willing to invest in training them. Finally, we observe that apart from the traditional arguments of stability and 'trainability', attributes of 'valuecongruence' and 'team-fit', have emerged as equally important when firms invest in training. This makes sense given that the firm environment has evolved over time, with firms moving towards higher reliance on teams and sometimes, towards lower levels

76 To note, creativity-dependence is just a context that defines a boundary condition for the complementarity. As such, any other context can also be examined to test the strength of the complementarity. However, the study examines the strength of the complementarity only in the context of varying creativity dependence and all theoretical arguments in this study are specific to creativity.

77 The strength of the complementarity relationship is not dependent on the creativity-dependence of firms in the NACE classified non-creative industries. 
of individual output-contractibility, making these attributes of 'value-congruence' and 'team-fit' also as valuable as the traditionally valued attributes of stability and trainability (Ouchi, 1979; Snell, 1992).

This study makes several contributions to the management accounting and control literature. First, our study contributes to the very important, but understudied, role of personnel controls in the management accounting literature (Widener, 2004; Prendergast, 2008; Campbell, 2012) by examining the relationship between two very commonly used forms of personnel control, namely, training and employee selection. Importantly, we provide direct evidence on the specific employee attributes that firms demand when they provide training. Second, this study contributes to an emerging stream of research in management accounting that highlights the benefits of personnel control for managing creative employees, a context where output-measurability and predictability is difficult and hence, limits the use of other forms of control (Ouchi, 1979; Eisenhardt, 1985; Snell, 1992; Caves, 2000; Widener, 2004; Gil and Spiller, 2007; Abernethy et al., 2015; Grabner \& Speckbacher, 2016; Baruah et al., 2021). Third, we are able to provide deeper insights into the control issues of creative firms by looking at specific attributes that these firms desire while screening their employees, thus, providing evidence to support some of the theories provided in the literature on creativity (Suojanen \& Brooke, 1971; Amabile, 1983, 1988; Mumford \& Gustafson, 1988; Amabile et al., 1996; Oldham \& Cummings, 1996; Fiest, 1999; Caves, 2000; Mumford et al., 2002; Shalley et al., 2004; Gil \& Spiller, 2007; Grabner, 2014). Finally, our study contributes to the literature that examines the interrelations of various forms of organizational controls (Milgrom \& Roberts, 1990; Brynjolfsson \& Hit, 1996; Athey $\&$ Stern, 1998; Bresnahan et al., 2002; Aral et al., 2012; Grabner \& Moers, 2013). This literature also suggests that the strength of these interdependencies is dependent on contextual factors, such as creativity-dependence (Grabner, 2014), as also shown in this study.

The next section describes the theoretical background and develops the hypotheses. In Section 4.3, we discuss our sample, data collection, and variable measurement. In Section 4.4, we present the empirical results for the main analysis, in Section 4.5 , we present results of additional tests and Section 4.6 concludes the study.

\subsection{Prior Literature and Hypothesis Development}

Personnel controls build on employees' natural tendencies to control and/or motivate themselves. Two of the major methods of implementing personnel controls are through (1) selection of employees, including search and screening, and (2) training (Merchant $\&$ Van der Stede, 2017). Spending time and resources into the process of selection of employees can take the form of (i) improving the search process and /or (ii) increasing 
the screening intensity for each applicant (including resources spent in assessing each applicant through interviews, tests etc.). While the first type of investment generally maximizes the possibility of achieving a relevant applicant pool (Zottoli \& Wanous, 2000; Baruah et al., 2021), the second type of investment raises the precision of the signals the employer obtains concerning each applicant's attributes (especially the unobservable ones) and thus, reduce the risk of hiring an unsuitable applicant (Barron et al., 1985; Barron. et al., 1989; Barron et al., 1997). Training, on the other hand, is intended to develop skills possessed by employees (either general or firm-specific skills) once they are hired, thus, improving the employees' productivity (Oyer \& Schaefer, 2011; Merchant \& Van der Stede, 2017).

Economic models on employee-firm matching and human capital seem to view investment in employee selection and training as substitutes, under the assumption that firms face a resource constraint (Abraham \& Farber, 1987; Altonji \& Shakotko, 1987; Topel, 1991; Neal, 1995; Woodcock, 2008).$^{78}$ These theoretical models suggest that when match-quality (in terms of matching a desired attribute of the employee to the needs of the firm) is the primary driver of productivity, then employers should invest more in selection than in training. However, when human capital is the primary driver of productivity, then firms should focus more on training than focus on employee selection. ${ }^{79}$ Theories that view these two forms of controls as substitutes assume that the returns to firm-specific training and the initial quality of employee-firm match are independent of each other. However, a few empirical studies (Cohen \& Pfeffer, 1986; Barron et al., 1997; Burdett \& Cunningham, 1998) have found a strong positive correlation between investment in employee selection and training, suggesting some type of complementarity rather than substitutability between these two forms of personnel controls. In particular, studies have shown that firms tend to spend more time and resources in selecting employees for jobs that entail high training expenditure. Cohen and Pfeffer (1986) document one of the earliest evidence of this relationship when they examined firms in the San Francisco Bay Area. They find that formal hiring standards (selection based on certain employee characteristics such as education) are positively related to the amount of training offered by the firm. ${ }^{80}$ Later, Barron et al. (1997) also find that employers increase their expenditures on screening and interviewing each applicant when these employees are given more training. Burdett and Cunningham (1998), studying the 1982 EOPP data, find that firms tend to spend more time in selection of employees, the more they invest in training these employees.

78 These theories are, somewhat, comparable to the decision of 'make or buy' (Miles \& Snow, 1984), but in the context of human resource management.

79 Although, this distinction might be straightforward theoretically, such a distinction is far more complex to observe empirically. See Lazear and Oyer (2009) for a summary of the literature on this topic.

80 Other early empirical studies which find a strong positive relationship between training investment and stricter hiring standards (via employee selection process) include Barron et al. (1985) and Barron et al. (1989). 
Most of these studies try to explain these findings through theoretical models that predict that the returns to training are dependent on one of the two broad attributes that firms screen for at the time of selection, namely, (i) the degree of stability and reliability of the employee (Salop \& Salop, 1976; Blinder \& Krueger, 1996; Acemoglu \& Pischke, 1998; Burdett \& Cunningham, 1998) and (ii) the trainability of employees, proxied by their pre-acquired/innate ability/skills (Thurow, 1975; Barron et al., 1985; Barron et al., 1989; Barron et al., 1997). In particular, Cohen and Pfeffer (1986) distinguish the demand for these two attributes as (i) a stability argument, and (ii) a technical argument respectively. The stability argument suggests that firm-specific training generates rent and hence, firms will want to ensure a stable employee-firm relationship prior to investing in training, so that the firm can reap the returns of the training (due to improved employee productivity) for a longer period. The technical perspective maintains that the returns to training depend on the employees' attributes which makes these employees trainable, which could range from observable education level or prior labor-market experience (Thurow, 1975; Cohen \& Pfeffer, 1986) to unobservable ability or talent (Clifton \& Harter, 2003; Gagne, 2004).

Screening, on the other hand, increases the precision of the assessment of the applicant's desired attributes (Barron et al., 1985). These attributes could be technical capabilities (including skills) and/or the applicant's general reliability and stability, or in some contexts, their socialization to norms and values desired by the organization (Thurow, 1975; Barron et al., 1985; Cohen \& Pfeffer, 1986; Clifton \& Harter, 2003; Gagne, 2004). As suggested by these studies, the need for higher investments in employee selection when the job entails a high expenditure in training could be driven by desire for either or both types of attributes, explained by (i) a stability argument, and (ii) a technical argument.

According to the stability argument, firms should be given some ex-post monopsony power over the employee's skill if the firm needs to invest in training. In short, the rent generated from improving the skills of the employee can be reaped by the firm only if the employee stays on with the firm beyond the training period. Salop and Salop (1976) show that when firms incur training costs, they prefer to hire employees with low quit probability. Acemoglu and Pischke (1998), using German apprentices data, show that when quits are (endogenously) high, firms provide little training because of limited monopsony power; on the other hand, when quits are low firms provide higher training. ${ }^{81}$ In order to explain firms' investment in skills, there must be certain

81 The expectation of the ex-post monopsony power, generated by a stable employee-firm relationship, is seen to encourage training for not only firm-specific skills but also general skills. This argument seems to support why firms offer training on general skills, contrary to the predictions of Becker's (1964) model explaining why firms should provide training on only firm-specific skills. See Lazear (2009) for the discussion on how firm-specific skills are mainly composed of generic skills that are weighted differently from one firm (or occupation) to the other. Nevertheless, the monopsony power provided to the firm seems to explain why firms choose to train their employees irrespective of whether it is generic skills or firm-specific skills as long as it is productivity enhancing. 
restrictions on the mobility of employees such that the firms can earn rents on the improved productivity of the trained employees. In line with this argument, Blinder and Krueger (1996) note that the failure of the U.S economy to generate as much training as Germany or Japan could be partly attributed to the high employee turnover rate in the United States.

According to the technical argument, the returns to training are limited by employee-specific attributes (either innate or pre-acquired skills). ${ }^{82}$ Thurow (1975) argues that more training either involves or produces more technically complex work, and hence, the returns to training should be dependent on the trainability of the employees. Thus, more training should be complemented by more selective hiring standards to ensure that employees who are hired are adequately trainable (Cohen \& Pfeffer, 1986). The trainability of an employee could depend on the employee's innate skills and/or preacquired skills (in some cases, proxied by level of education). In the extreme case, studies note that the extent of acquired skills (or acquired talents) largely depends on the innate ability (or innate talent) (Clifton \& Harter, 2003; Gagne, 2004). Along the same line of argument, Winner and Drake (2013) state that individuals will learn at a faster rate in the domain of their talent (or ability) than their non-talented peers. Cohen and Pfeffer (1986) find evidence to support the technical argument. They find that the more the firm invested in training, the higher were the screening efforts in terms of using more tests to assess the applicant's technical abilities or pre-acquired skills.

On the other hand, Lockwood and Ansari (1999) provide a completely different perspective to explain this positive correlation between investment in employee selection and training. They find that IT companies in the US used training, among other things (such as raising salary etc.), to retain their talented employees. They find that, in the early 1990s, IT skills were scarce (and hence highly demanded), and thus, attracting and retaining employees with IT skills were crucial to the success of these firms. As such, these firms used training to signal their intention to retain the employees. Through investment in training, these firms were signaling that they are willing to invest in the skills of the employees because they would like to retain them. Although the relationship between selection and training is still positive here, the motivation in this case is different from the previously held views. According to the other views, firms use selection (or screening) as a tool to minimize the likelihood of employee-quits when there are large training expenditures involved. In the case of these IT firms, training is used as a tool to minimize the employee-quits when high selection expenditures are incurred in identifying and attracting the scarce skills in the first place.

82 These attributes could be innate attributes that are specific to an individual or attributes that are developed through prior labor-market experience. Abowd et. al (1999) decompose employee skill into a time-invariant employee effect ("basic ability") and an experience effect that varies in proportion to labor-market experience. We do not distinguish between these two effects in this study, since it is not pivotal to our theory. 
To summarize, the positive relationship between investment in employee selection and that in training could be driven by either or both types of motivation. However, a common objective emerges-maximizing the quality of employee-firm match in terms of skills and stability. Quality of the employee-firm match could be improved by (i) investing in employee selection to attract and identify the employee's skills and/or general stability when jobs entail high training expenditure, and/or (ii) investment in training that improves the employee's productivity and/or signal retention motives of employers when they have invested hugely in attracting and identifying employees with desired skills and abilities. In both cases, it can be argued that having one of the two forms of personnel control increases the benefit of adopting the other. Thus, we expect a complementarity between the investment in employee selection and the investment in training. Thus, we hypothesize the following:

\section{H1: Investment in employee selection and investment in training are complements.}

Additionally, in line with the theoretical arguments of (i) stability and (ii) trainability provided to predict high investment in employee selection when there is high investment in training, we propose to test the following hypotheses:

H1.1: The demand for employees' general stability (as an attribute) is positively linked to training investments.

\section{H1.2: The demand for employees' trainability is positively linked to training investments.}

We argue that the proposed complementarity is not uniform, but context-specific and hence, we aim to provide a more detailed understanding of the boundary conditions regarding the proposed complementarity (Cassiman \& Veugelers, 2006; Grabner $\&$ Moers, 2013). In particular, we argue that contexts that (i) make the stability of employee-firm relationship a bigger concern than other contexts; and/or (ii) make the returns to training more sensitive to the employee's pre-acquired skills or innate ability/ talent, will play a moderating role in this relationship. One such context is when firms are highly dependent on the creativity of their core employees, to develop novel products or processes, for their competitive advantage (Nonaka, 1991; Amabile, 1996). ${ }^{83}$ Creativity dependency is, thus, a system-specific contextual variable whose value moderates the interdependence of these two personnel control choices (Athey \& Stern, 1998; Grabner

83 The context is not restricted to only creative industries and could include any environment that makes this relationship more pronounced can act as a moderator. Hence, creativity-dependence is just a context that defines a boundary condition for the complementarity. As such, any other context can also be examined to test the strength of the complementarity. However, the study examines the strength of the complementarity only in the context of varying creativity dependence and all theoretical arguments in this study are specific to creativity. 
\& Moers, 2013). We argue that management control practices might influence the behavior of creative employees in a different way compared to that of non-creative employees (Merchant \& Van der Stede, 2017).

At the outset, several studies acknowledge the importance of personnel control in firms that heavily depend on the creativity of their core employees. The most distinct features of the creative/innovative activities are the need for autonomy, and the lack of routineness (Grabner \& Speckbacher, 2016). These features render traditional output controls or behavioral controls, somewhat, difficult to implement (Amabile et al., 1996; Abernathy \& Brownell, 1997; Andersons et al., 2009;). Most importantly, the outcome of each creative process is unique, and the possible solutions to a given problem (be it the development of a new product or technology, the idea for a commercial or film, etc.) are impossible to define ex-ante and to assess ex-post, leading to some level of task uncertainty by design (Ouchi, 1979; Eisenhardt, 1985; Caves, 2000; Gil \& Spiller, 2007). Personnel control can serve as means of controlling employee behavior ex-ante because it regulates the antecedents of performance, namely, knowledge, skills, abilities, intrinsic motivation, and values (Snell, 1992). For example, Grabner and Speckbacher (2016) show that the emphasis on selection procedures are positively related with the perceived importance of employees' intrinsic motivation for their task, and with managers' lack of expert knowledge, both of which are important characteristics of creative work. Relatedly, Widener (2004) shows that behavioral uncertainty is positively linked to the use of personnel control. Moreover, Abernethy et al. (2015) report a positive relationship between a company strategy committed to organizational learning and control through selection processes.

The literature that focuses on management controls in creative industries (Suojanen \& Brooke, 1971; Amabile, 1983, 1988; Mumford \& Gustafson, 1988; Amabile et al., 1996; Oldham \& Cummings, 1996; Fiest, 1999; Caves, 2000; Mumford et al., 2002; Shalley et al., 2004; Gil \& Spiller, 2007; Grabner, 2014) have highlighted certain control issues that are particular to creative industries-the most important being the huge concern around creative employees only associating themselves with the creative task at hand, and not sharing the firm's value, or displaying any organizational commitment. It is often the case that intrinsically motivated employees (engaged in creative activities) allocate too much effort to "art for art's sake", with little regard to the profitability of the products (Suojanen \& Brooke, 1971; Caves, 2000; Gil \& Spiller, 2007; Grabner, 2014;). More importantly, creative people display high job involvement rather than organizational commitment, achievement motivation rather than power and affiliation motives (Amabile, 1983, 1988; Mumford \& Gustafson, 1988; Amabile et al., 1996; Oldham \& Cummings, 1996; Fiest, 1999; Mumford et al., 2002; Shalley et al., 2004). This makes stability of the employee-firm relationship a bigger concern exante for these firms than for firms that are less dependent on creative activities. Thus, creativity-dependent firms would benefit from investing in the employee selection 
process to assess the general stability of the applicant before hiring him/her and especially, when investing in training him/her. This higher concern for stability for these creativity-dependent firms, is thus, expected to positively moderate the complementary relationship between investments in employee selection and training.

From a technical perspective, creativity is inherently different from other performance dimensions, especially for the characteristics of the needed inputs—creativity requires imagination and insight (Grabner, 2014). Literature on talent management (Gagne, 2004; Biswas-Diener et al., 2011; Meyers et al., 2013) maintains that the construct of skills/talent is a continuum ranging from 'completely innate' to 'completely acquired'. Amabile (1983) also acknowledges that there is both an innate component (genetic component and/or intrinsic motivation) and a trainable component (domainspecific creative skills) in an individual's creative ability. However, a number of studies identify 'creative talent' as an innate talent that is necessary for training on creativity to be effective (Peterson \& Seligman, 2004; Biswas-Diener et al., 2011). Amabile $(1983,1988)$ also hint at the relatively higher importance of the innate component, especially intrinsic motivation, than the other trainable components. Thus, it can be argued that creative skills lie anywhere between 'completely innate' and 'completely acquired', but the extent of 'acquisition' is, to some extent, dependent on the initial level of 'innate talent'. Thus, the returns to training in a creativity-dependent firm are more sensitive to innate talents of the employees than the case would be for firms who rely less on the creativity of its employees.

To sum up both the stability argument and the technical argument, we hypothesize the following:

H2: Creativity dependence positively moderates the complementarity between investment in employee selection and investment in training.

H2.1: Creativity dependence positively moderates the positive relationship between demand for employee stability (as an attribute) and training investment

H2.2: Creativity dependence positively moderates the positive relationship between demand for employee trainability and training investment

\subsection{Empirical Method}

To test our hypotheses, we use data from a survey conducted for a large-scale research project on management control system design in creative versus non-creative industries (see also Grabner, 2014; Grabner \& Speckbacher, 2016). The sample comprises medium sized (50-500 employees), single line-of-business firms located in Austria, Germany, 
and Switzerland across six major types of industries. These are Manufacturing, Business Services (e.g., Wholesale and Retail Trade, Transportation, Consultancy) and Research and Development Activities in the non-creative industries sector, and Software Development, Advertising, Design in the creative industries sector. Because the project intended to capture the choice of management control practices (for this study, training and employee selection practices) at the organization level, our target respondent was the managing director. This is because in the case of medium-sized companies with a maximum of 500 employees, the managing director is responsible for, or at least makes the final decision on, the design of the control system. In addition, the survey clearly asks the respondents to answer all questions with respect to only the core function of the firm, such as its main business-line of goods and services. Responses should exclude all other peripheral functions such as administration, support services, and management activities. ${ }^{84,85} \mathrm{~A}$ total of 472 firms (17.3\%) returned the questionnaire, 15 of which were incomplete, resulting in a usable sample of 457.

\section{Variable Description}

All variables in this study were collected through a structured survey with closed-ended questions. Where possible, existing multi-item constructs were adopted from prior literature and slightly adapted to fit the specific empirical setting. The survey constructs are measured on a Likert scale with a range of 1 to 7 . Respondents were asked to assess to what extent the statements applied in their organizations, with the scales anchored at 1 (not accurate) and 7 (completely accurate). To arrive at the final score for our variables, we take standardized responses for each question with respect to the industry mean and standard deviation, and then take the average of the standardized values for each question (pertaining to one construct). Thus, all variables are created as follows:

\section{Variable $=$ Average $[$ standardized value $(\mathrm{Q} 1)+\ldots \ldots \ldots+$ standardized value $(\mathrm{Qn})]$}

As described in more detail in Grabner (2014), we took several steps to establish the validity of the survey variables: (1) pre-tests with practitioners and academics; (2) backtranslation into English by an independent academic; and (3) several empirical tests (i.e., confirmatory factor analysis, Cronbach's alpha, review of response range) to establish both content and construct validity. ${ }^{86}$

Appendix A shows the confirmatory factor analyses used to support the unidimensionality of the reflective constructs. For the formative constructs, we examine item weightings obtained from principal components analysis. The items on all formative

84 The survey does not exhibit any significant response bias, and appropriate steps to deal with a potential common method variance have been taken. For details on this, please refer to Grabner (2014).

85 Cohen and Pfeffer (1986) argue that hiring standards for different occupations within a given establishment will be positively correlated and are affected by similar organizational factors and processes, hence, the need to analyze the research question at a firm level seems justified.

86 The questionnaire was drawn up in English and then translated into German. 
constructs are positive and have weights above the recommended minimum of 0.30 (Hair et al., 2011; Bedford \& Malmi, 2015). The descriptive statistics reported in Table 4.1 indicate that all variables comprise a broad range with a minimum of (close to) 1 and a maximum of (close to) 7. Furthermore, the multi-trait matrix presented in Table 4.2 provides further support for the discriminant validity of the survey constructs, since the Cronbach's alphas (on the diagonal) of all reflective constructs exceed inter-item correlations in all cases (Churchill, 1979). 
Table 4.1: Descriptive Statistics

\begin{tabular}{|c|c|c|c|c|c|}
\hline Panel A & Mean & Median & Std. dev & Max & Min \\
\hline Selection & 4.89 & 5 & 1.18 & 7 & 1 \\
\hline Training & 5.22 & 5.33 & 1.10 & 7 & 1.33 \\
\hline Creativity dependence & 4.18 & 4.2 & 1.68 & 7 & 1 \\
\hline Selection on Stability & 5.25 & 5.25 & 0.82 & 7 & 1.95 \\
\hline Selection on Trainability & 5.31 & 5.37 & 0.82 & 6.94 & 2.94 \\
\hline Task Uncertainty & 3.81 & 3.75 & 1.13 & 7 & 1 \\
\hline Output measurability & 4.63 & 4.75 & 1.34 & 7 & 1 \\
\hline Need for Intrinsic Motivation & 5.77 & 6.00 & 0.88 & 7 & 1.33 \\
\hline Total employees & 145 & 94 & 108.7 & 500 & 50 \\
\hline Environmental Uncertainty & 4.39 & 4.40 & 0.95 & 7 & 1 \\
\hline $\mathrm{R} \& \mathrm{D}$ firms & $13 \%$ & 0 & 0.34 & & \\
\hline No. of observations & 457 & & & & \\
\hline Panel B & & & $\mathrm{CI}=1$ & $\mathrm{CI}=\mathbf{0}$ & Difference \\
\hline Selection & & & 5.11 & 4.75 & $0.365^{* * *}$ \\
\hline Training & & & 5.29 & 5.18 & 0.115 \\
\hline Creativity dependence & & & 4.75 & 3.81 & $0.938^{* * *}$ \\
\hline Selection on Stability & & & 5.40 & 5.16 & $0.24^{* * *}$ \\
\hline Selection on Trainability & & & 5.39 & 5.26 & $0.13^{*}$ \\
\hline Task Uncertainty & & & 4.04 & 3.66 & $0.385^{* * *}$ \\
\hline Output measurability & & & 4.60 & 4.66 & -0.056 \\
\hline Need for Intrinsic Motivation & & & 5.95 & 5.66 & $0.284^{* * *}$ \\
\hline Total employees & & & 130 & 155 & $-25.6^{* * *}$ \\
\hline Environmental Uncertainty & & & 4.49 & 4.33 & $0.166^{* *}$ \\
\hline No. of observations & & & 179 & 278 & \\
\hline
\end{tabular}

${ }^{* * *} \mathrm{p}<0.01 ;{ }^{* *} \mathrm{p}<0.05 ;{ }^{*} \mathrm{p}<0.10$ 


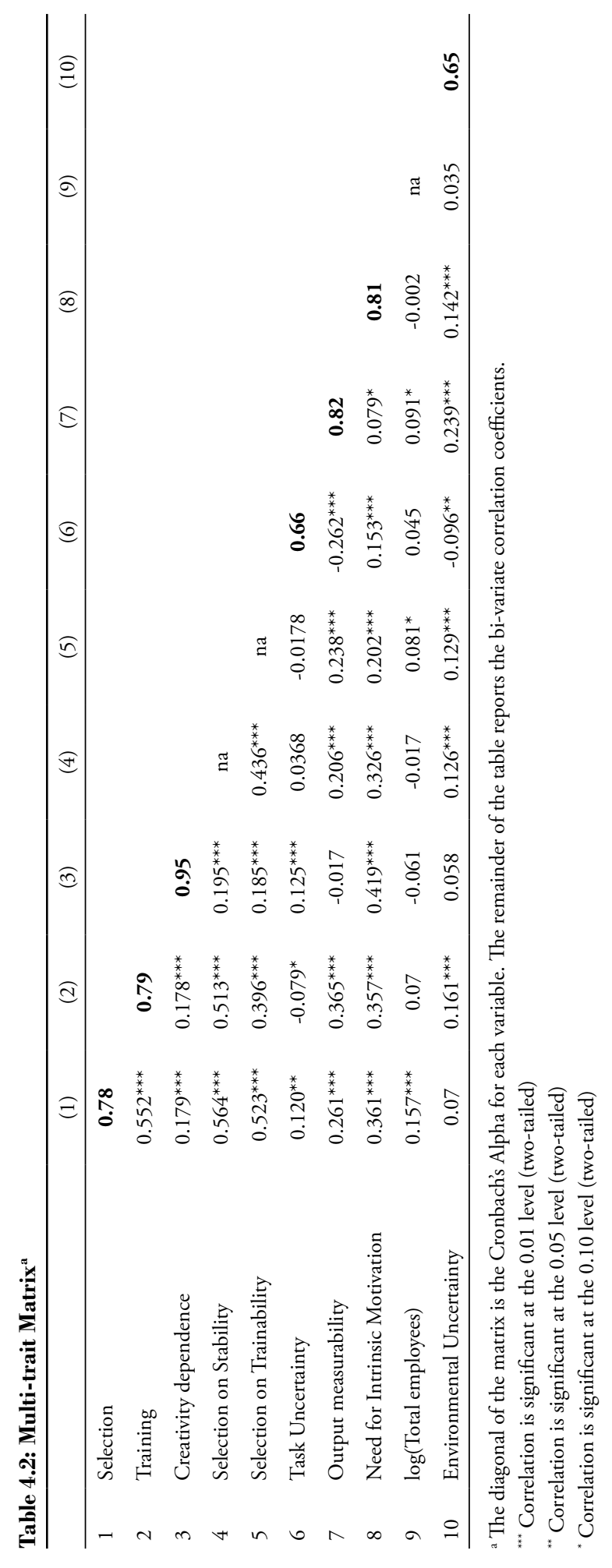




\section{Selection}

To measure Selection, we follow Grabner and Speckbacher (2016), and use the responses to questions that reflect the extent to which the firm emphasizes the extent of investment (in terms of time and resources) in the selection process for hiring employees. In particular, we use items that capture the extent to which (1) the firm places emphasis on the recruitment process; (2) the firm spends an above-average amount of time and money in the recruitment process; (3) the firm takes pride in being successful in hiring the best people from the labor market; and (4) the applicants are required to undergo a multi-staged application process before they are hired. All items load onto a single factor with a satisfactory reliability of $\alpha=0.78$.

\section{Selection on employee attributes}

To capture the employee attributes that firms search for when hiring candidates, we rely on items adapted from Geringer et al. (2002). In particular, we asked respondents to indicate to what extent their decision to hire a new employee is made on the basis of an assessment of a number of employee attributes: We proxy for Selection on Stability by the following formative dimensions along which the employee's expected fit with the firm, and thus the likelihood of long-term employment is assessed: (1) how well the applicant fits in with the corporate philosophy (values, approach to work), (2) the judgment of the employees who will be working with the applicant , (3) the applicant's ability to integrate into the existing team quickly, and (4) whether the applicant seeks long-term employment (5 years or longer). We proxy for Selection on Trainability by technical ability, measured by three formative dimensions capturing the applicant's (1) professional experience in a comparable job; (2) professional (technical) requirements for the job, and (3) analytical abilities (manner of approaching problems, handling of crisis situations).

\section{Training}

To create the Training variable, we use the responses to questions that reflects the extent to which the firm creates opportunities for employees to improve their skills through training. The items used are adapted from Snell (1992). For this analysis, we restrict the questions to represent firms' investments in training for non-managerial skills. In particular, we use the responses to the questions that capture the extent to which (1) employees are offered opportunities to improve and broaden their qualifications; (2) new employees receive extensive training upon entering the company; and (3) staff who have been with the company for a long time are actively involved in human resources development for younger employees. All items load onto a single factor with a satisfactory reliability of $\alpha=0.79$. 


\section{Creativity Dependence}

To create the Creativity Dependence variable, we rely on the construct developed in Grabner (2014) and use the responses to questions that reflect the extent to which the development of creative ideas is the firm's core competitive advantage and the importance of employees in achieving this competitive advantage. In particular, we use responses to the questions that capture the extent to which (1) employees' creativity is the primary source of value creation for a firm; (2) selling creative ideas is the company's largest source of revenue; (3) commercial success of the company is primarily dependent on employees' creativity; (4) the competitive advantage is based on the employees' creative abilities; and (5) the employees' creativity is the main input factor in the creation/ provision of products or services. All items load onto a single factor with a satisfactory reliability of $\alpha=0.95$.

\section{Control Variables}

Since there is vast empirical evidence of the influence of contextual factors such as task characteristics, firm size, industry and environmental uncertainty on control system design (see e.g., Chenhall, 2003 for a review), we add the following variables as control variables: (i) task characteristics, as measured by Snell (1992). This includes a measure for task-uncertainty that captures the extent to which the relations between employee actions and outcomes can be predicted and observed and a measure for output measurability that reflects the availability of quantitative output measures; (ii) following Grabner and Speckbacher (2016) we also control for reliance on intrinsic motivation that captures the extent to which firms rely on the intrinsic motivation of the employees to perform the tasks; (iii) Firm-size, measured by the natural logarithm of the total number of employees; (iv) Environmental Uncertainty adapted from Moers (2006) that relates to the predictability of the behavior of customers, competitors, and suppliers, as well as technological developments and labor market changes; (v) we also control for companies operating in the scientific research field, such as R\&D laboratories (these companies belong to the non-creative industries in our sample); (vi) finally, we also control for country fixed-effects because policy environment in different countries can vary and can impact the adoption of management control systems differently. ${ }^{87}$

87 Note that we use industry-adjusted variables and thus do not include industry-fixed effects in our regressions. 


\section{Empirical Models}

Hypothesis 1 predicts that there is a complementary relationship between investment in selection and that in training. To test for H1, we follow Aral et. al (2012) and estimate the following linear relationship using ordinary least square estimation: ${ }^{88}$

$$
\text { SELECTION }=\alpha_{0}+\alpha_{1} \text { TRAINING }+\sum \alpha_{\mathrm{k}} \text { Controls }+ \text { Country fixed-effects }+\varepsilon
$$

A significant and positive $\alpha_{1}$ supports a conditional correlation between selection and training (since these are standardized variables and a positive value of each signifies that the investment is higher than the industry average for each type of investment). This conditional correlation supports the hypothesis that firms tend to adopt a strategy of high training and high screening intensity together. Firms thus use both forms of personnel control (training and selection) as complementary to each other, implying that the benefits of investing in selection is higher when these firms also invest more than an average amount of resources in training its employees. These two forms of personnel control are viewed as interdependent, in line with the studies that propose that organizational level choices are generally quasi-fixed (Milgrom \& Roberts, 1990; Brynjolfsson \& Hit, 1996; Bresnahan et al., 2002; Aral et al., 2012; Grabner \& Moers, 2013).

To test for H1.1 and H1.2, we re-estimate equation (1) for the following dependent variables (i) Selection on Stability and (ii) Selection on Trainability.

To test for $\mathrm{H} 2$, which predicts that this complementary relationship is stronger when there is higher dependence on employees' creativity, we estimate the following linear relationship using ordinary least square estimation:

SELECTION $=\beta_{0}+\beta_{1}$ TRAINING $+\beta_{2}$ CREATIVITY DEPENDENCE

$+\beta_{3}$ TRAINING $\times$ CREATIVITY DEPENDENCE $+\sum \beta_{\mathrm{k}}$ Controls +

Country fixed-effects $+\varepsilon$

$\mathrm{H} 2$ predicts that $\beta_{3}>0$. A significant and positive coefficient on the interaction term between training and creativity (dependency) would indicate that the complementarity relationship between training and selection is stronger in the context of high creativity dependency.

To test for H2.1 and H2.2, we re-estimate equation (2) for the following dependent variables (i) Selection on Stability and (ii) Selection on Trainability.

88 We use standardized values for control variables measuring task characteristics such as output measurability, reliance on intrinsic motivation and environmental uncertainty. 
We use the 'creative dependence' variable instead of a creative industry (CI) dummy-variable as a proxy for creativity dependence. This is because using industry membership (creative vs. non-creative) as a proxy for creativity dependence means making the implicit assumption that firms in creative industries rely heavily on creativity, whereas firms in non-creative industries do not. While this might certainly be true for some firms, it does not necessarily hold for all the firms in either sample. As seen from Table 4.1 Panel B, the creativity dependence variable is higher for the firms in the creative (CI) industry than those in the non-creative industries (NCI), but there still exists some creativity-dependence in firms even in the NCI industry. In addition, we can exploit the variation of creativity dependence within creative industries to allow for a richer analysis.

\subsection{Empirical Results}

\section{Testing H1}

Table 4.3, Column I reports the results from estimating equation (1) using ordinary least square estimation methods (using robust standard errors). We find that there is a statistically significant positive correlation between high investment in selection and training $(\alpha=0.471, \mathrm{p}<0.01)$. This supports the hypothesis $(\mathrm{H} 1)$ that firms tend to adopt the two personnel controls as a system. Firms that invest more in training their employees (than the industry average) also tend to invest more than average in the selection process of employees at the time of hiring. As argued earlier, this result can be explained by the need to select employees who are either stable or trainable, or both. We test H1.1 and H1.2 and report the results in Column (II) and (III) of Table 4.3 respectively. We find strong support for both (i) selection on stability $(\alpha=0.343, \mathrm{p}<0.01)$ and (ii) selection on trainability $(\alpha=0.257, \mathrm{p}<0.01)$. 
Table 4.3: Results for H1, H1.1 and H1.2, OLS estimation of equation (1)

(I)

Selection

Dependent variable:

Training

Task uncertainty

Output measurability

Need for intrinsic motivation

$\log$ (total employees)

Environmental uncertainty

Country fixed effects

Observations

R-squared

F-Stat

${ }^{* * *} \mathrm{p}<0.01 ;{ }^{* *} \mathrm{p}<0.05 ;{ }^{*} \mathrm{p}<0.10$ (two-sided). Standard errors are robust.

$0.471^{* * *}$

$0.189^{* * *}$

$(0.047)$

$0.114^{* * *}$

$(0.044)$

$0.118^{* * *}$

(0.039)

$0.122^{* * *}$

$(0.040)$

$-0.069$

(0.049)

$-0.001$

(0.085)

Yes

457

0.383
(II)

(III)

Selection on Stability Selection on Trainability

$0.343^{* * *}$

$0.257^{* * *}$

(0.034)

(0.039)

$0.068^{*}$

0.028

(0.035)

(0.047)

0.038

$0.086^{* *}$

(0.035)

(0.038)

$0.137^{* * *}$

$0.076^{* *}$

(0.036)

(0.037)

$-0.045$

0.048

(0.037)

(0.039)

0.026

0.038

(0.039)

(0.044)

0.002

$-0.001$

(0.070)

(0.085)

Yes

Yes

457

457

0.314

0.182

19.05

\section{Robustness Test: Checking for omitted variables}

A key concern with these results is the potential existence of correlated omitted variables. That is, the association between the two practices might exist only because some confounding factors have not been included in the model (because they are unobservable). To examine how robust the results in Table 4.3 are to unobservable confounding factors, we use a partial identification strategy. We apply the technique developed by Oster (2019) and estimate the so-called coefficient of proportionality, which we label "Oster $\delta$ ". The Oster $\delta$ captures the degree of selection on unobservables relative to observables needed to explain away the result, i.e., produce a regression coefficient of zero. ${ }^{89}$ For example, an Oster $\delta$ of 2 implies that the unobservables need to be twice as important as the observables to produce a zero effect. The recommended cut-off for labeling a result as robust is an Oster $\delta$ larger than 1 (Oster, 2019). When

89 To estimate the Oster $\delta$, an assumption has to be made about what the $R^{2}$ would be when estimating the full equation, i.e., the equation including both observable and unobservable covariates, which is labelled $R_{\max }$. Based on simulations, Oster (2019) recommends to use $R_{\max }=\min [1.3 R, 1]$, where $R$ is the $R^{2}$ of the regression with observable covariates. See Oster (2019) for details. 
estimating the Oster $\delta$ for Training, we find that it is 1.51 for Selection as the dependent variable, 1.38 for Selection on Stability as the dependent variable, and 1.33 for Selection on Trainability as the dependent variable. This implies that, to overturn our results, the unobservables need to be almost 1.3 to 1.5 times as important as the observables to produce a zero effect. Such magnitudes are unlikely to be plausible (using the cutoff criteria of $\delta$ equal to 1 ), which implies that the results in Table 4.3 are robust to unobservable confounding factors.

\section{Testing H2}

Table 4.4 Column I reports results from estimating equation (2) using ordinary least square estimation methods (with robust standard errors). We find that the coefficient on the interaction term between training and creativity dependence is not statistically significant from zero $(\beta=0.036, p>0.10)$. This suggests that the extent of dependency on creativity of employees might not offer any contextual variation in the complementarity between training and selection, thus not supporting H2. Table 4.4, Column II and Column III report results for $\mathrm{H} 2.1$ and $\mathrm{H} 2.2$ respectively. We find that the interaction term between training and creativity dependence is positive and significant for selection on stability $(\beta=0.065, \mathrm{p}<0.10)$, indicating that the complementarity between Training and Selection on Stability increases in creativity dependence. We thus find support for $\mathrm{H} 2.1$. However, we do not find support for $\mathrm{H} 2.2(\beta=0.025$, $\mathrm{p}>0.10)$. 
Table 4.4: Results for H2, H2.1 and H2.2, OLS estimation of equation (2)

(I)

Selection

Dependent variable:

Training

Creativity Dependence

Training x Creativity Dependence

0.036
$(0.048)$

$0.471^{* * *}$

(0.045)

0.042

(0.037)

$(0.048)$

$0.186^{* * *}$

(0.048)

$0.115^{* *}$

Output measurability

(0.045)

Need for Intrinsic motivation

$0.102^{* *}$

(0.041)

$\log$ (Total employees)

$0.123^{* * *}$

(0.040)

Environmental Uncertainty

$-0.068$

(0.049)

$-0.006$

(0.085)

Country fixed effects

Observations

Yes

R-squared

457

0.386

28.43

F-Stat

(II)

(III) Selection on Stability Selection on Trainability $0.350^{* * *}$ $0.251^{* * *}$

(0.034)

(0.040)

0.018

$0.075^{* *}$

$(0.035)$

0.025

$(0.037)$

$(0.034)$

$0.070^{*}$

0.019

(0.036)

(0.047)

0.036

$0.089^{* *}$

(0.036)

(0.038)

$0.129^{* * *}$

0.049

(0.038)

(0.040)

$-0.048$

0.052

(0.037)

(0.040)

0.029

0.038

(0.038)

(0.044)

$-0.006$

$-0.005$

(0.085)

Yes

Yes

457

457

0.192

10.36

${ }^{* * *} \mathrm{p}<0.01 ;{ }^{* *} \mathrm{p}<0.05 ;{ }^{*} \mathrm{p}<0.10$ (two-sided). Robust standard errors are reported.

\section{Testing $\mathrm{H} 2$ on split samples}

We re-estimate equation (2) on the split samples of creative (CI) versus non-creative (NCI) industries. The classification of creative and non-creative industries is done as per Nomenclature Generale des Activities Economiques dans I'Union Europeenne (NACE) industry classification. According to this classification, the non-creative sector includes all industries except the public sector and the creative industries. The creative industries are further subdivided into four sectors - heritage, arts, media, and functional creations. Our sample is restricted to the functional creation sector, which is further divided into (1) design, (2) new media, such as software and video games, and (3) creative services, 
such as advertising. ${ }^{90}$ They can be distinguished from other industries because creativity is their primary source of value generation (Cunningham \& Hearn, 2003). ${ }^{91}$ As seen from Table 4.1 (Panel B), the firms operating in creative industries differs from those operating in non-creative industries in terms of most firm-level characteristics, and most importantly, in terms of their higher creativity-dependence than the latter.

The rationale for investigating the contextual variation in the complementarity relationship in the creative industries versus non-creative industries lies in the following findings (see Anderson et al., 2009): (i) the returns to talent are convex for creative industries; and (ii) firms in the creative industries engage the majority of their workforce in creativity dependent tasks, as opposed to firms in non-creative industries where only a small proportion of the workforce is engaged in creative activities. Thus, the returns on selection and training may differ systematically for CI than that for NCI, with increasing creativity dependence.

Table 4.1 Panel B reports the statistics for CI and NCI separately (and the difference between them). The average (unstandardized) value of creativity dependency is significantly higher $(\mathrm{p}<0.01$, two-tailed $)$ for the creative industries than the noncreative industries. Hence, if returns to training are dependent on the creative talents of employees, then there will be significant variation in returns to training between creative and non-creative industries, for each employee as well as for the entire workforce. Hence, analyzing the relationship between investment in training and that in selection in the context of varying creativity dependence in the sub-sample of creative industries will provide a sharper view to the analysis.

Column I in Table 4.5 shows the results from estimating equation (2) in the sub-sample of creative industries. On the other hand, Column II shows the results for the sub-sample of non-creative industries. We find that the coefficient on the interaction term between training and creativity is positive and statistically significant for the subsample of creative firms $(\beta=0.125, \mathrm{p}<0.05)$. Conversely, the coefficient for the subsample of non-creative industries is not statistically significant from zero $(\beta=-0.024$, $\mathrm{p}>0.10)$. This supports $\mathrm{H} 2$ for the sub-sample of firms in creative industries.

90 This sector comprises more demand-driven and service-oriented industries that create goods and services with functional purposes for which creative skills and people are essential (European Commission 2006; United Nations 2010).

91 It is important to distinguish a creative company from an innovative company. For the production of their core products, companies belonging to the creative sector necessarily require creative intangible inputs which add more economic value to the product than is added by traditional manufacturing (Cunningham \& Hearn, 2003), whereas the definition of an innovative organization is detached from the nature of the business. Innovative and non-innovative firms are distinguished by the intensity of innovation activities and the importance attributed to innovation strategies (Baldwin \& Johnson, 1996), whereas creative and non-creative companies are distinguished by the nature of their core products. This implies that innovative organizations can operate in any field, from cement companies to call centers. 
Table 4.5: Results for $\mathrm{H} 2$ in split sample (creative vs. non-creative industries)

\begin{tabular}{|c|c|c|c|c|}
\hline Dependent variable: Selection & $\begin{array}{c}(\mathrm{I}) \\
\mathrm{CI}=1\end{array}$ & $\begin{array}{c}\text { (II) } \\
\mathrm{CI}=0\end{array}$ & $\begin{array}{c}\text { (III) } \\
\mathrm{CI}=1 \& \mathrm{RD}=1\end{array}$ & $\begin{array}{c}(\mathrm{IV}) \\
\mathrm{CI}=\mathbf{0} \& \mathrm{RD}=0\end{array}$ \\
\hline \multirow[t]{2}{*}{ Training } & $0.470^{* * *}$ & $0.496^{* * *}$ & $0.502^{* * *}$ & $0.464^{* * *}$ \\
\hline & $(0.062)$ & $(0.061)$ & $(0.059)$ & $(0.067)$ \\
\hline \multirow[t]{2}{*}{ Creativity Dependence } & 0.041 & 0.058 & 0.036 & 0.060 \\
\hline & $(0.056)$ & $(0.051)$ & $(0.047)$ & $(0.061)$ \\
\hline \multirow[t]{2}{*}{ Training x Creativity Dependence } & $0.125^{* *}$ & -0.024 & $0.112^{*}$ & -0.031 \\
\hline & $(0.063)$ & $(0.064)$ & $(0.062)$ & $(0.075)$ \\
\hline \multirow[t]{2}{*}{ Task Uncertainty } & $0.225^{* * *}$ & $0.141^{* *}$ & $0.228^{* * *}$ & 0.119 \\
\hline & $(0.062)$ & $(0.071)$ & $(0.060)$ & $(0.079)$ \\
\hline \multirow[t]{2}{*}{ Output measurability } & $0.178^{* * *}$ & 0.067 & $0.121^{* *}$ & $0.114^{*}$ \\
\hline & $(0.065)$ & $(0.060)$ & $(0.060)$ & $(0.065)$ \\
\hline \multirow[t]{2}{*}{ Need for Intrinsic motivation } & $0.125^{* *}$ & 0.086 & $0.120^{*}$ & 0.078 \\
\hline & $(0.061)$ & $(0.056)$ & $(0.061)$ & $(0.055)$ \\
\hline \multirow[t]{2}{*}{$\log$ (Total employees) } & 0.103 & $0.166^{* * *}$ & $0.127^{* *}$ & $0.143^{* *}$ \\
\hline & $(0.065)$ & $(0.050)$ & $(0.056)$ & $(0.058)$ \\
\hline \multirow[t]{2}{*}{ Environmental Uncertainty } & -0.118 & -0.048 & $-0.117^{*}$ & -0.038 \\
\hline & $(0.080)$ & $(0.064)$ & $(0.068)$ & $(0.074)$ \\
\hline \multirow[t]{2}{*}{$\mathrm{R} \& \mathrm{D}$} & & 0.022 & -0.041 & \\
\hline & & $(0.090)$ & $(0.093)$ & \\
\hline Country fixed effects & Yes & Yes & Yes & Yes \\
\hline Observations & 179 & 278 & 238 & 219 \\
\hline R-squared & 0.415 & 0.384 & 0.41 & 0.378 \\
\hline F-Stat & 15.86 & 16.46 & 17.75 & 13.4 \\
\hline
\end{tabular}

${ }^{* * *} \mathrm{p}<0.01 ;{ }^{* *} \mathrm{p}<0.05 ;{ }^{*} \mathrm{p}<0.10$. Robust standard errors are reported.

In addition, due to the split in creative and non-creative industries as defined by NACE, the sample includes those firms with $R \& D$ laboratories within the noncreative sector. Given that $\mathrm{R} \& \mathrm{D}$ firms might be more similar in terms of reliance on creative workers to creative industries, we re-estimate equation (2) for the sub-sample of creative industries and firms with R\&D laboratories and find a positive and statistically significant coefficient $(\beta=0.112, \mathrm{p}<0.10)$ (Column III, Table 4.5) for this sub-sample.

These results show that the higher the creativity dependence the stronger is the complementarity between training and selection particularly in firms that operate in creative industries and in those that have $\mathrm{R} \& \mathrm{D}$ laboratories. The complementarity between selection and training does not seem to depend on the extent of creativity dependence in firms operating in non-creative industries. These results could be explained by the possibility that (i) the returns to talent are convex for creative industries, and 
(ii) firms in the creative industries engage the majority of their workforce in creativity dependent tasks, as opposed to firms in non-creative industries where only a small proportion of the workforce is engaged in creative activities (Anderson et al., 2009). Thus, the returns on selection and training may differ systematically for CI than that for $\mathrm{NCI}$, with increasing creativity dependence.

We test for H2.1 and H2.2 in the split-samples and report it in Table 4.6 and Table 4.7 respectively. As seen from Table 4.6, we find support for H2.1 in the noncreative industries sub-sample $(\beta=0.065, \mathrm{p}<0.10)$, indicating that the complementarity between selection on stability and training depends on the extent of creativity dependence in firms operating in non-creative industries, but not in firms operating in creative industries. The results are even stronger for the sub-sample of firms in the noncreative industries excluding R\&D laboratories $(\beta=0.077, \mathrm{p}<0.10)$.

Table 4.6: Results for H2.1 in split sample (creative vs. non-creative industries)

\begin{tabular}{|c|c|c|c|c|}
\hline Dependent variable: Selection on Stability & $\begin{array}{c}(\mathrm{I}) \\
\mathrm{CI}=1 \\
\end{array}$ & $\begin{array}{c}\text { (II) } \\
\mathrm{CI}=0\end{array}$ & $\begin{array}{c}\text { (III) } \\
\mathrm{CI}=1 \& \mathrm{RD}=1\end{array}$ & $\mathrm{CI}=\mathbf{0} \& \mathrm{RD}=\mathbf{0}$ \\
\hline \multirow[t]{2}{*}{ Training } & $0.357^{* * *}$ & $0.360^{* * *}$ & $0.340^{* * *}$ & $0.363^{* * *}$ \\
\hline & $(0.053)$ & $(0.044)$ & $(0.048)$ & $(0.049)$ \\
\hline \multirow[t]{2}{*}{ Creativity Dependence } & -0.016 & 0.049 & -0.022 & 0.055 \\
\hline & $(0.052)$ & $(0.036)$ & $(0.042)$ & $(0.043)$ \\
\hline \multirow[t]{2}{*}{ Training x Creativity Dependence } & 0.048 & $0.065^{*}$ & 0.045 & $0.077^{*}$ \\
\hline & $(0.064)$ & $(0.038)$ & $(0.051)$ & $(0.045)$ \\
\hline \multirow[t]{2}{*}{ Task Uncertainty } & 0.042 & $0.091^{*}$ & 0.057 & 0.077 \\
\hline & $(0.050)$ & $(0.050)$ & $(0.048)$ & $(0.055)$ \\
\hline \multirow[t]{2}{*}{ Output measurability } & -0.032 & 0.068 & -0.008 & $0.077^{*}$ \\
\hline & $(0.060)$ & $(0.043)$ & $(0.055)$ & $(0.046)$ \\
\hline \multirow[t]{2}{*}{ Need for Intrinsic motivation } & $0.183^{* * *}$ & 0.077 & $0.159^{* * *}$ & 0.089 \\
\hline & $(0.051)$ & $(0.052)$ & $(0.051)$ & $(0.057)$ \\
\hline \multirow[t]{2}{*}{$\log$ (Total employees) } & -0.074 & -0.031 & -0.020 & -0.076 \\
\hline & $(0.057)$ & $(0.047)$ & $(0.051)$ & $(0.053)$ \\
\hline \multirow[t]{2}{*}{ Environmental Uncertainty } & -0.014 & 0.068 & -0.004 & 0.066 \\
\hline & $(0.075)$ & $(0.043)$ & $(0.060)$ & $(0.051)$ \\
\hline \multirow[t]{2}{*}{$\mathrm{R} \& \mathrm{D}$} & & 0.002 & -0.013 & \\
\hline & & $(0.072)$ & $(0.077)$ & \\
\hline Country fixed effects & Yes & Yes & Yes & Yes \\
\hline Observations & 179 & 278 & 238 & 219 \\
\hline R-squared & 0.314 & 0.362 & 0.281 & 0.383 \\
\hline F-Stat & 7.34 & 13.61 & 8.01 & 11.95 \\
\hline
\end{tabular}

${ }^{* * *} \mathrm{p}<0.01 ;{ }^{*} \mathrm{p}<0.10$ (two-sided). Robust standard errors are reported. 
On the other hand, we find no support for H2.2 in any of the sub-samples, as seen from Table 4.7. The results for H2.1 seem very interesting (and contrary to our expectations) since there were no significant moderation effect of creativity dependence on the complementarity between selection on stability and training for firms operating in the creative industry. Hence, as an additional analysis, we investigate the specific personal attributes (that construct the selection on stability variable) in the following section.

Table 4.7: Results for H2.2 in split sample (creative vs. non-creative industries)

\begin{tabular}{|c|c|c|c|c|}
\hline Dependent variable: Selection on Trainability & $\begin{array}{c}\text { (I) } \\
\mathrm{CI}=\mathbf{1}\end{array}$ & $\begin{array}{c}\text { (II) } \\
\text { CI=0 }\end{array}$ & $\begin{array}{c}\text { (III) } \\
\mathrm{CI}=1 \& \mathrm{RD}=1\end{array}$ & $\begin{array}{c}(\mathrm{IV}) \\
\mathrm{CI}=\mathbf{0} \& \mathrm{RD}=0\end{array}$ \\
\hline \multirow[t]{2}{*}{ Training } & $0.225^{* * *}$ & $0.290^{* * *}$ & $0.241^{* * *}$ & $0.281^{* * *}$ \\
\hline & $(0.060)$ & $(0.052)$ & $(0.059)$ & $(0.055)$ \\
\hline \multirow[t]{2}{*}{ Creativity Dependence } & $0.156^{* * *}$ & 0.048 & $0.129^{* * *}$ & 0.049 \\
\hline & $(0.056)$ & $(0.046)$ & $(0.049)$ & $(0.052)$ \\
\hline \multirow{2}{*}{ Training x Creativity Dependence } & 0.049 & -0.011 & 0.040 & -0.017 \\
\hline & $(0.063)$ & $(0.045)$ & $(0.056)$ & $(0.051)$ \\
\hline \multirow[t]{2}{*}{ Task Uncertainty } & 0.061 & -0.011 & 0.068 & -0.033 \\
\hline & $(0.060)$ & $(0.070)$ & $(0.059)$ & $(0.074)$ \\
\hline \multirow[t]{2}{*}{ Output measurability } & $0.119^{*}$ & 0.042 & $0.109^{*}$ & 0.056 \\
\hline & $(0.063)$ & $(0.047)$ & $(0.057)$ & $(0.050)$ \\
\hline \multirow[t]{2}{*}{ Need for Intrinsic motivation } & -0.035 & $0.097^{*}$ & -0.019 & $0.107^{* *}$ \\
\hline & $(0.052)$ & $(0.056)$ & $(0.056)$ & $(0.054)$ \\
\hline \multirow[t]{2}{*}{$\log$ (Total employees) } & -0.005 & $0.096^{*}$ & 0.045 & 0.075 \\
\hline & $(0.061)$ & $(0.053)$ & $(0.053)$ & $(0.060)$ \\
\hline \multirow[t]{2}{*}{ Environmental Uncertainty } & $0.142^{*}$ & -0.005 & 0.063 & 0.020 \\
\hline & $(0.074)$ & $(0.052)$ & $(0.067)$ & $(0.061)$ \\
\hline \multirow[t]{2}{*}{$\mathrm{R} \& \mathrm{D}$} & & 0.003 & 0.004 & \\
\hline & & $(0.089)$ & $(0.093)$ & \\
\hline Country fixed effects & Yes & Yes & Yes & Yes \\
\hline Observations & 179 & 278 & 238 & 219 \\
\hline R-squared & 0.226 & 0.217 & 0.197 & 0.231 \\
\hline F-Stat & 6.02 & 7.26 & 5.92 & 7.61 \\
\hline
\end{tabular}

${ }^{* * *} \mathrm{p}<0.01 ;{ }^{* *} \mathrm{p}<0.05 ;{ }^{*} \mathrm{p}<0.10$ (two-sided). Robust standard errors are reported. 


\subsection{Additional Analysis: Types of desired attributes at the time of selection}

As an additional analysis, we dig deeper into specific personal attributes that might be desired at the time of selection. In particular we separately look at the items forming the "Selection for Stability" construct: (i) value congruence, (ii) team fit, (iii) and stability as personal traits (Refer to Appendix B for a complete description and the related survey questions). We make the following observations.

- All these attributes, namely, (i) value congruence, (ii) team fit, (iii) and stability are desired at the time of selection when the firm invests in higher than average levels of training [Column I, Table 4.8 -Table 4.10].

- In the creative industries, employees are selected based on their value-congruence when there is high training and high creativity dependence [Column III, Table 4.8]. This is also true for firms in the creative industries and those with R\&D laboratories [Column V, Table 4.8]. However, we do not observe any significant desire for this attribute for firms operating in non-creative industries [as seen from Columns IV and VI, Table 4.8].

- Employee's fit in the team is desired when there is high training and high creativity dependence in the full sample [Column II, Table 4.9], possibly driven by the significant effect observed in firms in the non-creative industries [Column IV, Table 4.9]. In fact, the results are even stronger for firms in the non-creative industries that do not have any R\&D activities [Column VI, Table 4.9]. However, we find no significant moderating effect of creativity dependence on selection on the attribute of team-fit in the sub-sample of firms operating in the creative industries [as seen from Columns III and V, Table 4.9].

- We find no significant moderating effect of creativity dependence on selection on stability for either of the sub-samples of firms in creative industries or in noncreative industries [Column II to Column VI, Table 4.10]. 


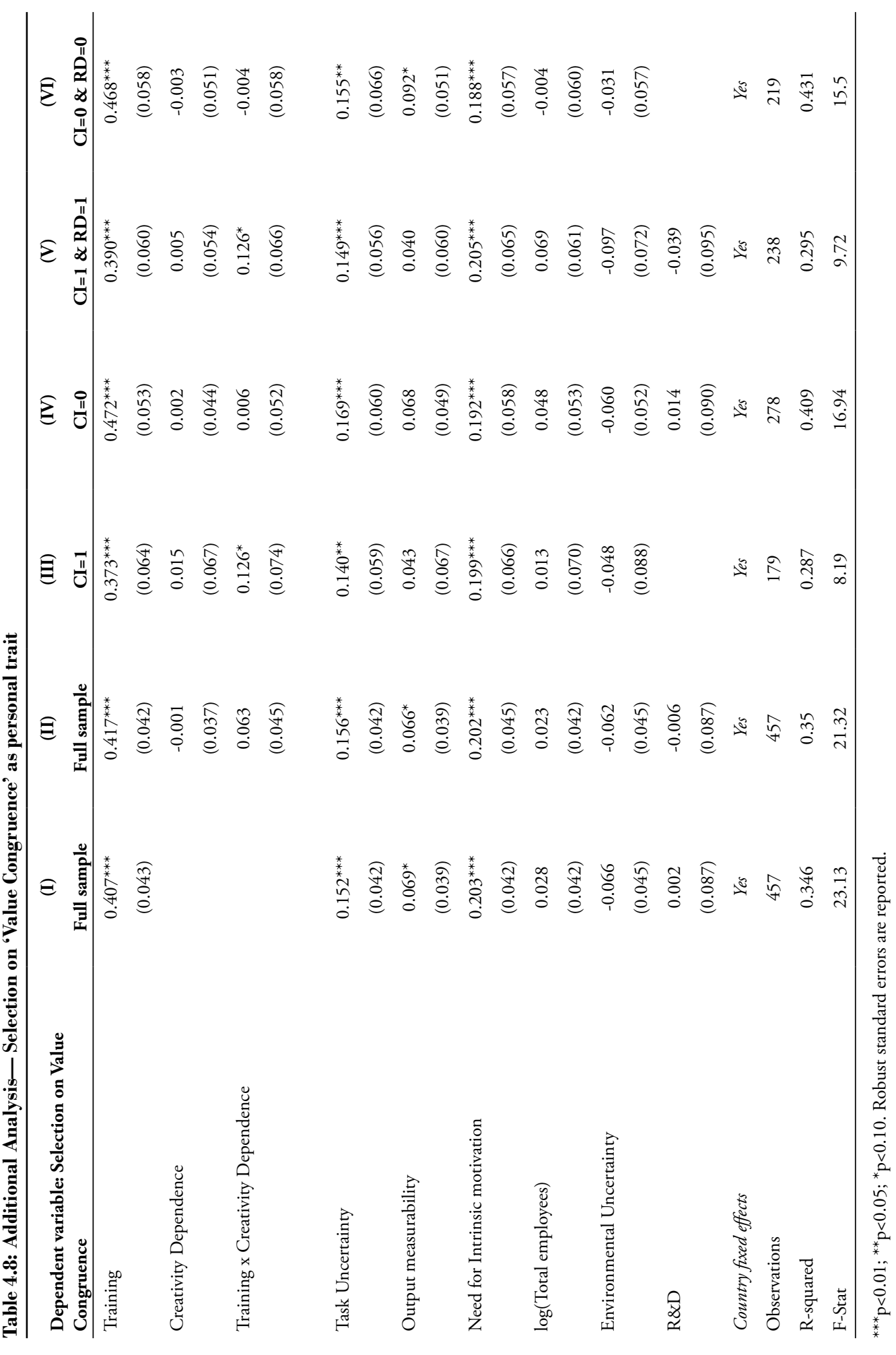




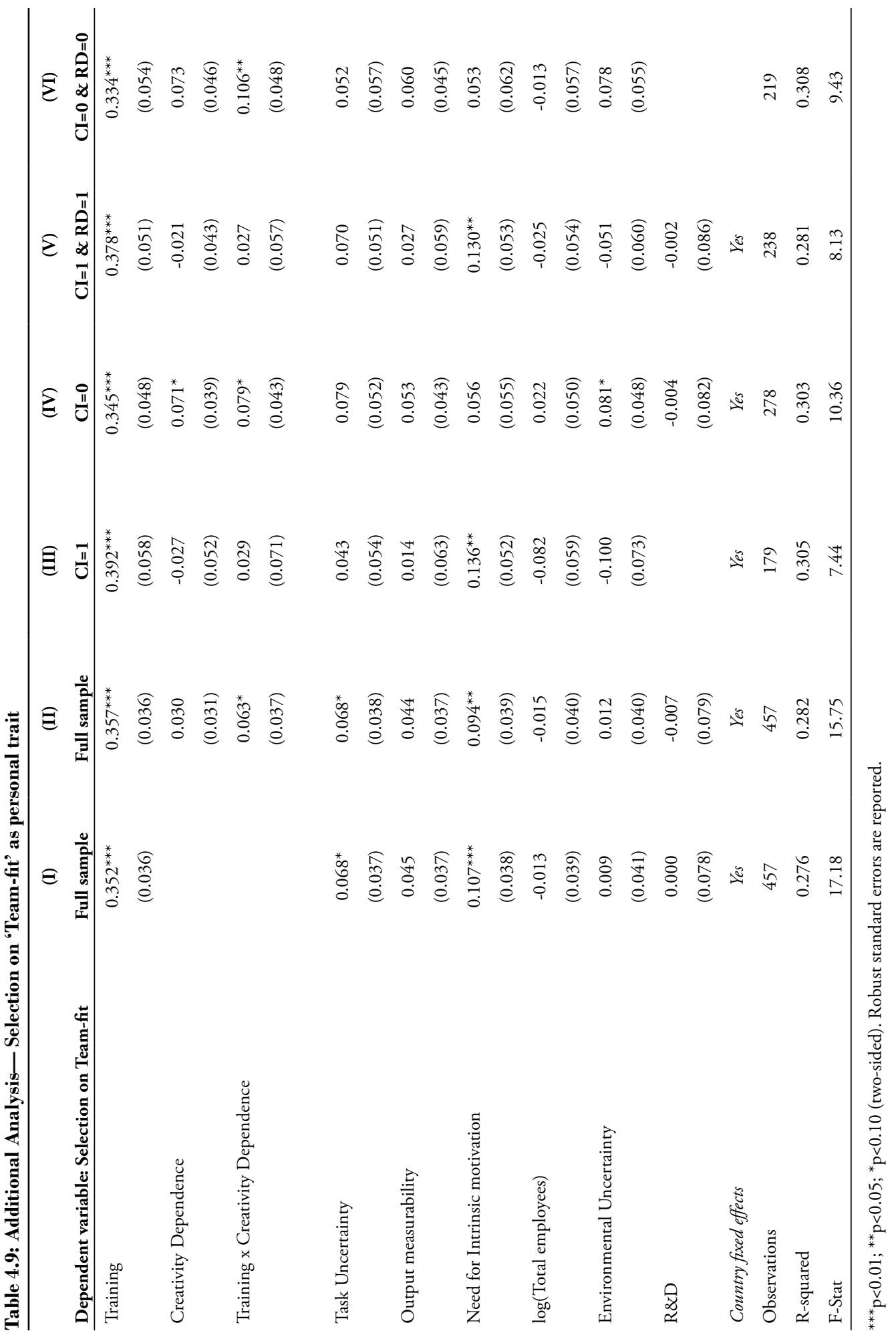




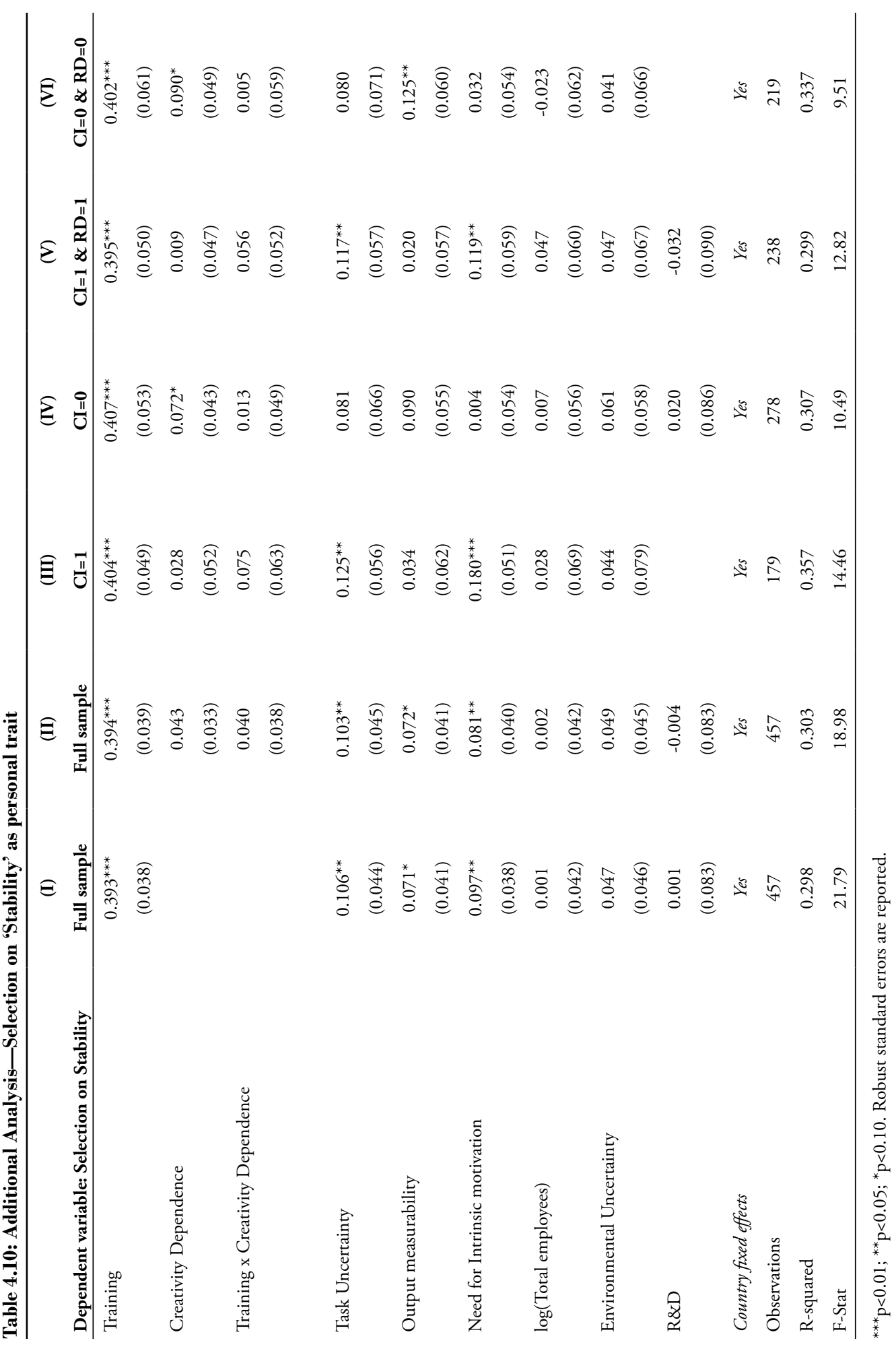


To summarize, we see that the types of attributes desired at the time of selection is distinct for creative versus non-creative industries when there is high dependency on the employees' creative abilities. In creative industries, firms emphasize the value congruence of employees. On the other hand, firms look for the employees' fit in the existing team in non-creative industries. The emphasis on value-congruence in creative industries could be seen as a way to mitigate the issues arising out of divergence of objectives between workers and firms engaged in creative industries. As pointed out by Nonaka (1991) and Amabile (1996), this divergence is often a result of workers associating themselves to only the creative activity and not to the firm's overall value. With value congruence, firms intend to align the workers' values to those of the firm and mitigate this divergence of objectives. On the other hand, firms in the non-creative industries are more concerned with the general productivity of the worker and of the team that they might engage with to do the creative activity. It might also be possible that since the proportion of workers engaged in creative activities in a firm in a noncreative industry might be smaller compared to that in a creative industry, these creative workers often need to work as a team. Hence, the emphasis on the fit of the worker is heightened. Interestingly, Anderson et al. (2012) finds that firms in the functional creative industries, such as software and gaming, offer the highest rewards for loyalty. A finding that suggests that loyalty might be a big concern of firms operating in the creative industries. However, in our analysis we did not find any significant results for stability (as a trait) of workers as a desirable attribute that are distinct to the creative industries.

Another interesting observation is that selection on technical abilities is not pronounced in the case of jobs with high creativity dependence in firms operating in the creative industries. This could be explained, to some extent, by the general observation that employees who are (or perceive themselves) to be more creative than others tend to anyway self-select themselves into jobs with high creativity dependence (Kachelmeier \& Williamson, 2010). This probably makes the effectiveness of the selection process (on the part of the firm) on technical talent somewhat less relevant than in jobs with less creativity dependence.

\subsection{Conclusion}

We find that firms seem to invest in both training and selection of their employees as a system. This can be interpreted as a complementary relationship, implying that investing in one increases the benefits of investing in the other. We show that this complementarity is driven by the need to select employees based on (i) the extent of value congruence between the worker and the firm, (ii) the degree of fit in an existing team, (iii) stability of the worker, all attributes related to the expected stability of the employer-employee 
relationship, when the firm is also investing in training these employees. Thus, we find support for the theories of allowing firms to enjoy a monopsony power, resulting from hiring a stable worker, when firms invest in training (Salop \& Salop, 1976; Blinder \& Krueger, 1996; Acemoglu \& Pischke, 1998). In addition, our results also support arguments of selecting employees based on their 'trainability', based on their innate or pre-acquired skills, when firms invest in training (Cohen \& Pfeffer, 1986; Winner $\&$ Drake, 2013). In addition, we provide new arguments such as the need for valuecongruence and team-fit to explain the complementarity relationship, depending on whether the firm is operating in a creative or non-creative industry.

We also find that this complementarity is stronger when firms have a higher than average level of dependence on the creativity of their core employees as their competitive advantage, especially in firms involved in $\mathrm{R} \& \mathrm{D}$ activities and those operating in the creative industries of (1) design, (2) new media, such as software and video games, and (3) creative services, such as advertising. Interestingly, these firms tend to place priority on selecting employees based on how congruent their values are to those of the firm, over other attributes such as pre-acquired/innate ability. This result seems in-line with prior studies (Amabile, 1983, 1988; Mumford \& Gustafson, 1988; Amabile et al., 1996; Oldham \& Cummings, 1996; Fiest, 1999; Mumford et al., 2002; Shalley et al., 2004) that highlight the unique control problem faced by firms operating in creative firms, namely, managing people who display high job involvement rather than organizational commitment. These employees seem to associate themselves with the creative task at hand, and not sharing the firm's value, or displaying any organizational commitment at large, hence, making the need for value-congruence a crucial control objective. Moreover, studies (Kachelmeier \& Williamson, 2010) also point out that screening applicants on their technical abilities for creative tasks might be redundant to some extent because it is observed that people seem to self-select to creative jobs based on their innate/pre-acquired creative talents, although self-perceived in some cases.

One limitation of the study is that the data is at the organization level and not at the employee level, hence, all inferences are drawn at the organization level. This is not a problem, per se, if one assumes that hiring/selection and training policies are decided at the organization level and not at an individual employee level (as argued by Cohen and Pfeffer (1986)). In addition, the study does not try to establish any causal relationships between investment in training and in employee selection. In fact, the study explicitly views these two forms of personnel control as a system, in line with the studies that propose that organizational level choices are generally quasi-fixed (Brynjolfsson \& Hit, 1996; Milgrom \& Roberts, 1990; Bresnahan et al. 2002; Aral et al., 2012; Grabner \& Moers, 2013).

To summarize, this study provides empirical evidence of a complementary relationship between investment in training and that in employee selection (at the time of hire) at an organizational level. In addition, it provides evidence of a moderating 
effect of creativity-dependence (at the organizational level) to this complementarity. But most importantly, the study provides the first-ever set of empirical evidence to support the stability and trainability argument that most existing studies propose through their theoretical models. To conclude, when firms invest in training (irrespective of whether the choice is strategic or a result of an exogenous shock), the most beneficial outcome of this training for the firm narrows down to the ability of achieving a stable employee-firm relation and reaping the benefits of this improved productivity (in the form of improved or new skills). This is more so when the firm relies heavily on the creativity of its core employees for their competitive edge.

The findings of the study echo the anecdotal findings of Merchant and Van der Stede (2012) when they described the control system of Jerry Reinsdorf, a successful entrepreneur and owner/chairman of the Chicago White Sox baseball club, as that of being dominated by selection and training when he said, "My management style is to hire good people and develop a relationship with them so that $95 \%$ of the time they'll know what decision I'd make and go ahead without asking me." 


\section{Appendix A}

\section{Construct validity}

Factor analysis: Explained variance per factor and factor loadings for reflective constructs

1. Selection

Factor (0.61)

1a Great emphasis is placed on the recruiting process of staff

$1 \mathrm{~b}$ An above-average amount of resources (time, money) is spent in the recruiting process

1c We take pride in the fact that we hire the best employees available on the market

1d Candidates are required to undergo a multi-stage application process before being hired

.737

2. Training

Factor (0.70)

2a Employees are offered many opportunities to improve and broaden their qualifications

.801

$2 \mathrm{~b} \quad$ New employees receive extensive training upon entering the company

2c Management staff who have been with the company for a long time are actively involved in human resources development for younger employees

3. Creativity Dependence

Factor (0.83)

3a Employee creativity is the primary source of value creation.

$3 \mathrm{~b}$ Selling creative ideas is our company's largest source of revenue.

$3 c$ The commercial success of our products primarily depends on employees' creativity

$3 \mathrm{~d}$ Competitive advantage primarily depends on employees' creative abilities

3e Creativity of our employees is the main input factor in the creation of products/services

.923

4. Task Uncertainty

4a It is possible to distinguish between effective and ineffective employees by observing them at work (R)

$4 \mathrm{~b}$ It is easy to assess how much of their resources (time, money, effort) employees have to invest in order to obtain results $(\mathrm{R})$

$4 \mathrm{c}$ It is difficult to predict the input-output relationship

4d It is difficult to predict whether an employee will be successful only based on working methods

5a The desired performance requirements (objectives) are clearly defined

$5 b$ Several sources of objective data are available which reflect the individual performance of employees.

5c Result indicators reflect precisely how much employees have achieved

$5 \mathrm{~d} \quad$ It is not possible to define completely unambiguous objectives for employees (R)

\section{Perceived Environmental Uncertainty}

6a Predictability of purchasing behaviour of our company's customers

$6 \mathrm{~b}$ Predictability of technical advances in our company's main industry

6c Predictability of behaviour and/or strategies of our suppliers

6d Predictability of behaviour and/or strategies of our competitors 
7a High-quality results can only be obtained if employees enjoy their work

$7 \mathrm{~b} \quad$ It is necessary to find employees who are motivated by a passionate interest in their work

\section{Appendix B}

Employee attributes at the time of selection

(i). Value Congruence

How well the applicant fits in with our corporate philosophy (values, approach to work)

\section{(ii). Personality and Team fit}

The judgment (opinion) of the employees who will be working with the applicant

The applicant's ability to integrate into the existing team quickly

(iii) Stability

Whether we are convinced (or believe) that the applicant seeks long-term employment (5 years or longer)

\section{(iv) Technical Ability}

Demonstrated professional experience in a comparable job

The applicant's fulfillment of professional (technical) requirements for the job

The applicant's analytical abilities (manner of approaching problems, handling of crisis situations) 



\section{Chapter 5}

Conclusion 


\subsection{Summary of main findings}

In this dissertation, I focus on the employee selection strategies engaged by firms given their different needs and contexts. In the three studies of this dissertation, I examine three different aspects of the employee selection process—recruitment channels, stockbased compensations, and resource-intensity (and direction) of the selection process.

In the first study (Chapter 2), I examine the complementarity between the recruitment strategy (in terms of recruitment channels) and compensation design (fixed pay versus incentive pay). I show, using an analytical model, that formal recruitment channels succeed in attracting more motivated workers than informal recruitment channels because of a higher application cost associated with formal channels than with informal channels, and that this is especially valuable when attracting workers into fixed-pay contracts. At the same time, firms benefit from offering fixed-pay contracts when they can select highly motivated workers. Thus, I show that fixed-pay and formal recruitment channels are complements-implying that the benefits of using fixedpay contracts increase by using these recruitment channels and vice-versa. This study therefore provides important insights into the interrelation of input-based and outputbased controls and has important implications for the design of recruitment strategies and compensation contracts in practice. In particular, firms that successfully align these practices can reap a productivity premium due to a more efficient match between their recruitment and compensation practices. These results also inform practice how firms can deal efficiently with the incentive problem in the absence of monetary incentives.

In the second study (Chapter 3), I investigate into the use of stock-based pay to sort Chief Economic Officers (CEOs) at the time of appointment when there is informational asymmetry about their fit in the firm. Using longitudinal data on S\&P 500 companies for the period 2011-2017, I find that contracts offered at the time of appointment have a higher share of stock-based pay relative to fixed-salary (and in total compensation) when there is more severe informational asymmetry about the CEO's fit in the firm. However, I find that this variation in the share of stock-based pay across different types of appointments (with variation in the degree of informational asymmetry) disappears over the CEOs' tenure, after controlling for all firm and CEO characteristics.

In the third study (Chapter 4), I examine the complementarity between resourceintensity of the employee selection process and training investments in a firm. Using cross-sectional survey data of 457 firms across Austria, Germany and Switzerland, I find a strong positive relationship between investment in training and in employee selection. Most importantly, I find that the complementarity between training and employee selection across all firms in the sample are driven by the need to select employees based on both the attributes of stability of the employee, and ability of the employee (innate or previously acquired). In addition, I also find that this positive relationship between 
employee selection and training investment gets stronger with increasing creativitydependence, especially in firms involved in $\mathrm{R} \& \mathrm{D}$ activities and those operating in the creative industries. Interestingly, I find that in the sub-sample of creative industries, the specific attribute that is prioritized when there is high creativity-dependence is the extent of value congruence between the employee and the firm, over any other attribute. On the other hand, the degree of fit in an existing team is very important in the noncreative industries when there is high creativity dependence.

\subsection{Contribution and implications}

The three studies of the dissertation contribute to the important, yet understudied, body of literature on the importance of employee selection processes and their role in various contexts. The research questions explored in this dissertation are crucial in understanding the various hiring strategies we observe in practice in the current times. The contribution of each study is discussed, in details, in the respective chapters. I highlight the important ones here.

The first study (Chapter 2) makes a very important contribution to the management accounting literature that focuses on personnel controls by drawing attention to the first stage of the employee selection process - the stage of attracting the relevant applicant pool from which employees are selected subsequently. While most studies have concentrated on subsequent stages of selection (such as screening), this study emphasizes the importance of the having the relevant applicant pool in the first step before proceeding to subsequent stages of selecting these applicants. In addition, this study formalizes (through the analytical model) the relative benefit of using formal channels over informal channels when there are fixed-pay contracts (and conversely, using informal channels when there are incentive-pay contracts). Contrary to the intuition that informal recruitment channels might be better suited to identify highly intrinsically motivated employees, the study shows that firms tend to rely on formal recruitment channels that pose high hurdles on their prospective employees at the time of applying (to discourage less motivated candidates from applying) when the provision of incentives is infeasible. Conversely, the results also imply that if firms tend to rely on formal recruitment channels for other reasons, less (costly) incentives would be needed to induce the same amount of effort, irrespective of their feasibility. The results from the study can be very helpful in understanding why firms tend to rely more on certain types of recruitment channels over others depending on the output contractibility environment. But most importantly, it provides a solution to firms by showing how to attract employees who are willing to perform to the best of their abilities even when paid fixed wages. 
The second study (Chapter 3) provides empirical evidence to a possible sorting explanation behind the variation in the share of stock-based compensation in contracts across CEOs. Most of the existing multi-disciplinary literature that focuses on the sorting role of stock-based pay at the top executive level are theoretical studies and there is a paucity of empirical studies on the topic. This study fills this gap by bringing some empirical evidence in support of the sorting theory. In addition, the study also provides an additional perspective to a long-standing debate on the justification and efficacy of using stock-based compensation. While most of the debate oscillates between the incentive story (risk-insurance tradeoff) and rent-seeking story (strongly linked to governance structures), this study is one of the first to provide another perspective, namely, a sorting perspective. One of the most important implications of the findings of this study is that the efficacy of using compensations (with its various components) must be judged using a broader lens to encompass other possible explanations such as sorting and moving beyond the widely debated view of incentives versus rent-seeking. By showing that the share of stock-based pay in compensation is strongly (positively) associated with the severity of informational asymmetry around a CEO's fit in a firm at the time appointment, the study emphasizes that the use of stock-based pay for sorting also depends on the (relative) need for sorting, which can be high with severe informational asymmetry. The results of the study are not only relevant for firms who are exploring the various tools for addressing their adverse selection concerns, but also to regulatory bodies who are constantly judging the increasing use of stock-based pay in CEO compensation.

The third study (Chapter 4) of the dissertation is one of the first empirical studies to examine what firms look for in their employees when they invest in training these employees. Existing studies have tried to reconcile their observation of a positive correlation between resource-intensity of employee selection and training with their theoretical models that rely on the need for stability and trainability of the prospective employee as the driving force for this observed correlation. This study, on the other hand, directly tests if firms are indeed looking for stability and trainability of the employees at the time of hiring. The study makes a very important contribution to the existing literature, that is mostly dated and lacks compelling empirical evidence, by providing fresh empirical evidence to support the theoretical explanations in place. In addition, the study also finds very interesting results on how creativity dependence of a firm moderates this complementarity positively for firms operating in creative industries, but not for firms operating in non-creative industries. Importantly, it shows that among the firms that operate in creative industries, the most desirable employee attribute is whether the prospective employee shares similar values with the firms (termed as value congruence), while for those firms operating in non-creative industries, the most desired attribute is whether the prospective employee fits well in the existing team in the firm. With these observations, the study makes the importance of context more 
salient than ever by not only showing that the strength of the complementarity depends on the context, but also shows that the driving forces may differ with context as well. This has significant implications for firms in terms of what to look for in prospective applicants given the nature of their operations and direct their resources accordingly. As for researchers, the study is a step towards opening the black box of why firms invest so much of their resources in employee selection and training at the same time.

\subsection{Limitations and future research}

As with any study, the studies in this dissertation are subject to certain limitations. These limitations are discussed in detail in the respective chapters. In this section, I briefly discuss the main limitations of each study, and open the discussion for future research opportunities.

The first study (Chapter 2) draws conclusions on the unobservable level of intrinsic motivation of the employees and links it to the observable choices of recruitment channels made by the firm. Although the study maintains (in theory) that intrinsic motivation refers to a particular task, empirically it is difficult to distinguish whether the self-selection is based on intrinsic motivation for a task or for a particular firm. It is also possible that the intrinsic motivation derived is because of the combination of the task and the firm. This does not take away the main findings of the analytical model, which hinges on the assumption that there is positive utility from effort regardless of whether that positive utility is derived from working on the task or from working in the firm or a combination of both. As a result, the complementarity between formal recruitment channels and fixed wages is unaffected. However, this distinction may have some bearing on the level of the optimal wages. That is, if intrinsic motivation is firm-specific, it increases the firm's monopsony power and allows it to extract more motivational rents compared to when intrinsic motivation is task-specific. Examining these differences is, however, beyond the scope of this study. In addition, intrinsic motivation, in this study, is a latent construct that has not been measured and tested empirically, as is the case with most cross-sectional firm-level studies on intrinsic motivation in the (accounting) literature. This is a limitation in the literature that merits research efforts in the future.

The second study (Chapter 3) hints at the possible use of stock-based pay to address adverse selection concerns, over and above moral-hazard concerns. The study, like most studies in the topic, attempts at drawing conclusion about a process from a snapshot view of the outcome of that process-in this case, the study draws conclusions about the possible sorting process around the CEO's appointment by looking at the contract the CEO agreed to accept at the time of appointment. This could be a limitation knowing that hiring at the top executive level is a complex process and could involve a lot of other unobservable processes that could confound our inferences. 
Nonetheless, the study is an attempt to draw reasonable inferences and provide a new direction of thought in explaining the observed variation in the outcome (with respect to compensation structure) of this complex process, even if limited by the availability of information on the process. As future research, studies could attempt at examining the process (if data permits) or examine the change in the firm's strategies as well as board structures post CEO hire to make inferences about (and exclude) other possible processes that could be at play at the time of appointment.

The third study (Chapter 4) examines the decision to invest in employee selection process and in training at the organizational level, mainly because of firms' desiring certain employee attributes of stability and trainability to maximize the returns from training. Although the explanation is rooted in an employee's stability and trainability capacity, the data on training and resource-intensity of employee selection process is at the organization level instead of at employee-level. This poses a limitation, especially because a one-to-one link between employee selection process and training investments is not possible at an individual employee level. The consolation at this stage is the general fact that decisions about both training and selection process are taken at the organizational level implying that although there might be variation across jobs and occupations within the organization, there is generally a strong correlation between jobs and occupations within the organization, as established in the literature. However, as future research, it would be ideal to invest in an employee-level survey (complementing the organizational level survey) to be able to validate such organizational level observations with employeelevel observations and bring robustness to the analysis. 


\section{BIBLIOGRAPHY}

Abernethy, M. A., \& Brownell, P. (1997). Management control systems in research and development organizations: the role of accounting, behavior and personnel controls. Accounting, Organizations and Society, 22(3-4), 233-248.

Abernethy, M. A., Dekker, H. C., \& Schulz, A. K. D. (2015). Are employee selection and incentive contracts complements or substitutes? Journal of Accounting Research, 53(4), 633-668.

Abowd, J. M., \& Kaplan, D. S. (1999). Executive compensation: six questions that need answering. Journal of Economic Perspectives, 13(4),145-168.

Abraham, K. G., \& Farber, H. S. (1987). Job Duration, Seniority, and Earnings. American Economic Review, 77(3), 278-297.

Acemoglu, D., \& Pischke, J. S. (1998). Why do firms train? Theory and evidence. The Quarterly Journal of Economics, 113(1), 79-119.

Acharya, V. V., Gabarro, M., \& Volpin, P. F. (2010). Competition for managers, corporate governance and incentive compensation. Corporate Governance and Incentive Compensation. CEPR Discussion Paper No. DP8936.

Akerlof, G. A., \& Kranton, R. E. (2005). Identity and the Economics of Organizations. Journal of Economic Perspectives, 19(1), 9-32.

Aldrich, H. A. N. L., and Langton, N. (1997). Human resource management practices and organizational life cycles. Frontiers of Entrepreneurship Research, Wellesley, MA: Babson College Center for Entrepreneurship, 349-357.

Altonji, J. G., \& Shakotko, R. A. (1987). “Do Wages Rise with Job Seniority?” Review of Economic Studies, 54(3), 437-459.

Altonji, J. G., \& Pierret, C. R. (2001). Employer learning and statistical discrimination. The Quarterly Journal of Economics, 116(1), 313-350.

Amabile, T. M. (1983). Social psychology of creativity: A componential conceptualization. Journal of Personality and Social Psychology, 45(2), 357-377.

Amabile, T.M. (1988). A model of creativity and innovation in organizations. Research in Organizational Behavior, 10(1),123-167.

Amabile, T.M. (1996). Creativity in context. Boulder, CA: Westview Press.

Amabile, T. M., Conti, R., Coon, H., Lazenby, J., \& Herron, M. (1996). Assessing the work environment for creativity. Academy of Management Journal, 39(5),1154-1184.

Andersson, F., Freedman, M., Haltiwanger, J., Lane, J., \& Shaw, K. (2009). Reaching for the stars: who pays for talent in innovative industries? The Economic Journal, 119(538), 308-332.

Aral, S., Brynjolfsson, E., \& Wu, L. (2012). Three-Way Complementarities: Performance Pay, Human Resource Analytics, and Information Technology. Management Science, 58(5), 913-931.

Armstrong, C.S., \& Vashishtha, R. (2012) Executive stock options, differential risk-taking incentives, and firm value. Journal of Financial Economics, 104(1),70-88.

Athey, S., \& Stern.S. (1998). An Empirical Framework for Testing Theories About Complementarity in Organizational Design. Working paper, National Bureau of Economic Research. 
Atkinson, J. \& Meager, N. (1994). Running to Stand Still: The Small Firm in the Labour Market, in Atkinson, J. and Storey, D. (Eds) Employment, the Small Firm and the Labour Market. Routledge, London.

Autor, D. H., \& Scarborough, D. (2008). Does job testing harm minority workers? Evidence from retail establishments. The Quarterly Journal of Economics, 123(1), 219-277.

Baker, G., Gibbons, R., \& Murphy, K. J. (1994). Subjective performance measures in optimal incentive contracts. The quarterly journal of economics, 109(4), 1125-1156.

Baldwin, J. R., \& Johnson, J. (1996). Business strategies in more- or less-innovative firms in Canada. Research Policy, 25(5), 785-804.

Banker, R. D., Li, S., \& Plehn-Dujowich, J. M. (2010). Screening Versus Sorting in a Principal-Agent Model with Moral Hazard and Adverse Selection. Available at SSRN 1659935.

Baron, J. N., and Kreps, D. M. (1999). Consistent human resource practices. California Management Review, 41(3).

Barron, J. M., and Bishop, J. (1985). Extensive search, intensive search, and hiring costs: New evidence on employer hiring activity. Economic inquiry, 23(3), 363-382.

Barron, J. M., Bishop, J., \& Dunkelberg, W. C. (1985). Employer search: The interviewing and hiring of new employees. The Review of Economics and Statistics, 67(1), 43-52.

Barron, J. M., Black, D. A., \& Loewenstein, M. A. (1989). Job matching and on-the-job training. Journal of Labor Economics, 7(1), 1-19.

Barron, J. M., Berger, M. C., \& Black, D. A. (1997). Employer search, training, and vacancy duration. Economic Inquiry, 35(1), 167-192.

Baruah, R., Grabner, I., \& Moers, F. (2021). Recruitment Strategy and Intrinsic Motivation. Working Paper.

Beaman, L., Keleher, N., \& Magruder, J. (2018). Do job networks disadvantage women? Evidence from a recruitment experiment in Malawi. Journal of Labor Economics, 36(1), 121-157.

Beasley, T., and Ghatak, M. (2005). Competition and Incentives with Motivated Agents. American Economic Review, 95(3), 616-636.

Bebchuk, L. A., Fried, J. M., \& Walker, D. I. (2002). Managerial power and rent extraction in the design of executive compensation (No. w9068). National Bureau of Economic Research.

Bebchuk, L. A., \& Fried, J. M. (2003). Executive compensation as an agency problem. Journal of Economic Perspectives, 17(3), 71-92.

Bebchuk, L. A., Cremers, K. M., \& Peyer, U. C. (2011). The CEO pay slice. Journal of financial Economics, 102(1), 199-221.

Becker, G. S. (1964). Human Capital. New York: Columbia University Press.

Becker, D. A. A. (1997). The effects of choice on auditors' intrinsic motivation and performance. Behavioral Research in Accounting, 9.

Beckmann, M., Cornelissen, T., and Kräkel, M. (2017). Self-managed working time and employee effort: Theory and evidence. Journal of Economic Behavior \& Organization, 133, 285-302.

Bedford, D. S., \& Malmi, T. (2015). Configurations of control: An exploratory analysis. Management Accounting Research, 27, 2-26.

Benabou, R., \& Tirole, J. (2003). Intrinsic and Extrinsic Motivation. The Review of Economic Studies, 70(3), 
489-520.

Bénabou, R., \& Tirole, J. (2016). Bonus culture: Competitive pay, screening, and multitasking. Journal of Political Economy, 124(2), 305-370.

Berns K. V. D. \& Klarner, P. (2017). A review of the CEO succession literature and future research program. Academy of Management Perspectives, 31(2), 83-108.

Biswas-Diener, R., Kashdan, T. B., \& Minhas, G. (2011). A dynamic approach to psychological strength development and intervention. The Journal of Positive Psychology, 6(2), 106-118.

Black, S. E., \& Lynch, L. M. (2001). How to compete: the impact of workplace practices and information technology on productivity. Review of Economics and Statistics, 83(3), 434-445.

Blau, G. (1990). Exploring the mediating mechanisms affecting the relationship of recruitment source to employee performance. Journal of Vocational Behavior, 37(3), 303-320.

Blinder, A. S., \& Krueger, A. B. (1996). Labor turnover in the USA and Japan: a tale of two countries. Pacific Economic Review, 1(1), 27-57.

Boeker, W., \& Goodstein, J. (1993). Performance and successor choice: The moderating effects of governance and ownership. Academy of Management Journal, 36(1),172-186.

Bragaw, N. A., \& Misangyi, V. F. (2017). The value of CEO mobility: contextual factors that shape the impact of prior CEO experience on market performance and CEO compensation. Human Resource Management, 56(2), 243-265.

Breaugh, J. A. (1981). Relationships between recruiting sources and employee performance, absenteeism, and work attitudes. Academy of Management journal, 24(1), 142-147.

Breaugh, J. A. (2013). Employee recruitment. Annual review of psychology, 64, 389-416.

Bresnahan, T.F., Brynjolfsson, E., \& Hitt, L.M. (2002). Information Technology, Work-place Organization, and the Demand for Skilled Labor: Firm-Level Evidence. The Quarterly Journal of Economics, 117(1), 339-376.

Brown, M., Setren, E. \& Topa, G. (2016). Do Informal Referrals Lead to Better Matches? Evidence from a Firm's Employee Referral System. Journal of Labor Economics, 34(1), 161-209.

Brynjolfsson, E., L., \& Hitt, M. (1996). Paradox lost? Firm-level evidence on the returns to information systems. Management Science, 42(4), 541-558.

Burdett, K., \& Cunningham, E. J. (1998). Toward a theory of vacancies. Journal of Labor Economics, 16(3), 445-478.

Burks, S. V., Cowgill, B., Hoffman, M., \& Housman, M. (2015). The value of hiring through employee referrals. The Quarterly Journal of Economics, 130(2), 805-839.

Casella, A. \& Hanaki, N. (2008) Information channels in labor markets: On the resilience of referral hiring. Journal of Economic Behavior and Organization, 66(3-4), 492-513.

Campbell, D. (2012) Employee Selection as a Control System. Journal of Accounting Research, 50(4), 931966.

Cadenillas, A., Cvitanic, J. \& Zapatero, F. (2005). Executive Stock Options as a Screening Mechanism. Working Paper, University of Southern California.

Cadman, B., Carrizosa,R., \& Peng, X. (2020). Inducement Grants, Hiring announcements and adverse selection for new CEOs. Review of Accounting Studies, 25, 279-312. 
Cannella, A. A. J., \& Lubatkin, M. (1993). Succession as a sociopolitical process: Internal impediments to outsider selection. Academy of Management Journal, 36(4), 763-793.

Cassiman, B., \& Veugelers, R. (2006). In search of complementarity in innovation strategy: Internal R\&D and external knowledge acquisition. Management science, 52(1), 68-82.

Castilla, E. J. (2005). Social networks and employee performance in a call center. American journal of sociology, 110(5), 1243-1283.

Caves, R. E. (2000). Creative industries: Contracts between art and commerce (No. 20). Harvard University Press.

Chan, W. (1996). External recruitment versus internal promotion. Journal of Labor Economics, 14(4), 555570.

Chapman, C. S., Grabner, I., \& Moers, F. (2020). Introduction to the AOS special issue on management control as system or package. Accounting Organizations and Society, 86.

Chen, G. (2015). Initial compensation of new CEOs hired in turnaround situations. Strategic Management Journal, 36(12), 1895-1917.

Chenhall, R. H. (2003). Management control systems design within its organizational context: findings from contingency-based research and directions for the future. Accounting, organizations and society, 28(2-3), 127-168.

Churchill Jr, G. A. (1979). A paradigm for developing better measures of marketing constructs. Journal of marketing research, 16(1), 64-73.

Clifton, D. O., \& Harter, J. K. (2003). Investing in strengths. Positive organizational scholarship: Foundations of a new discipline, 111-121.

Cohen, Y., \& Pfeffer, J. (1986). Organizational hiring standards. Administrative Science Quarterly, 31(1),124.

Coles, J.L., Daniel, N.D., \& Naveen, L. (2006). Managerial Incentives and Risk-Taking. Journal of Financial Economics, 79(2), 431-468.

Coles, J. L., Daniel, N. D., \& Naveen, L. (2014). Co-opted boards. The Review of Financial Studies, 27(6), 1751-1796.

Conyon, M. J., Core, J. E., \& Guay, W. R. (2011). Are US CEOs paid more than UK CEOs? Inferences from risk-adjusted pay. The Review of Financial Studies, 24(2), 402-438.

Core, J., \& Guay, W. (1999). The use of equity grants to manage optimal equity incentive levels. Journal of Accounting and Economics, 28(2), 151-184.

Core, J., \& Guay, W. (2002). Estimating the value of employee stock option portfolios and their sensitivities to price and volatility. Journal of Accounting Research, 40(3), 613-630.

Cremers, M., \& Palia, D. (2010). Tenure and CEO pay (june 18, 2010). Available at SSRN 1626950.

Cunningham, S., \& Hearn, G. N. (2003). Brisbane’s Creative Industries. Brisbane: Queensland University of Technology.

Datta, D. K., \& Guthrie, J. P. (1994). Executive succession: Organizational antecedents of CEO characteristics. Strategic Management Journal, 15(7), 569-577.

Deci, E.L. (1972). The Effects of Contingent and Noncontingent Rewards and Controls on Intrinsic Motivation. Organizational Behavior and Human Performance, 8(2), 217-229. 
Deci, E. L. (1975). Intrinsic motivation. New York, NY, US: Plenum Press, 10, 978-1.

Deci, E. L., \& Gagné, M. (2005). Self-determination theory and work motivation. Journal of Organizational behavior, 26(4), 331-362.

Deci, E. L., \& Ryan, R. M. (1985). The general causality orientations scale: Self-determination in personality. Journal of research in personality, 19(2), 109-134.

Deci, E. L., Koestner, R., \& Ryan, R. M. (1999). A meta-analytic review of experiments examining the effects of extrinsic rewards on intrinsic motivation. Psychological bulletin, 125(6), 627.

Deci, E. L., \& Ryan, R. M. (2000). Self-Determination Theory and the Facilitation of Intrinsic Motivation, Social Development, and Well-Being. American Psychologist, 55(1), 68-78 .

Delfgaauw, J., \& Dur, R. (2007). Signaling and Screening of Workers Motivation. Journal of Economic Behaviour and Organization, 62(4), 605-624.

Dixit, A. (2002). Incentives and organizations in the public sector: An interpretative review. Journal of human resources, 696-727.

Dohmen, T., \& Falk, A.(2011). Performance pay and multidimensional sorting: Productivity, preferences, and gender. American Economic Review, 101(2), 556-90.

Donnelly, A., Kennedy, F. A., \& Widener, S. K. (2018). Insights into the Relationships between Personnel Control, Action Control, and Intrinsic Motivation. Action Control, and Intrinsic Motivation (June 30, 2018).

Dustmann,C., Glitz, A. \& Schonberg, U. (2012). Referral-based Job Search Networks. Manuscript, University College London.

Edmans, A., Gabaix,X., \& Landier. A. (2009). A Multiplicative Model of Optimal CEO Incentives in Market Equilibrium. Review of Financial Studies, 22(12), 4881-917.

Edmans, A., Gabaix, X., Sadzik, T., \& Sannikov, Y. (2012). Dynamic CEO compensation. The Journal of Finance, 67(5), 1603-1647.

Edmans, A., \& Gabaix, X. (2009). Is CEO Pay Really Inefficient? A Survey of New Optimal Contracting Theories." European Financial Management, 15(3), 486-96.

Edmans, A., \& Gabaix, X. (2011). The Effect of Risk on the CEO Market. The Review of Financial Studies, 24(8), 2822-2863.

Edmans, A., \& Gabaix, X. (2016). Executive compensation: A modern primer. Journal of Economic literature, 54(4), 1232-87.

Eisenhardt, K. M. (1985). Control: Organizational and economic approaches. Management Science, 31 (2), 134-149.

Elsaid, E., Wang, X., \& Davidson, W. N. (2011). Does experience matter? CEO successions by former CEOs. Managerial Finance.

Etzioni, A. (1971). Policy research. The American Sociologist, 8-12.

Falato, A., Li, D., \& Milbourn, T. (2015). Which skills matter in the market for CEOs? Evidence from pay for CEO credentials. Management Science, 61(12) 2845-2869.

Farber, H. S., \& Gibbons, R. (1996). Learning and wage dynamics. The Quarterly Journal of Economics 111(4),1007-1047.

Fee, C. E., \& Hadlock, C. J. (2003). Raids, rewards, and reputations in the market for managerial talent. The 
Review of Financial Studies, 16(4), 1315-1357.

Feist, G. J. (1999). The influence of personality on artistic and scientific creativity. In Handbook of Creativity, edited by R. J. Sternberg. Cambridge, UK: Cambridge University Press, 273-296.

Fernandes, N., Ferreira, M. A., Matos, P., \& Murphy, K. J. (2012). Are US CEOs paid more? New international evidence. The Review of Financial Studies, 26(2), 323-367.

Fernandez, R. M., Castilla, E. J., \& Moore, P. (2000). Social capital at work: Networks and employment at a phone center. American journal of sociology, 105(5), 1288-1356.

Frank, K. A. (2000). Impact of a confounding variable on a regression coefficient. Sociological Methods \& Research, 29(2), 147-194.

Frey, B. S. (1997). On the relationship between intrinsic and extrinsic work motivation. International journal of industrial organization, 4(15), 427-439.

Friend, I., \& Lang, L.H.P. (1998). An empirical test of the impact of managerial self-interest on corporate capital structure. Journal of Finance, 43(2), 271-281.

Frydman, C. (2019). Rising through the ranks: the evolution of the market for corporate executives, 1936 2003. Management Science, 65(11), 4951-4979.

Frydman, C., \& Jenter, D. (2010). CEO compensation. Annual Review of Financial Economics, 2(1), 75102.

Gabaix, X., \& Landier, A. (2008). Why has CEO pay increased so much? The Quarterly Journal of Economics, 123(1), 49-100.

Gabaix, X., Landier, A., \& Sauvagnat, J. (2014). CEO pay and firm size: An update after the crisis. The Economic Journal, 124(574), F40-F59.

Gagné, F. (2004). Transforming gifts into talents: The DMGT as a developmental theory. High Ability Studies, 15(2), 119-147.

Galenianos, M. (2013). Learning of Match Quality and the Use of Referrals. Review of Economic Dynamics, $16(4), 668-690$.

Garicano, L. \& Santos, T. (2004). Referrals. The American Economic Review, 94(3), 499- 525.

Garvey, G. (1997). Marketable incentive contracts and capital structure relevance. Journal of Finance, 52(1), 353-378.

Garrett, D. F., \& Pavan, A. (2012). "Managerial Turnover in a Changing World.” Journal of Political Economy, 120(5), 879-925.

Garrett, D. F., \& Pavan, A. (2015). Dynamic managerial compensation: A variational approach. Journal of Economic Theory, 159, 775-818.

Gerakos, J. J., Ittner, C. D., \& Moers, F. (2018). Compensation objectives and business unit pay strategy. Journal of Management Accounting Research, 30(2), 105-130.

Geringer, J. M., Frayne, C. A., \& Milliman, J. F. (2002). In search of "best practices" in international human resource management: Research design and methodology. Human Resource Management: Published in Cooperation with the School of Business Administration. The University of Michigan and in alliance with the Society of Human Resources Management, 41(1), 5-30.

Gerson, W. F. (1976). The effects of a demanding application process on the applicant pool for teaching positions. (Doctoral dissertation, University of Pennsylvania, 1975). Dissertation Abstracts 
International, 36, 7773A.

Gibbons, R., \& Katz, L. F. (1991). Layoffs and lemons. Journal of labor Economics, 9(4), 351- 380.

Gibbons, R., \& Murphy, K.J. (1992). Optimal Incentive Contracts in the Presence of Career Concerns: Theory and Evidence. Journal of Political Economy, 100(3), 468-505.

Gil, R., \& Spiller, P. T. (2007). The organizational implications of creativity: the US film industry in mid-XXth century (No. w13253). National Bureau of Economic Research.

Gillan, S. L., Hartzell, J. C., \& Parrino, R. (2009). Explicit versus implicit contracts: Evidence from CEO employment agreements. The Journal of Finance, 64(4), 1629-1655.

Gormley, T.A., Matsa, D.A., \& Milbourn, T. (2013). CEO compensation and corporate risk: evidence from a natural experiment. Journal of Accounting and Economics, 56(2-3), 79-101.

Goldberg, M.S. (1982). Discrimination, Nepotism, and Long-Run Wage Differentials. Quarterly Journal of Economics, 97(2), 307-19.

Gorter, C., Nijkamp, P., \& Rietveld, P. (1996). Employers' recruitment behaviour and vacancy duration: an empirical analysis for the Dutch labour market. Applied Economics, 28(11), 1463-1474.

Grabner, I. (2014). Incentive system design in creativity-dependent firms. The Accounting Review, 89(5), 1729-1750.

Grabner, I., \& Moers, F. (2013). Management control as a system or a package? Conceptual and empirical issues. Accounting, Organizations and Society, 38(6-7), 407-419.

Grabner, I., \& Speckbacher, G. (2016). The cost of creativity: A control perspective. Accounting, Organizations and Society, 48, 31-42.

Graffin, S. D., Boivie, S., \& Carpenter, M. A. (2013). Examining CEO succession and the role of heuristics in early-stage CEO evaluation. Strategic Management Journal, 34(4), 383-403.

Guay,W. R. (1999). The Sensitivity of CEO Wealth to Equity Risk: An Analysis of the Magnitude and Determinants. Journal of Financial Economics, 53(1), 43-71.

Guay, W. R., Taylor, D. J., \& Xiao, J. J. (2015). Adapt or perish: Evidence of CEO adaptability to industry shocks. Available at SSRN 2234886.

Guthrie Datta, J. P. D. K. (1997). Contextual influences on executive selection: Firm characteristics and CEO experience. Journal of Management Studies, 34(4), 537-560.

Hair, J. F., Ringle, C. M., \& Sarstedt, M. (2011). PLS-SEM: Indeed a silver bullet. Journal of Marketing theory and Practice, 19(2), 139-152.

Hall, B. J., \& Murphy, K. J. (2003). The trouble with stock options. Journal of Economic Perspectives, 17(3), 49-70.

Hambrick, D. C., \& Mason, P. (1984). Upper echelons: The organization as a reflection of its top managers. Academy of Management Review, 9(2), 193-206.

Hamori, M. (2010). Who gets headhunted—and who gets ahead? The impact of search firms on executive careers. Academy of Management Perspectives, 24(4), 46-59.

Harris, D., \& Helfat, C. (1997). Specificity of CEO human capital and compensation. Strategic Management Journal, 18(11), 895-920.

Harris, M., \& Holmstrom, B. (1982). A Theory of Wage Dynamics. Review of Economic Studies, 49(3), $315-33$. 
Heath, R. (2018). Why do firms hire using referrals? evidence from bangladeshi garment factories. Journal of Political Economy, 126(4), 1691-1746.

Hemmer, T., Matsunaga, S., \& Shevlin, T. (1994). Estimating the 'fair value' of employee stock options with expected early exercise. Accounting Horizons, 8(4), 23-42.

Hermalin, B. E., \& Weisbach, M. S. (1998). Endogenously Chosen Boards of Directors and Their Monitoring of the CEO. American Economic Review, 88, 96-118.

Hermalin, B. E., \& Weisbach, M. S. (2012). Information Disclosure and Corporate Governance. Journal of Finance, 67(1), 195-233.

Hill, C. W., \& Phan, P. (1991). CEO tenure as a determinant of CEO pay. Academy of Management Journal, 34(3), 707-717.

Hoffman, M., Kahn, L. B., \& Li, D. (2018). Discretion in hiring. The Quarterly Journal of Economics, 133(2), 765-800.

Holmstrom, B. (1999). Managerial Incentive Problems: A Dynamic Perspective. Review of Economic Studies, 66(1), 169-82.

Holzer, H.J. (1987). Hiring Procedures in the Firm: Their Economic Determinants and Outcomes, Human Resources and Firm Performance, ed. by Richard Block, et. al. Industrial Relations Research Association.

Ichniowski, C., Shaw, K., \& Prennushi, G. (1997). The effects of human resource practices on manufacturing performance: A study of steel finishing lines. American Economic Review, 87(3), 291-313.

Ittner, C. D., Lambert, R.A. \& Larcker, D.F. (2003). The Structure and Performance Consequences of Equity Grants to Employees of New Economy Firms. Journal of Accounting and Economics, 34(13), 89-127.

Jensen, M., \& W. Meckling. (1976). Theory of the Firm: Managerial Behavior, Agency Costs, and Ownership Structure. Journal of Financial Economics, 3(4), 305-60.

Jensen, M. (1986). Agency costs of free cash ow, corporate finance, and takeovers. American Economic Review, 76(2), 323-329.

Jovanovic, B. (1979). Job matching and the theory of turnover. Journal of Political Economy, 87 (5, Part I), 972-990.

Kadous, K., \& Zhou, Y. (2019). How does intrinsic motivation improve auditor judgment in complex audit tasks? Contemporary Accounting Research, 36(1), 108-131.

Kennedy, F. A., \& Widener, S. K. (2019). Socialization mechanisms and goal congruence. Accounting, Organizations and Society, 76, 32-49.

Khurana, R. (2002). Market triads: A theoretical and empirical analysis of market intermediation. Journal for the theory of social behaviour, 32(2), 239-262.

Kirnan, J. P., Farley, J. A., \& Geisinger, K. F. (1989). The relationship between recruiting source, applicant quality, and hire performance: An analysis by sex, ethnicity, and age. Personnel Psychology, 42(2), 293-308.

Kunz, A. H., \& Pfaff, D. (2002). Agency theory, performance evaluation, and the hypothetical construct of intrinsic motivation. Accounting, organizations and society, 27(3), 275-295. 
Lazear, E. P. (1979). Why is there mandatory retirement? Journal of Political Economy, 87(6), 1261-1284.

Lazear, E. P. (1986). Salaries and piece rates. The Journal of Business, 405-431.

Lazear, E. P. (2000). Performance pay and productivity. American Economic Review, 90(5), 1346-1361.

Lazear, E.P. (2005). Output-based pay: incentives, retention or sorting? in Solomon W. Polachek (ed.) Accounting for Worker Well-Being. Research in Labor Economics, 23,1 -25.

Lazear, E. P. (2009). Firm-specific human capital: A skill-weights approach. Journal of political economy, 117(5), 914-940.

Lazear, E. P., \& Oyer, P. (2009). Personnel Economics. In Handbook of Organizational Economics, edited by Gibbons, R., \& Roberts, J.

Leland, H. (1998). Agency costs, risk management, and capital structure. Journal of Finance, 53(4), 12121243.

Leung, A. (2003). Different ties for different needs: Recruitment practices of entrepreneurial firms at different developmental phases. Human Resource Management: Published in Cooperation with the School of Business Administration, The University of Michigan and in alliance with the Society of Human Resources Management, 42(4), 303-320.

Lewellen, K. (2006). Financing decisions when managers are risk-averse. Journal of Financial Economics, 82(3), 551-589.

Lippert, R. L., \& Porter, G. (1997). Understanding CEO pay: A test of two pay-to-performance sensitivity measures with alternative measures of alignment and influence. Journal of Business Research, $40(2)$, 127-138.

Lockwood, D., \& Ansari, A. (1999). Recruiting and retaining scarce information technology talent: a focus group study. Industrial Management \& Data Systems.

Masschelein, S., \& Moers, F. (2020). Testing for complementarities between accounting practices. Accounting, Organizations and Society, 86, 101127.

Mc Pherson, M., Smith-lovin, L. \& Cook, J.M. (2001). Birds of a Feather: Homophily in Social Networks. Annual Review of Sociology, 27(1), 415-444

Merchant, K. A. (1985). Control in Business Organizations. Cambridge, MA: Ballinger.

Merchant, K. A \& Van Der Stede, W. (2012). Management control systems: performance measurement, evaluation and incentives. Pearson Publishers. Third Edition.

Merchant, K. A., Van der Stede, W. A., \& Zheng, L. (2003). Disciplinary constraints on the advancement of knowledge: the case of organizational incentive systems. Accounting, Organizations and Society, 28(2-3), 251-286.

Merchant, K. A., \& Van der Stede., W. A. (2007). Management Control Systems: Performance Measurement, Evaluation and Incentives. Englewood Cliffs, NJ: Prentice Hall, Inc.

Meyers, M. C., Van Woerkom, M., \& Dries, N. (2013). Talent-Innate or acquired? Theoretical considerations and their implications for talent management. Human Resource Management Review, 23(4), 305-321.

Milbourn, T. (2003). CEO reputation and stock-based compensation. Journal of Financial Economics, 68(2), 233-262

Miles, R. E., \& Snow, C. C. (1984). Designing strategic human resources systems. Organizational 
dynamics, 13(1), 36-52.

Milgrom, P., \& Roberts, J. (1990). The economics of modern manufacturing: Technology, strategy and organization. American Economic Review, 80, 511-528.

Moen, E. R., \& Rosen, Å. (2005). Performance pay and adverse selection. Scandinavian Journal of Economics, 107(2), 279-298.

Montgomery, J. D. (1991). Social Networks and Labor-Market Outcomes: Toward an Economic Analysis. The American Economic Review, 81(5), 1408-1418.

Mumford, M. D., \& Gustafson, S. B. (1988). Creativity syndrome: Integration, application, and innovation. Psychological bulletin, 103(1), 27.

Mumford, M. D., Scott, G. M., Gaddis, B., \& Strange, J. M. (2002). Leading creative people: Orchestrating expertise and relationships. The leadership quarterly, 13(6), 705-750.

Murphy, K. J. (1986). Incentives, Learning, and Compensation: A Theoretical and Empirical Investigation of Managerial Labor Contracts. RAND Journal of Economics, 17(1), 59-76.

Murphy, K. J. (1999). Executive compensation. Handbook of Labor Economics, 3, 2485-2563.

Murphy, K. J., \& Zabojnik, J. (2007). Managerial capital and the market for CEOs. Available at SSRN 984376.

Murphy, K. J. (2013). Executive Compensation: Where We Are, and How We Got There. In Handbook of the Economics of Finance, Volume 2A: Corporate Finance, edited by George M. Constantinides, Milton Harris, and Rene M. Stulz, 211-356. Oxford and Amsterdam: Elsevier, North-Holland.

Murphy, K. J., \& Jensen, M. C. (2018). The politics of pay: The unintended consequences of regulating executive compensation. USC Law Legal Studies Paper, (18-8).

Neal, D. (1995). Industry-Specific Human Capital: Evidence from Displaced Workers. Journal of Labor Economics, 13(4), 653-677.

Nonaka, I. (2007). The knowledge-creating company. Harvard Business Review, 85 (7-8),162-171.

Oldham, G. R., \& Cummings, A. (1996). Employee creativity: Personal and contextual factors at work. Academy of management journal, 39(3), 607-634.

Orlitzky, M. (2007). Recruitment strategy. The Oxford handbook of human resource management, 273-299.

Oster, E. (2019). Unobservable selection and coefficient stability: Theory and evidence. Journal of Business \& Economic Statistics, 37(2), 187-204.

Ouchi, W. G. (1979). A conceptual framework for the design of organizational control mechanisms. Management science, 25(9), 833-848.

Oyer, P., \& Schaefer, S. (2005). Why do some firms give stock options to all employees? An empirical examination of alternative theories. Journal of Financial Economics, 76(1), 99-133.

Oyer, P., \& Schaefer, S. (2011). Personnel Economics: Hiring and Incentives. Volume 4, Part B, Chapter 20 of Handbook of Labor Economics.

Pallais, A., \& Sands, E. G. (2016). Why the referential treatment? Evidence from field experiments on referrals. Journal of Political Economy, 124(6), 1793-1828.

Palomino, F., \& Peyrache, E. (2013). Internal versus external CEO choice and the structure of compensation contracts. Journal of Financial and Quantitative Analysis, 1301-1331.

Parrino, R. (1997). CEO turnover and outside succession a cross-sectional analysis. Journal of financial 
Economics, 46(2), 165-197.

Peterson, C., \& Seligman, M. E. P. (2004). Character strengths and virtues: A handbook and classification. New York: Oxford University Press.

Pinkston, J. C. (2009). A model of asymmetric employer learning with testable implications. Review of Economic Studies, 76(1), 367-394.

Porter, L. W., \& Lawler, E. E. (1968). Managerial attitudes and performance.

Prendergast, C. (1999). The Provision of Incentives in Firms. Journal of Economic Literature, 37(1), 7-63.

Prendergast, C. (2008). Intrinsic motivation and incentives. American Economic Review, 98(2), 201-05.

Rajagopalan, N., \& Zhang, Y. (2003). Explaining new CEO origin: Firm versus industry antecedents. Academy of Management Journal, 46(3), 327-338.

Rees, A. (1966). Information Networks in Labor Markets. The American Economic Review, 56(1-2), 559566.

Russo, G., Rietveld, P., Nijkamp, P., \& Gorter, C. (2000). Search channel use and firms' recruitment behaviour. De Economist, 148(3), 373-393.

Rynes, S. L., \& Lawler, J. (1983). A policy-capturing investigation of the role of expectancies in decisions to pursue job alternatives. Journal of applied psychology, 68(4), 620.

Salop, J., \& Salop, S. (1976). Self-selection and turnover in the labor market. The Quarterly Journal of Economics, 619-627.

Schwab, D. P. (1982). Organizational recruiting and the decision to participate. Personnel management, 103-128.

Schwartz, K. B., \& Menon, K. (1985). Executive succession in failing firms. Academy of Management Journal, 28(3), 680-686.

Scott, M., Roberts, I., Holroyd, G., \& Sawbridge, D. (1989). Department of Employment Research Paper No. 70. Management and Industrial Relations in Small Firms.

Sebora, T. C., \& Kesner, I. F. (1996). The CEO selection decision process: Bounded rationality and decision component ordering. Journal of Multi-Criteria Decision Analysis, 5(3),183-194.

Shalley, C. E., Zhou, J., \& Oldham, G. R. (2004). The effects of personal and contextual characteristics on creativity: Where should we go from here? Journal of management, 30(6), 933-958.

Shemesh, J. (2017). CEO social status and risk-taking. Quarterly Journal of Finance, 7(02), 1750004.

Simon, C. J., \& Warner, J. T. (1992). Matchmaker, matchmaker: The effect of old boy networks on job match quality, earnings, and tenure. Journal of labor economics, 10(3), 306-330.

Snell, S. A. (1992). Control theory in strategic human resource management: The mediating effect of administrative information. Academy of management Journal, 35(2), 292-327.

Spence, M. (1974). Competitive and optimal responses to signals: An analysis of efficiency and distribution. Journal of Economic theory, 7(3), 296-332.

Spence, A. M. (1981). The learning curve and competition. The Bell Journal of Economics, 49-70.

Stiglitz, J. E. (1985). Information and economic analysis: a perspective. The Economic Journal, 95, 21-41.

Stulz, R. (1990). Managerial discretion and optimal financing policies. Journal of Financial Economics, 26(1), 3-27.

Suojanen, W. W., \& Brooke, S. (1971). The management of creativity. California Management Review, 14(1), 
$17-23$

Taubman, P., \& Wales, T. (1975). Education as an Investment and a Screening Device. In Education, income, and human behavior (pp. 95-122). NBER.

Taylor, L. A. (2013). CEO Wage Dynamics: Estimates from a Learning Model. Journal of Financial Economics, 108(1), 79-98.

Taylor, M. S., \& Schmidt, D. W. (1983). A process-oriented investigation of recruitment source effectiveness. Personnel Psychology, 36(2), 343-354.

Topel, R. (1991). Specific Capital, Mobility, and Wages: Wages Rise with Job Seniority. Journal of Political Economy, 99(1), 145-176.

Thurow, L. C. (1975). Generating inequality. Basic books.

Ullman, J. C. (1966). Employee Referrals-Prime Tool for Recruiting Workers. Personnel, 43(3), 30-35.

Vallerand, R. J. (1997). Toward a hierarchical model of intrinsic and extrinsic motivation. In Advances in experimental social psychology, 29, 271-360

Vallerand, R. J. (2000). Deci and Ryan's self-determination theory: A view from the hierarchical model of intrinsic and extrinsic motivation. Psychological inquiry, 11(4), 312-318.

Vancil, R. F. (1987). Passing the baton: Managing the process of CEO succession. Cambridge, MA: Harvard University Press.

Waldman, M. (1984). Job assignments, signalling, and efficiency. The RAND Journal of Economics, 15(2), 255-267.

Waldman, M. (1990). Up-or-out contracts: A signaling perspective. Journal of Labor Economics, 8(2), 230250.

Widener, S. K. (2004). An empirical investigation of the relation between the use of strategic human capital and the design of the management control system. Accounting, Organizations and Society, 29(3-4), 377-399.

Winner, E., \& Drake, J. E. (2013). The rage to master: The decisive role of talent in the visual arts. The complexity of greatness: Beyond talent or practice, 333-366.

Wooldridge,J. (2019). Applying Instrumental Variables and Control Function Methods. Management Accounting Section Midyear Meeting. American Accounting Association.

Xu, J., \& Yang, J. (2016). Golden hellos: Signing bonuses for new top executives. Journal of Financial Economics, 122(1), 175-195.

Zhang, J., Zhang, Y., Song, Y., \& Gong, Z. (2016). The different relations of extrinsic, introjected, identified regulation and intrinsic motivation on employees' Performance. Management Decision.

Zottoli, M. A., \& Wanous, J. P. (2000). Recruitment source research: Current status and future directions. Human Resource Management Review, 10(4), 353-382. 


\section{IMPACT-PARAGRAPH}

The three studies in the dissertation discuss the relevance of various hiring strategies (termed as employee selection in the dissertation) in attracting and selecting the right employees for the firm. The main findings of the dissertation show that hiring strategies are in line with what firms seek from their employees, whether it is a high level of motivation, or a good fit in terms of skills, risk-appetite that makes them behave in the desired way. The dissertation emphasizes the need to hire the right employees who would perform to the best of their abilities given the firm's environment (for example, how do firms motivate their employees). In particular, one of the main findings of the dissertation is how highly motivated employees can be hired by using certain recruitment channels when the firm cannot offer performance-pay contracts (Chapter 2). On the other hand, one of the studies finds that firms can use stock-based performance pay contracts to successfully attract the right Chief Executive Officers when the firm has little knowledge about how the CEO would fit in the firm's goals (Chapter 3). Finally, the dissertation finds that firms generally choose to invest in the hiring process to select employees who are stable and trainable when they invest in training these employees after they are hired (Chapter 4).

The dissertation, with its studies, makes a significant contribution to the research field of management accounting by addressing an important, yet understudied, question of 'why and how to hire the right employee?'. Most of the current literature in the field seems to focus on what the firm does to incentivize (via pay-schemes) or develop its employees (through training), without paying much heed to the fact that every individual is different (in terms of motivation, ability, skills, risk-appetite) and not everyone reacts to incentives (or training) in the same way. Acknowledging this heterogeneity in individuals is crucial to understand how/if these incentives and development initiatives will be effective. Hence, by focusing on the question of 'why and how to hire the right person?, this dissertation offers new insights on how the effectiveness of firm level controls (such as pay-scheme, training) and the type of individual hired are inter-linked. Thus, the dissertation highlights some of the optimal strategies firms employ that link their hiring strategies to the firm environment.

The findings of this dissertation are relevant to the firms that are in stages of experimentation and would likely benefit from the discussion (and findings) on how firms benefit from implementing certain hiring practices when they have certain needs from their employees, that are in line with the firm's environment. For example, the findings of the first study (Chapter 2) show that using recruitment channels that entail a high application cost for applicants results in discouraging less motivated individuals from applying. This is especially useful when firms need to hire highly motivated employees for the job because of the limited possibility of offering these employees payfor-performance type of pay-schemes. Similarly, the findings of the third study (Chapter 
4) show how firms could invest in their employee selection process to select individuals who are generally more stable and possess higher ability, especially when the firms also invest in training these employees once hired. In addition, the findings of the second study (Chapter 3) can benefit the regulatory bodies who are examining the efficacy of the type and magnitude of compensation paid to CEOs by providing them a less discussed, yet equally convincing explanation behind using stocks and options in compensation, which is to sort CEOs at the time of hiring when little is known about them. 


\section{SUMMARY}

Individuals are heterogenous, in terms of motivation, skills (innate and pre-acquired), and risk-appetite, among other aspects. Hence, these individuals might react to firm level (management) controls, such as monetary incentives and training, in different ways. To achieve the objective of aligning the employee's actions in the desired direction, firms need to acknowledge this heterogeneity in individuals when implementing the various management controls. Most importantly, the firm needs to address the concern of "who is the right person for the job?" and "how to attract and select this right person?" who would react to the other controls in the most desirable way. Thus, the dissertation examines research questions within the topic of employee selection and its importance in addressing the various needs of the firm from its employees, that is in line with the firm's environment (choice of other controls).

Alternatively, it is proposed that once firms hire individuals based on certain attributes, they must use other action-based controls (or other forms of personnel control), such as monetary incentives (or training), in such a way that they increase the benefits of hiring these specific individuals. For instance, the choice of a recruitment channel (or employee selection intensity) and the choice of compensation design (or the use of training) must be viewed as mutually beneficial (or productivity enhancing). Two of the studies of the dissertation (Chapter 2 and Chapter 4) view control choices as a part of a system, in line with the studies that propose that organizational level choices are generally quasi-fixed. Thus, our empirical methodology for these two studies is to test for complementarity between control choices, which can be interpreted as assessing whether pre-existing firm differences in using certain controls (for example, using certain recruitment channels) influence the productivity return from using the other control (for example, using fixed-pay contracts), and vice-versa. The remaining study (Chapter 3) examines the use of compensation design (stock-based pay) in addressing sorting needs of the firm at the time of appointing a Chief Executive Officer (CEO).

Within the broader topic of employee selection, this dissertation, with its three studies, examines the following main research questions:

- Chapter 2: Which recruitment strategy is complementary to compensation design (fixed-pay contract versus incentive-pay contract)?

- Chapter 3: Do firms use stock-based compensation to sort Chief Executive Officers when there is severe informational asymmetry around their fit in the firm?

- Chapter 4: Is investment in employee selection complementary to investment in training? What drives this complementarity? In addition, does context matter for the complementarity? 


\section{Key findings}

The first study (Chapter 2) argues that recruitment channels that impose an application costs (such as implicit search costs and/ or explicit application fee) on candidates can serve in discouraging less motivated people from entering the applicant pool. This study analytically shows that higher application costs result in a higher likelihood of attracting highly intrinsically motivated candidates but results in a lower likelihood of filling the vacancy. The economic intuition is relatively straightforward-higher application costs make the job opening less attractive, which discourages candidates and especially those who have less intrinsic motivation for the job. Thus, compared to informal channels, formal channels induce a more favorable self-selection of candidates based on their unobservable intrinsic motivation for the job, albeit fewer candidates might get attracted for the job. Intuitively, when a firm can only provide fixed wages, then it needs to rely on the intrinsic motivation of the candidates, which triggers a preference for formal channels over informal channels because of the higher sorting capability of the former compared to the latter. Alternatively, the greater the incentives a firm can provide, the less it cares about attracting highly intrinsically motivated candidates (since incentive contracts might be enough to direct effort) and in turn, the more it cares about filling the vacancy per se. This triggers a preference for informal channels over formal channels since the former has a relative advantage of reaching a larger number of candidates (irrespective of their level of intrinsic motivation) compared to the latter. Relatedly, the study argues that the marginal benefits of providing incentives are lower when using a formal channel compared to using an informal channel. Using data for a cross-section of 337 British firms (surveyed by 2011 Workplace Employment Relations Survey (WERS), the study shows that formal channels (informal channels) and fixed wages (incentives) are complements. Broadly, the study argues and shows that recruitment strategy (in particular, recruitment channels) and compensation design are complements.

The second study (Chapter 3 ) relies on the general idea that using stock-based component in compensation induces self-selection of the 'right fit' $\mathrm{CEO}$ (into a contract). However, the study argues that the relative benefit of using stock-based pay for sorting is higher when the need for sorting is higher. This is crucial because using additional stock-based pay for sorting needs imposes additional firm-risk on the risk-averse CEO affecting her actions sub-optimally, which can be viewed as implicit costs of using stockbased pay for sorting. Hence, going beyond the existing studies that only focus on the benefits of using stock-based pay for sorting, this study argues that for firms to use stock-based pay for sorting profitably the need (or benefit) of using it should outweigh the associated costs (both implicit and explicit). In particular, the study examines if the use of stock-based pay (in lieu of fixed-salary) is positively linked to the severity of informational asymmetry around the CEO's fit in the firm. The argument being that with severity of informational asymmetry the need of using stock-based pay for sorting exceeds the associated costs. However, over the CEO's tenure, the firm is expected to 
learn more about the CEO's fit in the firm and hence the variation in the informational asymmetry across all types of CEO-firm appointments decreases with tenure, all else equal. Thus, the study hypothesizes that the variation in the stock-based component in a CEO's compensation at the time of appointment is associated with the varying degree of informational asymmetry around the CEO's fit in the firm - the higher the severity in the informational asymmetry, the higher the share of stock-based pay in compensation at the time of appointment. In addition, the study also hypothesizes that the difference in the share of stock-based compensation in total compensation observed at the time of appointment across CEOs reduces with tenure. Using a pooled cross-section of S\&P 500 firms with 3,162 firm-year observations for the period 2011-2017, the study finds empirical support for both the hypotheses. The results strongly support the possibility of firms using stock-based pay to sort CEOs when there is (relatively) little information about their fit in the firm.

The third study (Chapter 4) examines if investment in employee selection process and in training are complements. The study argues that the investment in employee selection when there is training is driven by the need for selecting employees based on their stability and trainability, that are expected to affect the returns to training. In addition, the study argues that the need for selecting employees on stability and trainability when the firm invests in training increases with the creativity dependence of the firm. Using rich survey data on 457 firms located in Austria, Germany and Switzerland, between the size of 50-500 employees, the study finds that there is a strong positive relationship between investment in training and in employee selection. Most importantly, it finds that the complementarity between training and employee selection across all firms is indeed driven by the need to select employees based on both the attributes of stability and trainability. In addition, the study also finds that this positive relationship between resource intensity of employee selection and that of training is stronger with high creativity-dependence, especially in firms involved in R\&D activities and those operating in the creative industries of (a) design, (b) new media, such as software and video games, and (c) creative services, such as advertising. While such firms do not seem to put an increased emphasis on selecting on trainability, the study finds evidence that they have a demand for a specific attribute that might contribute to the stability of the employee-firm relationship, namely, value congruence of the employee (with the firm's values). On the other hand, the degree of fit in an existing team is very important for firms in the non-creative industries. 


\section{SAMENVATTING (DUTCH SUMMARY)}

Individuen zijn verschillend, onder meer wat betreft motivatie, vaardigheden (aangeboren en reeds verworven) en risicobereidheid. Daarom kunnen individuen op verschillende manieren reageren op beheersingsmechanismen op bedrijfsniveau (management), zoals financiële stimulans en training. Om gewenst gedrag van werknemers te bewerkstelligen, moeten bedrijven deze heterogeniteit in individuen erkennen bij het implementeren van de verschillende beheersingsmechanismen. Het belangrijkste is dat een onderneming zich buigt over de vraag "wie is de juiste persoon voor dit werk?" en "hoe kunnen we deze juiste persoon aantrekken en selecteren?" die op de meest wenselijke manier zou reageren op de andere beheersingsmechanismen. Dit proefschrift onderzoekt daarom onderzoeksvragen binnen het onderwerp van personeelsselectie en het belang ervan om tegemoet te komen aan de verschillende werknemersbehoeften van de onderneming, die in overeenstemming zijn met de omgeving van de onderneming (keuze van andere beheersingsmechanismen).

Anderzijds wordt voorgesteld dat zodra bedrijven individuen aanwerven op basis van bepaalde karakteristieken, zij andere op actie gebaseerde beheersingsmechanismen moeten gebruiken (of andere vormen van personeelsbeheersing), zoals financiële stimulansen (of opleiding), zodanig dat zij de voordelen van het aanwerven van deze specifieke individuen vergroten. Zo moet de keuze van een aanwervingskanaal (of de selectie-intensiteit van de werknemers) en de keuze van het compensatieontwerp (of het gebruik van opleiding) als wederzijds voordelig (of productiviteitsverhogend) worden beschouwd. Twee van de studies in dit proefschrift (Hoofdstuk 2 en Hoofdstuk 4) beschouwen beheersingskeuzes als onderdeel van een systeem, in lijn met de studies die voorstellen dat keuzes op organisatieniveau over het algemeen quasi-vaste keuzes zijn. De empirische methode voor deze twee studies bestaat uit het testen van het bestaan van complementariteit tussen de beheersingskeuzes, wat kan worden geïnterpreteerd als het nagaan of reeds bestaande verschillen tussen ondernemingen bij het gebruik van bepaalde beheersingselementen (bijvoorbeeld het gebruik van bepaalde wervingskanalen) een invloed hebben op het productiviteitsrendement van het gebruik van het andere beheersingselement (bijvoorbeeld het gebruik van contracten met vaste lonen), en viceversa. De derde studie (Hoofdstuk 3) onderzoekt het gebruik van de vormgeving van de beloning (op aandelen gebaseerde beloning) in de behoefte van de onderneming om kandidaten te rangschikken ("sorting") op het moment dat een Chief Executive Officer (CEO) wordt benoemd. 
Binnen het bredere onderwerp van personeelsselectie, onderzoekt dit proefschrift, met zijn drie studies, de volgende hoofdonderzoeksvragen:

- Hoofdstuk 2: Welke wervingsstrategie is complementair aan het beloningsontwerp (contract met vast loon versus contract met variabele beloning)?

- Hoofdstuk 3: Maken bedrijven gebruik van op aandelen gebaseerde beloning om Chief Executive Officers te rangschikken wanneer er sprake is van ernstige informatie-asymmetrie rond hun 'fit' met het bedrijf?

- Hoofdstuk 4: Zijn investeringen in de selectie van werknemers complementair met investeringen in opleiding? Wat bepaalt deze complementariteit? En is de context van belang voor de complementariteit?

\section{Belangrijkste bevindingen}

In de eerste studie (Hoofdstuk 2) wordt beargumenteerd dat wervingskanalen die sollicitatiekosten (zoals impliciete zoekkosten en/of expliciete sollicitatiekosten) opleggen aan kandidaten, minder gemotiveerde mensen kunnen ontmoedigen om deel te nemen aan de sollicitantenpool. Deze studie toont analytisch aan dat hogere sollicitatiekosten resulteren in een grotere kans op het aantrekken van zeer intrinsiek gemotiveerde kandidaten, maar resulteert in een kleinere kans op het invullen van de vacature. De economische intuïtie is relatief eenvoudig- hogere sollicitatiekosten maken de vacature minder aantrekkelijk, wat kandidaten ontmoedigt, vooral diegenen die minder intrinsiek gemotiveerd zijn voor de baan. In vergelijking met informele kanalen leiden formele kanalen dus tot een gunstigere zelfselectie van kandidaten op basis van hun niet-waarneembare intrinsieke motivatie voor de baan, hoewel het mogelijk is dat minder kandidaten voor de baan worden aangetrokken. Intuïtief is het zo dat wanneer een bedrijf alleen een vast loon kan bieden, het moet vertrouwen op de intrinsieke motivatie van de kandidaten, wat een voorkeur betekent voor formele kanalen boven informele kanalen, omdat formele kanalen een groter selectievermogen hebben dan informele kanalen. Een andere mogelijkheid is dat hoe groter de stimulansen zijn die een bedrijf kan geven, hoe minder het zich moet bekommeren om het aantrekken van zeer intrinsiek gemotiveerde kandidaten (aangezien prestatiebeloning voldoende kan zijn om de inspanning te sturen) en hoe meer het zich moet bekommeren om het invullen van de vacature op zich. Dit leidt tot een voorkeur voor informele kanalen boven formele kanalen, aangezien informele kanalen het relatieve voordeel hebben dat zij een groter aantal kandidaten bereiken (ongeacht hun niveau van intrinsieke motivatie) dan formele kanalen. In de studie wordt ook betoogd dat de marginale voordelen van het geven van prikkels lager zijn wanneer een formeel kanaal wordt gebruikt dan wanneer een informeel kanaal wordt gebruikt. Gebruikmakend van gegevens voor een dwarsdoorsnede van 337 Britse bedrijven (geënquêteerd door de Workplace Employment Relations Survey (WERS) van 2011), toont de studie aan dat formele kanalen (informele kanalen) en vaste 
lonen ('incentives') complementair zijn. In het algemeen betoogt en toont de studie aan dat aanwervingsstrategie (in het bijzonder aanwervingskanalen) en beloningsstructuur complementair zijn.

De tweede studie (Hoofdstuk 3) gaat uit van het algemene idee dat het gebruik van op aandelen gebaseerde beloning in de beloning leidt tot zelfselectie van de "juiste" CEO (in een contract), zogenaamde "sorting". In de studie wordt echter betoogd dat het relatieve voordeel van het gebruik van op aandelen gebaseerde beloning voor sorting groter is wanneer de behoefte aan sorting groter is. Dit is van cruciaal belang omdat het gebruik van extra op aandelen gebaseerde beloning de risicomijdende CEO een extra bedrijfsrisico oplegt dat haar acties suboptimaal kan beïnvloeden, wat kan worden gezien als impliciete kosten van het gebruik van op aandelen gebaseerde beloning voor sorting. Deze studie gaat dus verder dan de bestaande studies die zich enkel richten op de voordelen van het gebruik van op aandelen gebaseerde beloning voor sorting, en stelt dat als ondernemingen op aandelen gebaseerde beloning voor sorting op een winstgevende manier willen gebruiken, de noodzaak (of het voordeel) om het te gebruiken groter moet zijn dan de bijbehorende kosten (zowel impliciet als expliciet). In het bijzonder onderzoekt de studie of het gebruik van op aandelen gebaseerde beloning (in plaats van vaste beloning) positief samenhangt met de ernst van de informatieasymmetrie rond de geschiktheid van de CEO in de onderneming. Het argument is dat met de ernst van de informatie-asymmetrie de noodzaak van het gebruik van op aandelen gebaseerde beloning voor sorting groter is dan de bijbehorende kosten. In de loop van de ambtstermijn van de $\mathrm{CEO}$ zal de onderneming naar verwachting echter meer te weten komen over de geschiktheid van de CEO voor de onderneming, zodat de informatieasymmetrie bij alle soorten benoemingen tussen $\mathrm{CEO}$ en onderneming afneemt met de ambtstermijn, ceteris paribus. In de studie wordt dus verondersteld dat de variatie in de op aandelen gebaseerde component in de vergoeding van een $\mathrm{CEO}$ op het moment van zijn aanstelling verband houdt met de variërende mate van informatieasymmetrie rond de geschiktheid van de CEO voor de onderneming - hoe groter de informatieasymmetrie, hoe groter het aandeel van op aandelen gebaseerde vergoeding in de vergoeding op het moment van de aanstelling. Bovendien wordt in de studie ook verondersteld dat het verschil in het aandeel van de op aandelen gebaseerde verloning in de totale verloning op het ogenblik van de aanstelling tussen CEO's vermindert met de duur van hun mandaat. Gebruikmakend van een panel data van S\&P 500 bedrijven met 3.162 observaties van bedrijfsjaren tijdens de periode 20112017, vindt de studie empirische ondersteuning voor beide hypotheses. De resultaten ondersteunen sterk de mogelijkheid dat ondernemingen op aandelen gebaseerde beloning gebruiken om CEO's te rangschikken wanneer er (relatief) weinig informatie is over hun 'fit' met de onderneming.

In de derde studie (Hoofdstuk 4) wordt nagegaan of investeringen in de selectie van werknemers en in opleiding elkaar complementeren. De studie stelt dat 
de investering in de selectie van werknemers wanneer er opleiding anwezig is, wordt gedreven door de noodzaak om werknemers te selecteren op basis van hun stabiliteit en trainbaarheid, die naar verwachting van invloed zijn op het rendement van de opleiding. Bovendien stelt de studie dat de noodzaak om werknemers te selecteren op stabiliteit en trainbaarheid wanneer de onderneming in opleiding investeert, toeneemt met de creativiteitsafhankelijkheid van de onderneming. Op basis van uitgebreide enquêtegegevens van 457 ondernemingen in Oostenrijk, Duitsland en Zwitserland, met tussen de 50 en 500 werknemers, blijkt dat er een sterk positief verband bestaat tussen investeringen in opleiding en in de selectie van werknemers. De belangrijkste bevinding is dat de complementariteit tussen opleiding en de selectie van werknemers in alle ondernemingen inderdaad het gevolg is van de noodzaak om werknemers te selecteren op basis van zowel stabiliteit als trainbaarheid. Bovendien blijkt uit de studie dat deze positieve relatie tussen de middelenintensiteit van personeelsselectie en die van opleiding sterker is naarmate de afhankelijkheid van creativiteit groter is, vooral in bedrijven die zich bezighouden met R\&D-activiteiten en bedrijven die actief zijn in de creatieve industrieën van (a) design, (b) nieuwe media, zoals software en videospelletjes, en (c) creatieve diensten, zoals reclame. Hoewel dergelijke bedrijven geen grotere nadruk lijken te leggen op het selecteren van trainbaarheid, vindt de studie aanwijzingen dat zij een vraag hebben naar een specifieke eigenschap die kan bijdragen tot de stabiliteit van de werknemer-bedrijf relatie, namelijk waardecongruentie van de werknemer (met de waarden van het bedrijf). Anderzijds is de mate van 'fit' met een bestaand team zeer belangrijk voor bedrijven in de niet-creatieve industrieën. 


\section{CURRICULUM VITAE}

Raginee Baruah was born on $6^{\text {th }}$ October 1984 in the state of Assam, India, which is well-known for their tea. In 2006, she received her bachelor's degree in the field of Economics from Delhi College of Arts and Commerce (Delhi University). It was not her first choice of field of study, but she grew to love and even admire it, to the extent that she went on to receive a master's degree in the field of Economics from Delhi School of Economics (Delhi University) in 2009. After graduation, Raginee worked in PricewaterhouseCoopers (PwC) Pvt. Ltd. in New Delhi for three years as a consultant, working on projects related to electricity pricing and power sector regulations. As much as she enjoyed her work at $\mathrm{PwC}$, she wanted to explore a different work profile. So, she joined Asian Development Bank in New Delhi and worked on a research project that examined the regulatory environment for firms operating in the apparel manufacturing industry. During her two-year long stint at $\mathrm{ADB}$, Raginee discovered her love for research and decided to pursue a career in research.

In 2014, Raginee moved to Maastricht in The Netherlands to pursue a second master's degree in the field of Economics and Financial Research at Maastricht University (UM). During her Master program, she also worked as a Research Assistant at the Research Centre for Education and the Labour Market (ROA, UM) and learnt a few useful skills as a researcher. In September 2016, she joined the department of Accounting and Information Management (UM) as a PhD student. During her doctoral studies, she visited Vienna University of Economics and Business (WU). She also presented her work at several conferences and workshops, such as AAA Management Accounting Section Midyear Meeting and Doctoral Colloquium, EAA Doctoral Colloquium, EAA Annual Congress, and EAISM Conference on Performance Measurement \& Management Control. She summarizes her $\mathrm{PhD}$ journey as one filled with many self-discoveriesher love for teaching being one of them.

As of September 2020, Raginee works as an assistant professor at the Faculty of Accounting, Control and Legal Affairs at EDHEC Business School in Lille, France and is enjoying this new chapter of her academic life. 


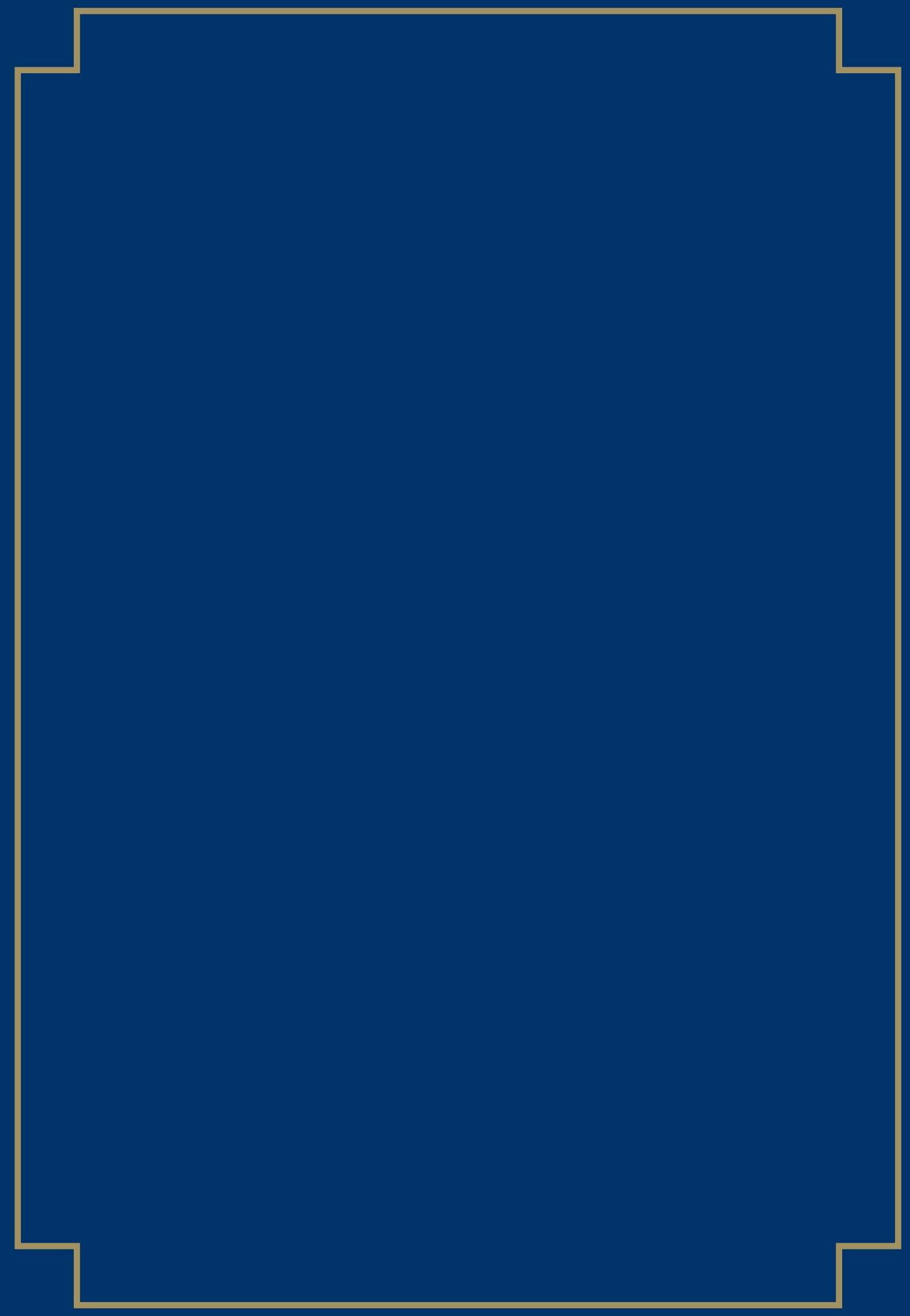

